\title{
Optimized blood management for elective orthopaedic surgery
}

Citation for published version (APA):

Weber, E. W. (2003). Optimized blood management for elective orthopaedic surgery. [Doctoral Thesis, Maastricht University]. Datawyse / Universitaire Pers Maastricht. https://doi.org/10.26481/dis.20031210ew

Document status and date:

Published: 01/01/2003

DOI:

10.26481/dis.20031210ew

Document Version:

Publisher's PDF, also known as Version of record

\section{Please check the document version of this publication:}

- A submitted manuscript is the version of the article upon submission and before peer-review. There can be important differences between the submitted version and the official published version of record.

People interested in the research are advised to contact the author for the final version of the publication, or visit the DOI to the publisher's website.

- The final author version and the galley proof are versions of the publication after peer review.

- The final published version features the final layout of the paper including the volume, issue and page numbers.

Link to publication

\footnotetext{
General rights rights.

- You may freely distribute the URL identifying the publication in the public portal. please follow below link for the End User Agreement:

www.umlib.nl/taverne-license

Take down policy

If you believe that this document breaches copyright please contact us at:

repository@maastrichtuniversity.nl

providing details and we will investigate your claim.
}

Copyright and moral rights for the publications made accessible in the public portal are retained by the authors and/or other copyright owners and it is a condition of accessing publications that users recognise and abide by the legal requirements associated with these

- Users may download and print one copy of any publication from the public portal for the purpose of private study or research.

- You may not further distribute the material or use it for any profit-making activity or commercial gain

If the publication is distributed under the terms of Article $25 \mathrm{fa}$ of the Dutch Copyright Act, indicated by the "Taverne" license above, 
OPTIMIZED BLOOD MANAGEMENT FOR ELECTIVE ORTHOPAEDIC SURGERY 
ISBN 9052783942

(c) Ewert Withelm Geert Weber, San 2003

Layour and Printing: Darawyse/ Universitaire Pets Mastricht

The printing of this thesis was finanwally supported by Janssen-Cilag b.v. Astra Tech b.w. Bochringer-Ingetheim b.v. Now Nordisk Farma b.w. and the Stichting rot bevordering der Anesthesiologie. 


\title{
OPTIMIZED BLOOD MANAGEMENT FOR ELECTIVE ORTHOPAEDIC SURGERY
}

\author{
PROEFSCHRIFT \\ ter verkrijging van de graad van doctor \\ aan de Universiteit Mastricht \\ op gezag van de Rector Magnificus \\ Prof. dr. A. C. Nieuwerhuijzen Kruseman, \\ volgens het besluit van het College van Decanen \\ in het openbar te verdedigen op \\ woensdag 10 december 2003 \\ om 16.00 unt \\ door \\ Evert Wilhelm Geert Weber
}

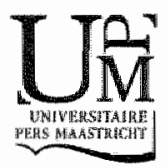


PROMOTOR

Prof,dr. M.E. Durieux

COPROMOTOR

Dr. R. Slappendel (St. Maartenskliniek, Nijmegen)

\section{BEOORDELINGSCOMMISSIE}

Prof.dr. R.G.T. Geesink (voorzinter)

Dr. S.K. Bulstra

Dr. M.A.E. Marcus

Prof.dr. B.E. de Pauw (UMC St. Radboud, Nijmegen)

Prof.dr. G.J. Scheffer (UMC St. Radboud, Nijmegen) 
Gabriel Garcia Marquez 2003 


\section{CONTENTS}

\section{Chapter 1}

Introduction and aims of the study 8

\section{Chapter 2}

A brief history of blood and blood transfusion 14

\section{Chapter 3}

Haemovigilance 24

\section{Chapter 4}

"The impact of a blood product transfusion protocol on requirement for red blood cell transfusions $\quad 36$

\section{Chapter 5}

Perioperative blood transfusions and delayed wound healing after hip replacement surgery: effects on duration of hospitalisation 42

\section{Chapter 6}

Does ibuprofen increase perioperative blood loss during hip arthroplasty? $\quad 56$

\section{Chapter 7}

COX-2 selectivicy of NSAIDS and perioperative blood loss in hip-surgery - a randomised comparison of indometacin and meloxicam 64

\section{Chapter 8}

Effects of epoetin alpha on blood transfusions and postoperative recovery in orthopaedic surgery

The European Epoetin alpha Surgery Trial (EEST) 72

\section{Chapter 9}

Optimal use of epoetin alpha in orthopaedic surgery. Calculation of factor EO- $40,000 \quad 90$ 


\section{Chapter 10}

Clinical efficacy of post-operative autotransfusion of filrered shed blood in hip and knee arthroplasty $\quad 98$

\section{Chapter 11}

An algorithm to reduce homologous red blood cell transfusions for major orthopaedic surgery 108

\section{Chapter 12}

General discussion and summary

\section{Chapter 13}

Algemene beschouwing en samenvatting 130

Acknowledgements $\quad 138$

Curriculum vitae $\quad 140$ 
CHAPTER 1 


\section{INTRODUCTION}

Next to pain and deep venous thrombosis, blood loss is one of the most important complications in elective orthopaedic surgery. Although blood transfusions have been used for many years to treat this complication, much remains unclear regarding indications, risks and side effects.

In the $20^{\text {th }}$ century a series of discoveries dramatically improved the safery of blood transfusion, to the point where, after World War II, blood transfusion seemed a safe procedure (1). Then, during the middle of the 70 's of the last century, it appeared that pre-transplant blood transfusion induced an immunologic reaction in the acceptor $(2,3)$. In fact, every blood transfusion should be considered a "organ transplant", albeit a remporary one (4). Other immunomodulatory effects are an increase in cancer recurrence and possibly an increased infection incidence observed in patients receiving blood transfusions. In the middle 80 's physicians and parients became more aware of the possible infection risks associated with blood transfusions (HIV, HepC, $\mathrm{rCVJD}$ etc.). This awareness, as well as a persistent shortage of donor blood, was a major reason for a re-evaluation of the indications for and alternatives to transfusion of allogeneic blood. It has come to be realized that it is not necessary to transfuse a parient unless the blood loss has deleterious effects on the oxygen supply to the tissues. As a result, the transfusion trigger has shifted from an "optimal" haemoglobin level $(10 \mathrm{~g} / \mathrm{dl})(5)$ to that level of haemoglobin necessary to meet the patient's tissue oxygen demands $(6,7)$. However, how to determine this level is still a matter of debate.

At this time, we find ourselves in the interesting situation where blood transfusions are safer than ever before, yer, people have become highly concerned abour their risks. Blood transfusions are unlikely ever to be completely safe (8), and therefore transfusions should only be given when truly necessary. Other reasons to be reluctant with blood transfusions are altruism, scarcity and financial motives.

One of the main issues in this field, then, is to determine by what means we can avoid transfusions altogether. In addition, if blood has to be given, what blood transfusion management will make the practice as safe and effective as possible? This thesis will address several of these issues. 


\section{HYPOTHESIS}

Our general hypotheses are as follows: (1) Blood transfusions should be minimized as, even in the absence of major complications, they detrimentally affect postoperative recovery; (2) the optimal manner to minimise the need for transfusion is by a multi-modal approach.

\section{AIMS OF THE STUDY}

In order to test our general hypotheses, we will address the following issues:

1. If a blood transfusion is required, what effect does this have on infections and duration of hospitalisation after elective major orthopaedic surgery?

2. Perioperative transfusions can be minimized by a variety of approaches.

a. Alternatively, transfusions are likely to be decreased if perioperative blood loss is limited. Whereas this is mostly a surgical issue, we will investigate one approaches to this issue of relevance to the anaesthesiologist: affecting perioperative blood loss by using different (routinely used) NSAID's?

b. Optimalisation of the pre-operative haemoglobin will result in a decreased need for transfusion. We will investigate if is it possible to reduce blood transfusions by optimisation of the pre-operative haemoglobin concentration using epoetin alpha, and, if so, determine the optimal dose regimen?

c. Can perioperative transfusion rates be influence by re-infusion of the patient's own blood postoperatively?

d. Although no universally applicable transfusions triggers exist, can an approach be designed that is safe and ensures sufficient oxygen delivery to all tissues? What are the effects of transfusion guidelines on the transfusion incidence in clinical practice?

3. How effecrive can blood transfusion management be?

\section{ORGANIZATION OF THE THESIS}

\section{The thesis is organized as follows.}

In order to place our investigations in context, we will briefly review the developments in blood transfusion up to the present rime. Chapter 2 will provide a historical overview of the concept of transfusion, whereas Chapter 3 will focus spe- 
cifically on the issue of hemovigilance-a recent development attempting to assure optimal use and maximal safery of blood transfusion.

In Chapter 4 we will address the first part of the hyporhesis, and present evidence that transfusion per se is a predictor of prolonged hospital stay and wound closure disturbances.

The next series of chaprers will address the second part of the hypothesis, investigating different approaches to minimization of blood transfusion. Chaprer 5 presents the results of the implementation stricr transfusion guidelines. Then two chapters investigate the role of non-steroidal anti-inflammatory drugs in peri-operative blood loss: Chapter 6 determines the effect of ibuprofen, and Chapter 7 investigates if use of cox- 2 selective compounds may be beneficial in this serting. The next two chapters address the use of pre-operatively administered erythropoietin. Chapter 8 presents results of an international multicenter trial investigating the effects of erythropoietin administration on perioperative outcome. Chaprer 9 calculates the optimal dosage for the individual patient. Chapter 10 looks at a post-operative approach to minimizing transfusions: the re-infusion of drain blood.

The practical application of this multi-modal approach is presented in Chapter 11 , in the form of algorithms that can be applied by the practicing physician. Finally, in Chapter 12, we discuss the findings and summarise the thesis.

\section{REFERENCES}

1. de Jongh, D. S., C. S. Feng, S. Frank and M. Wallace (1983). "Improved urilization of blood for elective surgery." Surg Gynecol Obstet 156(3): 326-8.

2. Opelz, G., D. P. Sengar, M. R. Mickey and P. 1. Terasaki (1973). "Effect of blood transfusions on subsequent kidney transplants." Transplant Proc 5(1):253-9.

3. Edirorial: "Pretransplant blood-transfusion-bad or good?" (1975). Lancet 2(7942):959-60.

4. Brand, A. and D. I. van Rhenen (1997). "IImmunological effects of erythrocyte and leukocyte transfusion. Work Group Blood Group Serology of the Medical Advisory Commission of the College for Blood Transfusion of the Netherlands Red Cross]." Ned Tijdschr Geneeskd 141(3): $136-40$

5. Carson, J. L. and L. R. Willerr (1993), "Is a hemoglobin of $10 \mathrm{~g} / \mathrm{d}$ required for surgery?" Mad Clin North Am 77(2): 335-47. 
12 CHAPTER I

6. "Practice Guidelines for blood component therapy: A report by the American Sociery of Anesthesiologists Task Force on Blood Component Therapy." (1996). Anesthesiology 84(3): $732-47$.

7. Hill, S. R., P. A. Carless, D. A. Henry, J. L. Carson, P. C. Hebert, D. B. McClelland and K. M. Henderson (2002). "Transfusion thresholds and other strategies for guiding allogeneic red blood cell transfusion." Cochrane Darabase Syst Rev(2): CD002042.

8. Kitchen, A. D. and J. A. J. Barbara (2000). "Which agents threaren blood safety in the furure?" Bailliere's Best Practice and Research in Clinical Haematology 13(4): 601-614. 



\section{CHAPTER 2}


As common as the concept of the blood circulation may now appear to us, it has a long and convoluted history behind it. Similarly, the concept of transfusing blood of one human into another did not suddenly appear on the scene, but developed slowly-with some carastrophes along the way. In this chapter, we will briefly trace these developments through time.

\section{BLOOD AND THE CIRCULATION}

\section{The Egyptians and Greeks}

For centuries people saw blood as a magical substance, a "humor" whose ebb and flow in the body mirrored the balance of the elements in the universe. That belief was reflected in the system of humoral medicine, developed by the Greeks, in which health was maintained by bloodletting, among other things. But even the Egyptians, as early as $2500 \mathrm{BC}$, used bleeding to treat patients, as seen on contemporary illustrations, where parients were bled from foot and neck.

In $500 \mathrm{BC}$ the Greek thinker Alcmaeon of Croton practiced animal dissection, and observed that arteries and veins are dissimilar. Later in $450-400 \mathrm{BC}$ Empedocles, a Greek philosopher in Sicily, believed that the organ of sense is the heart and theorizes that all matter is comprised of four "roots" (or elements) earth, fire, air, and water (1).

\section{Hippocrates}

Influenced by the ideas of Empedocles, Hippocrates, the pre-eminent physician of antiquity, postulated that, similar to the four elements, the body is comprised of four humors - blood, phlegm, black bile, and yellow bile - and that their imbalance causes disease. In addition to this "humoral theory", Hippocrates and his followers set forth tenets that form the basis of much of Western medicine: disease results from natural as opposed to magical causes, patients should be observed and symptoms of disease should be noted, and physicians should adhere to a strict erhical code of conduct.

Prior to the time of Hippocrates ( 460 to 377 B.C.), all illness was attributed to one disease with variable symptoms. Careful clinical observations by Hippocrates led to the recognition of specific disease states with identifying symptoms. It was 
during this time that the concept of body humors developed. The four fluid substances of the body were blood, phlegm, yellow bile, and black bile. Health depended on the proper balance of these humors. Bloodletting was, therefore, a method used for adjusting one of the four body humors to proper balance. This clinical concept led to the decline in the doctrine of evil spirits in disease.

\section{Aristotle}

The Greek philosopher Aristotle (350 BC) believed that the heart was the central organ of the body and therefore the seat of the soul. He conducted dissections of many different animalls and described their anatomical structures. Based on his observations, Aristotle presumed that the heart was a three-chambered organ, even in humans. Around $300 \mathrm{BCE}$, in Alexandria, Egypt, Herophilus of Chalcedon, one of the first Greek anatomists to publicly dissect human cadavers, determined that arteries are thicker than veins, and carry blood.

\section{Claudius Galenus}

Through his studies of anatomy, successful treatment of patients, and voluminous writings on medicine and the philosophy of medicine, Claudius Galenus (130-200 BC), known as Galen, became one of the most important physicians in history, second only to Hippocrates in influence. In his fourteenth year Galen attended lectures given by Stoic, Platonic, Peripatetic, and Epicurean philosophers from Pergamon. In 157 Galen returned to Pergamon, where he "had the good fortune to think out and publicly demonstrate a cure for wounded tendons" which gained him, in 158, the position of physician to the gladiators. He was reappointed annually until the outbreak of the Parthian W/ar in 161. The rraumatic injuries of the arena provided Galen with excellent opportunities to extend his knowledge of anatomy, surgery, and therapeutics, and throughout his life he drew on this fund of experience to illustrate his arguments. Dissecting and experimenting on animals, he proved that arteries contain blood, but he also suggested that the systems of arteries and veins are completely distinct, and that blood. forms in the liver, travels through the veins to all parts of the body, and passes between the ventricles through pores in the septum. His ideas, not all of which are correct, formed the core of the medical canon for centuries. Gallen believed that the Hippocratic writings were never wrong - merely obscure - and he saw his own work as the exrension and clarification of the Hippocratic corpus $(2,3,1)$. 
The perception of the circulation developed much later, and very slowly. In the mid-1200s the eminent Cairo physician and author Ibn al-Nafis discovered and described the pulmonary circulation, the flow of blood to and from the lungs. Again much later in 1553, unaware of al-Nafis" findings, the Spanish physician and theologian Michael Servetus suggested that blood flows from one side of the heart to the other via the lungs instead of through the wall between the ventricles, in contrast to Galen's theory. He was burned at the stake as a heretic for denying the Trinity. Fabricius, the anatomist from Padua, in 1603 published his work "On the Valves in Veins" featuring the first drawings of vein valves. And then in 1628 the British physician William Harvey published his masterwork "Exercitatio Anatomica de Motu Cordis et Sanguinis in Animalibus" (Anatomical Essay on the Motion of the Heart and Blood in Animals), in which he explained that blood circulates within the body and is pumped by the heart. "De Motu Cordis", which elicited great criticism, is the culmination of Harvey's years of experiments on animals - and even on the surface veins of arms of living subjects $(4,1)$.

\section{TRANSFUSION}

\section{Animal transfusion}

It has been suggested the early Egyptians may already have performed blood transfusions. It appears, however, that this may have been a incorrect interpretation of the fact that Egyptian kings bathed in human blood as a cure for ellephantiasis. Although there are descriptions of a blood transfusion of Pope Innocent VIII (1432-1492), these are of doubtful validity. In 1657 Christopher Wren performed the first intravenous drug injection. Once this rechnique became available, it was Richard Lower in 1665 who performed the first recorded blood transfusion in animals. With a crude syringe made of goose quill and bladder, he connects the jugular vein of a dog he had bled to the neck artery of second dog, thereby resuscitating the former $(5,6,1)$.

\section{Mammalian blood transfusion to man}

In June of 1667, the French physician Jean-Baptiste Denis transfused nine ounces of lamb's blood into a teenage boy suffering from a persistent fever. $\mathrm{He}$ attached the lamb's carotid artery to a vein in the boy's forearm, without the 
patient suffering any negative consequences. Denis used the procedure on several other parients, until the death of Antoine Mauroy, whom Denis transfused twice with calfs blood in December of the same year. Antoine Mauroy was a middle-aged man suffering from mad rages. Denis believed that by transfusing the blood of a calf into the man the man would assume the placid nature of the calf $(7,8)$. The experiment appeared to work: the toxicity of the transfused blood probably made the subject very ill and therefore very placid. It is now believed. that the man was in fact suffering from syphilis, which induced his violent behawiour. The symptoms of the syphilis would also have been relieved by the high fever that the toxic blood would have induced. Eventually the man died and Denis was arrested for his murder. Further investigations revealed, however, that the man had not in fact died from the blood but from cyanide placed in his food by his wife. Denis was eventually exonerated, but, 10 years later, the procedure was prohibited by law in France as well as in Iraly and was also forbidden by the Royal Society of Medicine in England $(9,1)$.

\section{Homologous blood transfusion}

For the next 150 years, there was little interest in transfusion, but it is significant that Nuck in 1714 and Cantwell in 1749 declared that this procedure would be of value in severe thaemorrhage. When interest in transfusion was revived by James Blundell in $1818(10,11,12,13)$, it was to replace lost blood in puerperal haemorrhage, and after a series of experiments in which he had demonstrated that human blood loses none of its "vital properties" by passage through transfusion equipment. Blundell failed in his first four desperate attempts to save women on the point of death from postpartum haemorrhage, but he succeded in five of the next six attempts.

It appears that the technique rapidly gained in popularity. In 1875, Landois (14), in a comprehensive monograph on transfusion, collected 347 cases in which human blood had been used and 129 cases in which animal blood had been used. By this time, important studies on the physiology of the blood were being performed by a number of qualified observers, and some physicians, such as Fordyce Barker, advocated transfusion "... not exclusively in those desperate cases where favourable results are hardly looked for but ... before parients have arrived at, and fallen inro, this desperate condirion"-a very modern-sounding concept. Techniques in use included transfusion with defibrinated blood, immediate transfu- 
sion with pure blood, immediate transfusion from vein to vein, and immediate transfusion from artery to vein.

Although the indications and rarionale of blood transfusion were by this time apparently quite well understood, the indications during the last quarter of the 19 th century again became vague and irrational, the procedure was employed indiscriminately, and the number of severe reactions and fatalities increased. As a result, transfusion again began to be considered as a hazardous, and even a disreputable procedure, to be employed only as a last resort and in desperation.

During the first years of the $20^{\text {th }}$ century, a blood transfusion was frequently a more difficult technical procedure, and sometimes a procedure fraught with greater risks, than a major operation. Its development as an effecrive and safe therapeutic method required solutions to of a number of special problems.

\section{BLOOD COAGULATION}

The first efforts to overcome coagulation difficulties were made in 1835 , with the use of defibrinated blood by Bischoff, and concluded in 1914 with the successful use of sodium citrate by Hustin, Weil, and Lewisohn $(15,16)$.

\section{BLOOD TYPES}

The way was opened to a solution of the vexing problem of agglutination and haemolysis from admixture of incompatible bloods, when Landsteiner (17) in 1900 published his epochal work on the identification of blood groups, based on his previous demonstration of the presence of isoagglutinating and isoagglutinable substances in the blood. Jansky in 1907 and Moss 3 years later, without knowledge of Jansky's studies, worked out the reciprocal agglutinating reactions of the four blood groups and classified them accordingly. The confusion that arose because of differences in nomenclature was eliminated after World War I, when the numbers previously used to designate blood groups were replaced by the letrers $A, B, A B$, and $O$, each group being designated by the agglutinogens in Landsteiner's original scheme. 
Communications in the early years of the $20^{\text {th }}$ century were often slow, and fo eign medical literature had only a limited circulation in the United States. N practical use, therefore, was made of Landsteiner's work until 1907, wht Ottenberg (18), at Mount Sinai Hospital in New York, was the first to matr donor and recipient before giving blood and thus made transfusion a safe proc dure from the standpoint of compatibility. The validity of Ottenberg's work w not immediarely realized; his offer to perform compatibility tests for the surgeos ar his own hospital had no general acceptance for almost 5 years because suc tests were considered unnecessary or misleading. In 1911, Ottenberg demos strated that it was safe to use as a donor a person whose serum agglutinated th recipient's red cells, but unsafe and dangerous to use one whose red cells we acted upon by the recipient's serum. This demonstration eventually led to th widespread employment of group $O$ donors as universal donors, since the rt blood cellis of this blood group are not agglutinable by the serum of any oth blood group.

\section{TECHNICAL DIFFICULTIES}

Until 1913, direct transfusion was used to the exclusion of any other techniqu This was a difficult and time-consuming method, requiring a specially traine team to carry it out and totally unsuited for use in sudden emergencies. In 189: von Ziemssen of Munich had performed transfusion by the syringe techniqu but his report attracted no atrention and when Lindeman (19) described it $\mathrm{i}$ 1913, it was, for all practical purposes, a new method. With this technique, n dissection of blood vessels was necessary in either donor or recipient, and th exact quantity of blood transfused was known. The technique, however, require a trained team of at least four persons and the use of a large number of expensi syringes. Also, rapid injection of the blood was mandatory. In 1915, Unger (2C introduced an apparatus based on the principle of the two-way stopcock, whic overcame many of these difficulties. Dozens of variations of this apparatus wer introduced during the next 15 years.

\section{INFECTION}

Infection ceased to be a major problem after first antiseptic, and then asepti techniques came into general use, and as long as transfusion was employed onl 
in hospitals and on what amounted to elective indications. The open containers originally used to collect blood for indirect transfusion first became impractical, and then a real source of danger, when indicarions for transfusion were extended.

\section{BLOOD STORAGE}

From the First to the Second World War, scientists and physicians made rapid progress in the large-scale storage and use of blood. War was not an incidental factor to these developments, as it created unprecedented demand for the lifesaving fluid. Much as the Spanish Civil War was a prelude to World War II, so was blood first transporred to the front lines of battle in Spain. By the time war had spread through Europe, the Allied forces were aided by a well-organized blood supply. Even prior to U.S. military involvement, two Americans had revolutionized the storage and distribution of blood.

A plasma shortage in Britain during World War II prompted the U.S. to organize the Plasma of Britain campaign, run by Dr. Charles Drew from a central laboratory at Presbyterian Hospital in New York. Building on techniques he had already developed to separate and preserve blood plasma, which he considered to be a viable substitute for whole blood, Dr. Drew devised a modern and highly sterile system to process, test, and store plasma for shipment overseas by the Red Cross.

Searching for a durable substiture for liquid plasma, Harvard biochemist Edwin Cohn invented a method to separare out its different proteins (or fractions). In a series of steps that are repeated, with slight variations in temperature and chemical conditions, plasma is mixed with the solvent ethyl alcohol and centrifuged. Through this process, dubbed fracrionation, Cohn and his team were able to isolare the plasma components fibrinogen (Fraction I), gamma globulin (Fraction II and III), and albumin (Fraction V). Each of these fractions was thought to have different therapeutic properties. After World War II, the science of blood reached new heights - and setbacks. The invention of the plastic blood-collection bag grearly reduced the external contamination of donated blood; the commercial introduction of Rh immunoglobin saved the lives of many Rh-positive babies born to Rh-negative mothers; and the development of Factor VIII concentrate offered hemophiliacs a new lease on life. Yet these improvements were soon overshadowed by contaminated blood supplies. Hepatitis and, more drastically and 
farally, the HIV virus were transmitted to many transfusion recipients anc haemophiliacs, the very people who had come to rely on the blood of others. As: result of new policies responding to this tragedy, blood supplies are now safe than ever before.

At the same time, these issues have made it clear that - whatever the safery nets it place - blood should only be transfused when necessary. The remaining chapter of this thesis will address various approaches to this issue.

\section{REFERENCES}

1. Starr, D. (1998). An Epic History of Medicine and Commerce. New York. Alfed A. Knopf

2. Pearcy, L. T. (1985). "Gallen: a Biographical Sketch." Archaeology (November December).

3. Gale (1998). Encyclopedia of World Biography, The Gale Group.

4. Harvey, W. (1628). On The Morion Of The Heart And Blood In Animals.

5. Lower, R. (1666). "The succes of the experiment of transfusing the blood of one animal int another." Philos Trans R Soc London 1: 352.

6. Lower, R. (1666). "The method obserwed in cransfusig the "bloud"out of one animal int anorher." Philos Trans R Soc London 1:353- 358.

7. Denis, J. (1667). "Touching a late cure of an inveterate phrensy by the transfusion of "bloud". Philos Trans R Soc London 3: 617 - 624.

8. Denis, 1. (1668). "The difference risen about the transfusion of "bloud"." Philos Trans R So London 3: $710-715$.

9. Socieries, A. C. o. L. (1980). Dictionary of Scientific Biography, American Council c Learned Societies.

10. Blundell, J. (1828). "Experiments on the Transfusion of Blood by the Syringe." M. Chi Tr.(London) (9.): 56-92.

11. Blundell, J. (1828). "Obserwations on Transfusion of Blood. With a Description of $\mathbb{H}$ Gravitater." Lancet( 2): 321-326.

12. Blundell, J. (1829). "Successful Case of Transfusion." Lancet. (1): 431-432.

13. Schmidi, P. J. and A. G. Leacock (2002). "Forgotten transfusion history" John Leacock * Barbados." Bimj 325(7378): 1485- 7 .

14. Landois, L. (1875). Die Transfusion des Blutes. Leipzig, F. C. W. Vogel.

15. Lewisohn, R. (1944). "The Development of the Technique of Blood Transfusion Since 190 With Special Reference to Contriburions by Members of the Staff of the Mount Sin Hospital." I. Mr. Sinai Hosp. 10: 605-622.

16. Lewisohn, R. (1955). "Blood Transfusion: 50 Years Ago and Today." Surg. Gynec. ' Obst. (101): $362-368$.

17. Landsteiner, K. (1900). "Zur Kentniss der antifermentativen lytischen und agglutinierende Wirkungen des Blutserums und der Lymphe." Zentralbl. Bake. (28): 357-362.

18. Ortenberg, R. (1937). "Reminiscences of the History of Blood Transfusion." I. Mr. Sin Hosp. (4): 264-271. 
19. Lindeman, E. (1913). "Simple Syninge Transfusion with Special Cannulas. A New Method Applicable to Infants and Adults." Am. J. Dis. Child. (6):28-32.

20. Unger, L. J. (1915). "A. New Method of Syringe Transfusion." JAMA 64: 582-584. 
CHAPTER 3 


\section{INTRODUCTION}

Transfusion of blood and blood products can give rise to many complications. Although these risks are slowly declining, they still have to be considered as potential fatal. In this chapter we will review the main complications of blood transfusions. The approaches taken to prevent such complications are grouped together under the term "haemovigilance".

We will discuss the following issues:

1. Infectious complications

2. Transfusion reactions:
a. Haemolytic
b. Febrile non-haemolytic
c. Allergic
d. Non-immune haemolysis

3. Post-transfusion purpura

4. Transfusion-associated graft-versus-host disease

5. Transfusion-related acute lung injury

6. Transfusion-related immunomodulatory effects
a. Renal graft survival
b. Crohn's disease
c. Recurrent spontaneous abortion
d. Tumour recurrence
e. Postoperative infections

Finally, we will discuss the concept of haemovigilance systems.

\section{INFECTIOUS COMPLICATIONS OF TRANSFUSION}

Whilst transmission of syphilis and hepatitis B virus (HBV) have been recognized for many years, it was the identification of human immunodeficiency virus (HIV) and hepatitis $\mathrm{C}$ virus (HCV) that opened many eyes not only to the potential of transfusion as a route of infection, but also to its efficiency in the transmission of a whole range of infectious agents. Viruses, bacteria and protozoa have been clearly demonstrated to be transmitted by transfusion of blood and blood products. Fungi have not been reported to have been transmitted and there is uncertainty over whether prions are acrually transmitted by transfusion of blood and blood producrs (table 1). There are four main properties that generally 
Table 1 Infecrions agents who are reponted ro have becn transmitted by blood transfusion.

\begin{tabular}{|c|c|c|}
\hline Iruses: & Hepantis unuses. & Hepatitis A virus (HAV) \\
\hline & & Hepatitis B virus (HBV) \\
\hline & & Hepatitis C virus (HCV) \\
\hline & & $\begin{array}{l}\text { Hepatits D virus (HDV) (requires co-infection with } \\
\text { HBV) }\end{array}$ \\
\hline & Retrovinuiges & $\begin{array}{l}\text { Human Immunodeficiency virus }(H V) 1+2(+ \text { other } \\
\text { subtypes) }\end{array}$ \\
\hline & & Human $\mathrm{T}$-cell leukremia virus $(\mathrm{HTLV})+2$ \\
\hline & Herpes viruses & Human gromegallo virus (CMV) \\
\hline & & Epstein-Bart virus (EBV) \\
\hline & & Human Herpes wirus $8(\mathbb{H H V}-8)$ \\
\hline & Parrovinus & Parvovirus B19 \\
\hline & Miscellaneous viruses & $\mathrm{GBC} C$ \\
\hline enta & Endogenous & Treponema Pallidum (syphilis) \\
\hline & & Borrelia Burgdorferi (Lyme disease) \\
\hline & & Brucella melirensis (Brucellosis) \\
\hline & & Yersinia enterocoliticia / Salmonella spp. \\
\hline & Exogenous & $\begin{array}{l}\text { Environmental spectes - Staplyyloccocal spp / } \\
\text { pseudomonas / Serratia spp. }\end{array}$ \\
\hline & Ricketrsine & Ricketrsia rickertsil (Rodky Mountain spotted fever) \\
\hline & & Coxiella burnetii ( $Q$ fever) \\
\hline Prolozo & & Plasmodium sppu (mallaria) \\
\hline & & Jrppanosoma cruzi (Chagas disease) \\
\hline & & Toxoplasna gondil (roxoplasmosis) \\
\hline & & Babesia microni/divergens (babesiosis) \\
\hline & & Leishmania sp (Leishmaniasis) \\
\hline
\end{tabular}

need to be met for an agent to be transmitted by transfusion; it should give rise to an asymptomatic infection; be present in the blood stream; transmitred parenterally; and it should be able to survive during storage of the blood.

1. The agent must be capable of giving rise to asymptomatic infection in the infected potential donor. In the presence of an adequate selection and ques- 
tioning procedure the infected donor will be presumed healthy, and will be bled.

2. To transmit the disease, the infectious agent must be present in the blood or blood products. It must be carried free in the plasma or be present in the leucocytes or erythrocytes which will be transfused.

3. Only those infectious agents that are transmitted parenterally are considered transfusion-transmissible infectious agents (TIA).

4. Blood and blood products are stored under a number of different temperatures, and the infectious agent present has to survive these storage conditions in order to infect the recipient.

Bacterial infections are mostly caused by asymptomatic bacteraemia, skin contamination at the phlebotomy site or contamination during processing of the blood products.

The risk of a TTA can be reduced by several approaches. Although laboratory screening for a specific set of markers of infection is important, even more important is identification and deferral of porential high risk donors. Because a window period exist between infection and the detection in the screening test, donors of the high risk group have a greater risk of transmission of the infectious agent to the blood product pool.

\section{HAEMOLYTIC TRANSFUSION REACTIONS}

Most prominent are the acute and delayed haemolytic transfusion reactions (HTR). HTR result from immune-mediated destruction of transfused incomparible packed red blood cells (PRBC). Acute haemolytic transfusion reactions (AHTR) occur within $24 \mathrm{hr}$ after the transfusion, whereas the delayed haemolytic transfusion reaction (DHTR) typically occurs 5-7 days after the transfusion (1). HTR are caused by immunological incompatibility between blood donor and recipient. The haemolysis can be predominanty intravascular and characterized by gross haemoglobinaemia and haemoglobinuria, or extravascular when the only feature may be the decrease in haemoglobin. Most $\mathrm{ABO}$-incompatible transfusions are due to errors in identification of the patient, or to errors in the system of release or administration of the blood products (2) (figure 1). Estimates of $\mathrm{ABO}$-incompatible transfusions vary and may be underestimated, but two recent surveys have found a frequency of 1 in 30.000 transfu- 


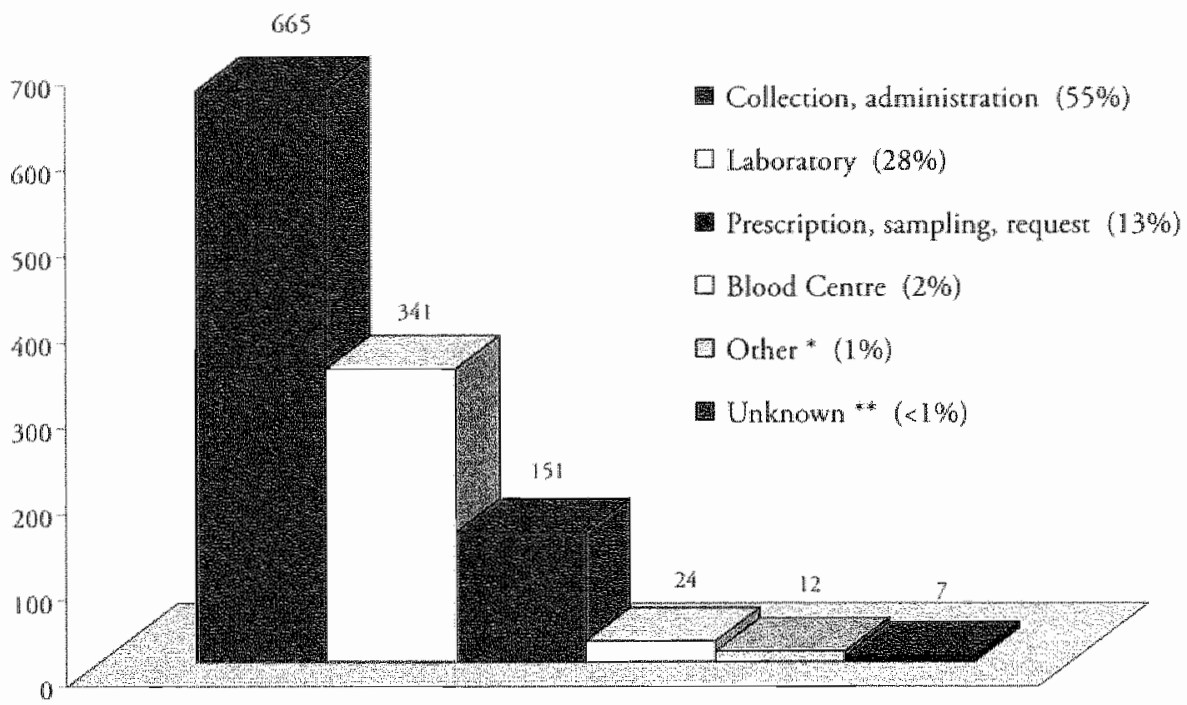

Figure 1 From SHOT Annual Report 2000/2001, These are accumulated data from 5 years of SHOT reporting on serious transfission complications in the UK Distribution of errors in IBCT cases 1996/97 - 2000/01 (no. cases=699, no. errors=1200) Incorrect Blood Component Transfusion is still the largesr category in Transfiusion Relared Complications. As the figure shows, errors are being nade in the whole process. Like in previous years multiple errors were implicated in many "wrong blood" incident, up to 7 errors $(\mathrm{n}=2)$ are reported.

sions $(3,4)$. Not all ABO-incompatible transfusions cause morbidity and mortality; However, as little as $30 \mathrm{ml}$ group A cells given to a Group O recipient can be fatal. Less frequent, Kell, Kidd and Duffy antibodies can be responsible for haemolytic transfusion reactions.

\section{FEBRILE NONHAEMOLYTIC TRANSFUSION REACTIONS}

Febrile Nonhaemolytic Transfusion Reacrions (FNHTR) are suspecred in recipients of blood components who experience an increase in temperature of $1{ }^{\circ} \mathrm{C}$ or more in the absence of other identifiable causes for the fever. They are the most common encountered transfusion teaction (5). FNTHR are generally self-limited, but the recipient may experience anxiety and discomfort. Because the clinical presentation of fever and chills may represent a life-threarening AHTR, the first step is to discontinue the transfusion. If transfusion is still required following resolution of a reaction, other PRBC should be issued. 


\section{ALLERGIC TRANSFUSION REACTIONS}

Mild allergic reactions may present as generalized urticaria, pruritis, and flushing, whereas more severe reactions are characterized by stridor, wheezing, dyspnoea and cyanosis, up to circulatory instability and anaphylaxis. Restarting the infusion is not recommended.

\section{NONIMMUNE HAEMOLYSIS OF RBC}

Non-immune haemolysis involves destruction of $\mathrm{RBC}$ within the circulation due to osmotic, thermal chemical or mechanical damage. These are rarely life-threatening and mostly preventable.

\section{POST-TRANSFUSION PURPURA}

Post-Transfusion Purpura (PTP) is a self limiting thrombocytopenia that develops 5-10 days after transfusion of blood components containing platelet antigens. PTP is a rather rare complication of transfusion, but can account for mortality due to intracranial haemorrhage during extreme thrombocytopenia (6).

\section{TRANSFUSION-ASSOCIATED GRAFT VERSUS HOST DISEASE}

TA-GVHD is a rare complication of allogenic uransfusion, but is likely to be underreported. The mortality is presumed to be higher then $90 \%$. TA-GVHD is caused by replication of competent donor lymphocyte in the cellular blood product, which engraft and lead to immune-mediated destruction of host tissues. The development of TA-GVHD reflects the inability of recipients's immune system to reject the transfused lymphocytes (7).

\section{TRANSFUSION RELATED ACUTE LUNG INJURY}

Transfusion related lung injury (TRALI) is a syndrome of acute hypoxia due to non-cardiogenic pulmonary edema. The syndrome is clinically indistinguishable from adult respiratory distress syndrome (ARDS). TRALI is thought to contrib- 
ute significantly to mortality in 5 to 10 percent of patients who experience the reaction and is the third leading cause of ransfusion-related mortality. Symptoms typically commence within 1 to 2 hours of transfusion but can occur as late as 6 hours. The syndrome has been described following infusion of any plasma-containing blood component, including RBCs, whole blood, FFP, cryoprecipitate, apheresis platelets, platelet concentrates. TRALI was first recognized as a discrete dinical entity almost 20 years ago (8). Before that time, there were several reports of noncardiogenic pulmonary edema, associated with transfusion, which were likely TRALI reactions. These reactions were given descriptive names such as noncardiogenic pulmonary edema, pulmonary hypersensitivity reaction, and severe allergic pulmonary edema.

Although the exact mechanism of lung injury in TRALI is not completely understood, the preponderant evidence favors an antigen-antibody-mediated model. The exact manner in which antibodies trigger a TRALI reaction has not been determined. The assumption has been that granulocytes with adherent antibodies localize in the pulmonary microvasculature and release cytokines locally, resulting in increased vascular permeability and pulmonary edema.

TRALI needs to be recognized as a serious consequence of transfusion, and must be diagnosed, reported, and managed appropriately (9). Evaluation should include a thorough search for an antibody-antigen reaction. Donors directly implicated in a case of TRALI should be deferred from donating plasma-containing blood components.

\section{TRANSFUSION IMMUNOMODULATORY EFFECTS}

One fascinating development has been the discovery of the effects of transfused blood products on the immune system. A number of such effects have been described, some of them beneficial, others decidedly cletrimental.

\section{Enhanced renal allograft survival}

The beneficial effect of prior transfusion on renal allograft surviwal was described more then 20 years ago. It became standard policy to expose patients on the transplant waiting list to multiple transfusions. Still, the exact mechanism of the beneficial effects has not been elucidated. 


\section{Crohn's Disease}

Some retrospective studies have shown a significant benefit (i.e. decrease in relapse rate) in patients with Crohn's disease receiving blood transfusions $(10,11)$. However, this has not been demonstrated in all investigations (12).

\section{Recurrent spontaneous abortion}

Women with recurrent spontaneous abortion have been treated with infusion of their partner's or third-party leucocytes in order to induce immunological tolerance of the foetus. Although some studies in the past showed possible effects, subsequent randomised trials showed no effect (13).

\section{Tumour recurrence}

Over 70 clinical studies have examined the possible effect of transfusion on recurrence of a number of cancers. Meta-analysis of these studies suggests a deleterious effect of blood transfusions on cancer recurrence rate $(14,15)$. Srill, adequate randomised controlled trials have to be performed before this issue can be considered certain.

\section{Postoperative infections}

The evidence for transfusion as an independent risk factor for infection commonly seen after elective surgery is increasing $(16,17)$.

\section{HAEMOVIGILANCE SYSTEMS}

The aim of haemovigilance is to detect and to analyse all unwanted effects of blood transfusion in order to correct their cause and to prevent recurrence, and to improve the safery of blood transfusion. Haemovigilance is defined as: "a set of surveillance procedures covering the whole transfusion chain (from the collection of blood and its components to the follow-up of its recipients), intended to collect and assess information on unexpected or undesirable effects resulting from therapeutic use of labile blood products, and to prevent their occurrence and recurrence" (18). The term was probably created in France and has Greek and Latin toots: haema ("blood"), and vigilans ("paying a particular attention to"). 
Table 2 SHOT Annual Report $2000 / 2001$. Owerall mortality/norbidiny figures by filly andysed questionnaires $1996 / 97-2000 / 01(n-1148)$ These are accunulated data from 5 years of SHOT reporting on serious ransfusion complications in the UK. The tables shows data on transfusion complications concerning Incorrect Blood Component Transfused, Acure Transfusion Reaction, Delayed Transfusion Reactions, Post Iransfusion Purpura, Transfusion-Associated Graft Veisus Host Disease, Transfusion Relared Acure Lung Injury and Transmilssion Transinired Infections (UC = Un Classiffed).

Toral IBCT ATR DTR PIP TA. TRALI TT UC $\mathrm{GNOD}$

\begin{tabular}{|c|c|c|c|c|c|c|c|c|}
\hline Minor or no morbidity & 819 & 566 & 121 & 103 & 24 & 0 & 0 & \\
\hline Major morbidicy & 165 & 69 & 3 & 18 & 11 & 0 & 49 & 2 \\
\hline $\begin{array}{l}\text { Death definitely } \\
\text { artubuned to transfusion }\end{array}$ & 38 & 5 & 2 & 4 & 1 & 13 & 6 & \\
\hline $\begin{array}{l}\text { Death probably } \\
\text { atuributed to innsfusion }\end{array}$ & 3 & 1 & 0 & 0 & 0 & 0 & 2 & \\
\hline $\begin{array}{l}\text { Death possibly artributed } \\
\text { to transfusion }\end{array}$ & 21 & 5 & 4 & 1 & 1: & 0 & 10 & \\
\hline $\begin{array}{l}\text { Dealh unrelated to } \\
\text { transfusion }\end{array}$ & 90 & 56 & 13 & 14 & 3 & 0 & & \\
\hline Oukcome unkinown & 12 & 6 & 3 & 1 & 0 & 0 & & \\
\hline Totals & 1148 & & & 1 & & & & \\
\hline
\end{tabular}

Haemovigilance, as a safety concept, appeared in the beginning of the $1990 \mathrm{~s}$ in France, and the first nation-wide mandatory haemovigilance sytem was set up in 1992 in the same country. The United Kingdom followed in 1996 with the voluntary "Serious Hazards of Transfusion" (SHOT) steering group (http://www.shot.demon.co.uk/) (table 2).

On the European level, haemovigilance was accorded interest around 1995. The European Council published its resolution of June 2, 1995 and a communication on "Blood Safery and Self-Sufficiency in the Community" with the aim to improve public confidence in the safery of blood supply. The results of the project should be threefold: a. identify objectives, methods and means related to the establishment of a Community-wide haemovigilance network which would also serve to improve exchange of information between the Member States; b. promote co-operation between Member States on the systematic monitoring of risks and hazards associared with blood collection and transfusion and provide guidance in this respect; $c$. determine the measures that add value to the actions and 
measures of Member Stares and which need to be proposed to the European Commission in order to enhance the safety of the blood chain. In Paris, on the 16th of July 2001 the European Haemovigilance Nerwork (EHN) was started (hrtp//www.ehn-org.net/). In order to continuously improve safery in blood transfusion, the EHN advocated the following:

Member States should introduce and matntain efficient haemovigilance systems that collect data on side effects $/$ adverse events in recipients, dur ing and after transfusion of blood and blood components gather data on incidents in donors, during and after donation, as well as epidemiological data on donors (especially in relation with incidence and prevalence rates of infectious diseases markers).

Rapid Alent / Early Warning should be incorporated in the haemovigilance system to allow instant reaction in case of emerging threat to the blood supply, of any kind.

In 1996 the Dutch Inspectorate of Health enquired whether a national surveillance system for haemovigilance could be developed for the Netherlands. This request was inspired by the Untied Kingdom's initiative to install a reporting system for SHOT. An independent foundation named Transfusion Reactions in Patients (TRIP) was established, owned by the professional medical societies engaged in blood transfusion. TRIP was formally launched at the 5 th European Haemovigilance Seminar in Amsterdam on February 6-7, 2003. The TRIP office has the aim to anonymously collate, register, analyze and report on the safety of blood transfusion (rable 3). In addition, TRIP aims to enhance the safety of blood transfusion by educational programs on this topic. The TRIP program closely resembles the British SHOT system, in being a voluntary system supporting professionals and in its focus on serious adverse events. It is recognized that underreporting may exist, but it is felt that in the Netherlands a voluntary system would be more productive than a compulsory system. TRIP holds the wiew that the correct and optimal use of blood is as important for blood transfusion safery as is the prevention of adverse advents. 
Table 3 The list of ransfusion complications TRP requests hospitals to report to them.

1. Incorrect blood product transfused

2. Acute Haemolytic Transfusion Reaction

3 Delayed Type (Haemolytic) Transfusion Reaction

4. Allergic Reaction

5. Bactetial Contamination

6. Transfusion-related Lang Injury (TRALI)

7. Transfusion-associated Guafr Versus Hose disease (TA-GVHD)

8. Post-nansfusion Purpura (PTP)

9. Post-transfusion Viral Infect

10. Post-transfusion malaria and other parasitic infection

11. Circulatory Overload

12. The novo appearance of antibodies to blood group antigens or HLA

13. Non haemolytic febrile transusion reactions $>$ oC

\section{CONCLUSION}

Although a blood transfusion has never been safer, transfusion still accounts for some major morbidity and mortality. In this aspect haemovigilance systems have an important function in safeguarding transfusion medicine. Errors have to be prevented and improvement in the use of blood products might be achieved through an audit process based on simple indicators, providing the responsible clinician with continuous feedback of results obtained.

This can only be achieved if as much incidents are reported as possible, and is only possible if all prescribing physicians are aware of the complications of blood transfusion and are willing to report to the haemovigilance systems.

\section{REFERENCES}

1. Vamvakas, E. C. A. A. Pineda, R. Reisner, P. J. Santrach and S. B. Moore (1995). "The differentiation of dellayed themolytic and delayed serologic transfusion reactions: incidence and predictors of hemolysis." Transfusion 35(1): 26-32.

2. Sazama, K. (1990). "Repors of 355 mansfusion-associated deaths: 1976 through 1985." Transtusion $30(7): 583-90$ 
3. Linden, J. V., B. Paul and K. P. Dresster (1992). "A report of 104 transfusion errors in New York State." Transfusion 32(7): 601-6.

4. Linden, J. V., K. Wagner, A. E. Voytovich and I. Sheehan (2000), "Transfusion errors in New York State: an analysis of 10 years' experience." Transfusion $40(10): 1207-13$.

5. DeChristopher, P. J. and R. R. Anderson (1997). "Risks of transfusion and organ and rissue transplantation: practical concerns that drive practical policies." Am I Clin Pathol 107(4 Suppl 1): $\$ 2-11$.

6. Taaning, E. and A. Svejgaard (1994). "Post-transfusion purpura: a survey of 12 Danish cases with special reference to immunoglobulin $\mathrm{G}$ subdasses of the platelet antibodies." Transfus Med 4(1): 1-8.

7. Ahya, R., J. G. Douglas and H. G. Warson (1998). "Transfusion associated graft versus host disease in an immunocompetent individual following coronary artery bypass grafting." Heart 80(3): 299-300.

8. Popovsky, M. A. and S. B. Moore (1985). "Diagnostic and parhogeneric considerations in transfusion-related acute lung injury." "Transfusion 25(6): 573-7.

9. Kopko, P. M., T. G. Paglieroni, M. A. Popowsky, K. N. Muto, M. R. Mackenzie and P. V. Holland (2003). "TRALL: correlation of antigen-antibody and monocyte activarion in donor-recipient pairs." Transfusion 43(2): 177-84.

10. Peters, W. R., R. D. Fry, J. W. Fleshman and I. J. Kodner (1989). "Multiple blood transfusions reduce the recurrence rate of Crohn's disease." Dis Colon Rectum 32(9): 749-53.

11. Silvis, R., W. H. Steup, A. Brand, K. A. Zwinderman, C. B. Lamers, G. Griffioen and H. G. Gooszen (1994). "Protective effect of blood transfusions on postoperative recurrence of Crohn's disease in parous women." "Transfusion 34(3): 242-7.

12. Hollaar, G. L.. H. G. Gooszen, S. Post, J. G. Willians and L. R. Sutherland (1995). "Perioperative blood transfusion does not prevent recurrence in Crohn's disease. A pooled analysis." J Clin Gastroenterol 21(2): 134-8.

13. Ober, C., T. Karrison, R. R. Odem, R. B. Barnes, D. W. Branch, M. D. Stephenson, B. Baron, M. A. Walker, J. R. Scott and J. R. Schreiber (1999). "Mononuclear-cell immunisation in prevention of recurrent miscarriages: a randomised trial." Lancer 354(9176): 365-9.

14. Vamvakas, E. C. (1995). "Perioperariwe blood ransfusion and cancer recurrence: meta-analysis for explanation." Transfusion 35(9): 760-8.

15. Amaro, A. C. and M. Pescatori (1998). "Effect of perioperative blood transfusions on recurrence of colorectal cancer: meta-analysis stratified on risk factors." Dis Colon Recum 41(5): 570-85.

16. Vamvakas, E. C. S. B. Moore and M. Cabanela (1995). "Blood transfusion and septic complications after hip replacement surgery." Transfusion 35(2): 150-6.

17. Vamvakas, E. C. and J. H. Carven (1998). "Transfusion of white-cell containing allogeneic blood componenrs and postoperative wound infection: effect of confounding factors." Transfus Med 8(1): 29-36.

18. Faber, J. C. (2002). "Haemovigilance around the world." Vox Sang 83 Suppl 1: 71-6. 


\section{CHAPTER 4}

E.W.G. Weber, R. Slappendel, D.B. van der Schaaf and J.D. Oosting:

Published: Nederlands Tijdschrift voor Orthopedie 2000; 7:10-12. 


\section{ABSTRACT}

National guidelines for the clinical practice of red blood cell transfusions have been transformed at the Sint Maartenskliniek into a protocol. Pretransfusion hemoglobin level is the sole indicator of need for red blood cell transfusions. In combination with other factors, such as technique of anesthesia and use of COX-2 selective NSAID's, the guidelines for clinical practice did reduce the need for red blood cell transfusions by $50 \%(\mathrm{p}<0.001)$.

\section{INTRODUCTION}

Blood loss is a common complication during orthopaedic surgery and often requires homologous blood transfusion (HBT). With a HBT, a patient is exposed to transfusion-related infections, transfusion reactions, the effecrs of immunomodulation, and potential complications due to human errors in the administration of the packed red blood cells (PRBC) (1). At the same time, PRBC are donated voluntarily (in the Netherlands) and the pool of PRBC in the Netherlands is not infinite. These were the reasons to develop a nationwide consensus for PRBC transfusions in the perioperative period. This nationwide consensus resulted in a transfusion protocol for our hospital in which the haemoglobin concentration was the sole indication for $\mathrm{HBT}$. In this study we investigated the HBT ratio before and after the introduction of the new protocol.

\section{PATIENTS AND METHODS}

We based our HBT protocol on the national consensus agreement for transfusions(1). A HBT would only be administered if the haemoglobin concentration of the patient was known (unless active bleeding occurred). Although in the intra-and postoperative phase a haemoglobin concentration of at least $8.8 \mathrm{~g} / \mathrm{dl}$ was advocated, a lower haemoglobin concentration $(8 \mathrm{~g} / \mathrm{dl})$ was accepted as transfusion trigger, as patients in the perioperarive phase are frequently hacmodiluted with crystalloids or colloids. For the cardiac compromised patients we accepted $10.4 \mathrm{~g} / \mathrm{dl}$ as trigger, and for patients who predonated autologous blood we accepted $11.2 \mathrm{~g} / \mathrm{dl}$. 
Table 1 Transfusion protocol.

All patients in the post-operative phase

Wirhin 4 hours after the operation

More than 4 hours afrer the operation

$\mathrm{Hb}>8 \mathrm{~g} / \mathrm{dl}=0$ packed cells

$\mathrm{Hb}>8 \mathrm{~g} / \mathrm{dl}=1$ packed cells

$\mathrm{Hb}>8 \mathrm{~g} / \mathrm{dl}-1$ packed cells

$\mathrm{Hb}<8 \mathrm{~g} / \mathrm{dl}=2$ packed cells

$\mathrm{Hb}<72 \mathrm{~g} / \mathrm{dl}=2$ packed cells

$\mathrm{Hb}<7.2 \mathrm{~g} / \mathrm{dl}=3$ packed cells

Cardiac compromised paticns

Within 4 hours after the operation

More than 4 hours after the operation

$\mathrm{Hb}<8.8 \mathrm{~g} / \mathrm{dl}=1$ packed cells

$\mathbb{H b}<8 \mathrm{~g} / \mathrm{dl}=2$ packed cells

$1 \mathrm{~b}<8 \mathrm{~g} / \mathrm{dl}=2$ packed cells

$\mathrm{Hb}<8 \mathrm{~g} / \mathrm{dl}=3$ packed cells

$\mathrm{Hb}<72 \mathrm{~g} / \mathrm{dl}=3$ packed cells

$\mathrm{Hb}<72 \mathrm{~g} / \mathrm{dl}=3$ packed cells

Patiens who predonated autologous blood

$1 \mathrm{~b}, 1 \mathrm{l} 2 \mathrm{~g} / \mathrm{dl}=1$ packed cells

This protocol was introduced in May 1996 in our Postoperative Care / Inrensiy Care Unit (PACU/ICU), and after September 1997 it was applied hospital-wic (table 1). After the introduction of the protocol a HBT was nor delivered unless known haemoglobin concentration was available which met the transfusion tri! ger. Since 1991 our hospital, specialized in elective orthopaedic surgery, h: maintained an extensive database of all variables concerning blood loss, oper: tion, duration, surgeon, anaesthesia etc. "The data about HBT is retained for : least 10 years after delivery of the PRBC. These databases were merged for th period of January 1, 1998, until September 30, 1998. We compared three per ods: (1) Period A, the old situation From January 1995 until May 1996; (' Period B, from June 1996 until August 1997, when the protocol was only impl. mented on the PACU/ICU; and (3) Period C, from September 1997 until Sel tember 1998 when the protocol was implemented hospital-wide. The number HBT was compared in these three periods. Proportions were analysed wirh stati tics Chi-square and Fisher's exact test. A p-value of less than 0.05 was presume significant.

\section{RESULTS}

In Periods A, B and C, respectively 4620,5703 and 4264 patients were con pared for the incidence of blood transfusions. Patient populations and types , 
Table 2 Results.

Operations

$\begin{array}{ccc}\text { Period A } & \text { Period B } & \text { Perod C } \\ 4620 & 5703 & 4264\end{array}$

Type anaesthesia:

- General [\%] 38

- Neuraxial [\%]

- Peripheral nerve [\%]

Male [\%]

Age [yr.]

Operation time [min.]

Blood loss [ml.]

Packed cell usage per operation [n]

0.48

$0: 33$

Type of anaesthesia, more combinations can be possible $(*=0<0,001)$.

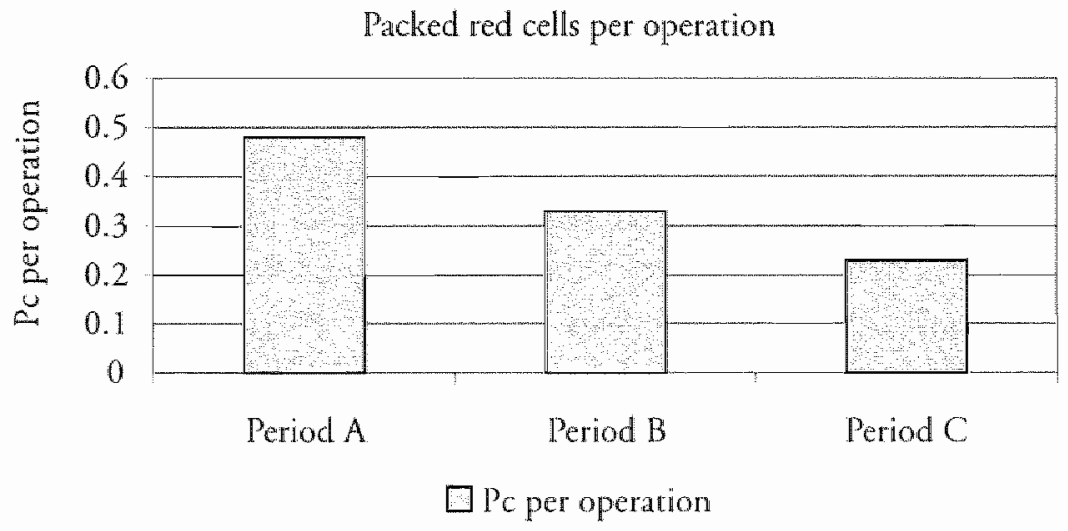

Figure 1 Packed red cells per operation.

operation in the 3 patient groups were comparable (table 2 ). The mean consumption of PRBC per operation was 0.48 in period $A, 0.33$ in period $B$ and 0.23 in period $C$. The differences berween period $A$ and $B$, period $A$ and $C$, and period $B$ and $C$ were significanr ( $p<0.001$ ) (figure 1). The mean blood loss per operation showed a tendency to decrease, respectively $251 \mathrm{~mJ}, 206 \mathrm{ml}$ and 189 ml for the periods $A, B$, and C (figure 2 ). 
Mean blood loss [ml]

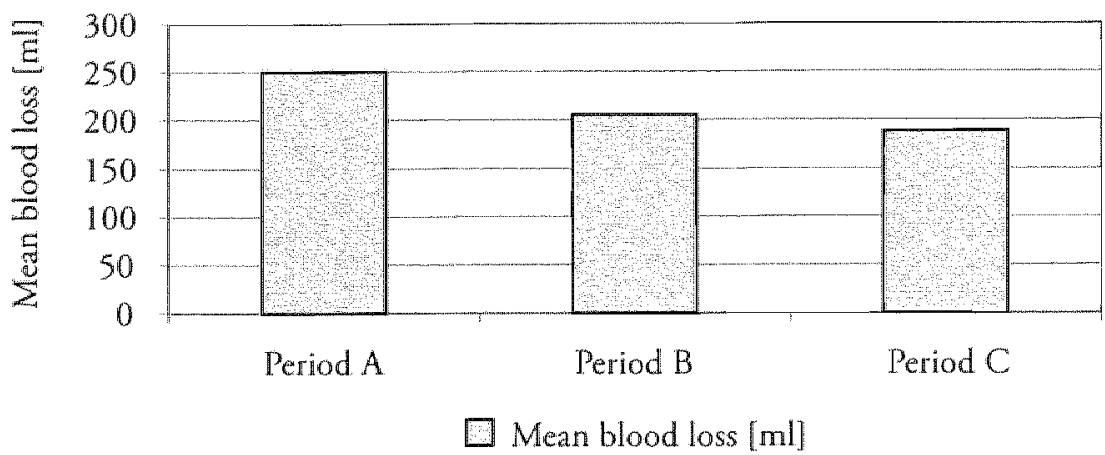

Figure 2 Mean blood loss.

\section{DISCUSSION}

The options to reduce HBT are numerous. Examples include transfusion guidelines, perioperative blood saving techniques, novel surgical techniques, anticoagulation management, autologous predonation and the perioperative use of erythropoietin (2). The responsibility for determining the indication for the administration of a blood transfusion rests with the transfusion commission, surgeons and anaesthesiologists. In our hospital the responsibility for transfusion guidelines and perioperative cell saving techniques is delegated to the anaesthesiologists, whereas the responsibility for operative technique and anticoagulation management rests with the orthopaedic surgeons. In absence of a known transfusion trigger, feedback with the prescribing physician is essential for maintenance of a transfusion protocol. Guidelines for autologous predonations and preoperative administration of erythropoietin are changing, but since the year 2000 erythropoietin is registered for pre-operative use in major orthopaedic surgery for patients with a haemoglobin concentration less then $13 \mathrm{~g} / \mathrm{dl}$.

Of course is it not possible to maintain all confounding factors constant that can affect per-operative blood loss during a period of evaluation as long as the present study. Several important factors changed in our hospital during the evaluation period. Changes occurred in the surgical staff, and the percentage of loco-regional anaesthesia increased. Also, during the evaluation period the introduction of more COX-2 selective NSAID's took place. Undoubtedly, these other factors are likely to be to some extend responsible for the decreased blood loss and 
thus for decreased perioperative transfusion requirements $(3,4)$. Still, our study showis clearly the benefits of employing strict perioperative transfusion guidelines, as a $50 \%$ decrease in PRBC transfusions was seen during the observation period compared to the $25 \%$ decrease in blood loss during the same periods.

Perioperative transfusions are responsible for $60 \%$ of all transfusions in the Netherlands. For $40 \%$ of these, the indication were poorly specified: blood loss, rourine practice, cardiovascular changes, weakness or fatigue were cited. Current guideline, as well as the results of the present study, indicate that in the perioperative period a patient should only be transfused if the haemoglobin concentration is known (5).

\section{REFERENCES}

1. CBO/MWR (1997). Tweede herziening Consensus Bloedtransfusiebeleid: $20-9$.

2. Kearing. E. M. (1999). "Current options and approaches for blood management in orthopaedic surgery." Instr Course Lect 48: 655-65.

3. An, H. S., W. E. Mikhail, W. T. Jackson, B. Tolin and G. A. Dodd (1991). "Effects of hypotensive anesthesia, nonsreroidal anriinflammatory drugs, and polymerhymethacrylate on bleeding in total hip arthroplasty patients." I Arthroplasty 6(3): 245-50.

4. Hilleman, D. E., S. M. Mohinddin and B. D. Lucas, Jr. (1993) "Nonsteroidal antiinflammarory drug use in patients receiving warfarin: cmphasis on nabumetone." Am J Med 95(2A): 30S-34S.

5. Buiting, A. M. and R. B. Dinkelaar (1998). "TSurvey on blood transfusion policy within Dutch hospitals: wide discrepancies. Central Guidance Organization for Peer Reviewl." Ned Tijdschr Geneeskd 142(6): 293-7. 


\section{CHAPTER 5}

Eric W.G. Weber Robert Slappendel, Martin H. Prins, Dick B. van der Schaaf and Marcel E. Durieux.

Submitted. 


\section{SUMMARY}

Pacients who receive any homologous blood transfusion (HBT) after major orthopaedic surgery have a longer duration of hospitalisation (DOH), which can not be explained by a greater incidence of infections in the transfused patients. To determine if minor wound healing disturbances (WHD) are increased by HBT, and if such disturbances are correlated with DOH, we performed an observational study in 444 consecutive patients scheduled for elective primary hip surgery. Transfusion, wound and infection parameters were collected at five time points during treatment. Of the 444 consecutive patients studied, 92 received blood transfusions during their perioperative course, and 352 did not. Thirty-one percent of transfused patients developed WHD vs. $18 \%$ of the non-transfused group $(p<0.05)$; HBT was the only significant predicror for development of WHD. DOH was prolonged in transfused patients (12.3 vs. 9.8 days), and could be predicted by four significant variables: requirement for blood transfusion (adds $2.71 \pm 0.47$ days), presence of WHD (adds $1.25 \pm 0.45$ days), duration of operation (adds $0.2 \pm 0.08$ days $/ 10 \mathrm{~min}$ ), and patient age (adds $0.9 \pm 0.16$ days/ 10 years). These data suggest that HBT may increase the incidence of WHD, and that prevention of HBT may be of relevance in limiting duration of admission after elective orthopaedic surgery.

Keywords. blood transfusion, immunomodulation, infections, wound disturbance.

\section{IMPLICATION STATEMENT}

Homologous blood transfusion during elective orthopaedic surgery is associated with an increase in minor wound healing disturbances. Requirement for transfusion and present of wound healing disturbances are the main factors predicting duration of hospitalisation in these patients.

\section{INTRODUCTION}

Perioperative blood loss is still a major problem in elective orthopaedic surgery. Homologous blood ransfusion (HBT) is the standard approach to trear potentially detrimental decreases in thaemoglobin $(\mathrm{Hb})$ concentration. However, HBT 
is associated with various adverse events, including febrile reactions induced by leukoagglutinins and transmission of infectious diseases. Moreover, HBT has an immunomodulatory effect, which is hypothesized to increase the frequency of postoperative infections $(1,2)$. This issue is far from resolved, as observational cohort studies comparing patients who had or did not have transfusions produced conflicting results $(3,4,5,6)$. A recent meta-analysis found no evidence that autologous versus homologous blood transfusion reduced postoperative infections ( 7 ). In a similar fashion, recent randomised controlled trials on the effect of leukocyte-depleted blood transfusions yielded conflicting results as to the frequency of postoperative infections $(8,9,10,11,12,13,14,15)$.

Nonetheless, the clinical observation that patients who receive any HBT after major orthopaedic surgery do stay in the hospital significantly longer is undisputed (16). As postoperative infections are relatively rare $(1-3 \%)$, and as the role of HBT herein is not yet established (17), other factors are likely to be responsible for the prolonged hospital stay. A host of other factors (age, length of surgery, use of implants etc.) might influence the incidence of post-operative infections as well, and, in addition, the endpoint of frank wound infecrion may nor be an appropriate one. Less severe rypes of wound healing disturbance could occur after transfusion and lead to subsequent complications or prolonged hospitalisation. To address these issues we undertook this prospective observational study. In 444 patients who underwent elective total hip arthroplasty, we studied (among orher parameters) the frequency of HBT, wound disturbances, superficial and deep wound infections, and length of hospital admission.

\section{PATIENTS AND METHODS}

We performed an observational study in 444 consecurive patients hospitalised to undergo total hip replacement in the St. Maartens Hospital, Nijmegen, The Netherlands. The hospital's Insriturional Review Board approved the study, and all patients gave written informed consent after having received information and explanation of the study. Inclusion criteria included: planned elective primary total hip arthroplasty; age at least 18 years; living in The Netherlands or otherwise available for follow-up for at least 6 weeks post-surgery. Exclusion criteria were: any infection of any body system at screening as determined by symptoms, by erythrocyte sedimentation rate (ESR) $>20 \mathrm{~mm}$ (unless known to be pre-existent); any blood transfusion received in the six weeks before surgery; any surgery 
in the six weeks before surgery. Patients who donated autologous blood before surgery were excluded. from the study. During admission patients received standard care according to hospital protocol. Transfusions of packed red blood cells were administered according to the following transfusion triggers: $\mathrm{Hb}<8.1 \mathrm{~g} / \mathrm{dl}$ $(5.0 \mathrm{mmol} / 1)$ during surgery and until 4 hours post surgery; and $\mathrm{Hb}<8.9 \mathrm{~g} / \mathrm{dl}$ $(5.5 \mathrm{mmol} / 1)$ more than 4 hours post surgery. For subjects suffering from cardiovascular disease all transfusion triggers were increased by $0.8 \mathrm{~g} / \mathrm{dl}(0.5 \mathrm{mmol} / 1)$. Packed red blood cells were supplied by the local blood bank and consisted of buffy coat-depleted red cells, mean volume $320 \mathrm{ml}, \mathrm{Hb} 17.8 \mathrm{~g} / \mathrm{dl}, \mathrm{Hr} 0.58$ leukocytes $0.4 \times 10^{9} / 1$

\section{DATA COLLECTION}

Data were collected at five time points during treatment: 1 : last week prior to surgery (screening); 2: on the day of surgery (POD0); 3: one day after surgery (POD1); 4: four days after surgery (POD4); 5 : at discharge.

At all these time points, we recorded vital signs, any signs of infection present and other relevant parameters. In addition, the following data were collected at specific time points: At screening: informed consent, medical history "physical examination, use of antibiotics, transfusion information over the past 3 months (including pre-transfusion $\mathrm{Hb}$, volume and type of product transfused, and routine clinical laboratory tests (including at least: $\mathrm{Hb}, \mathrm{ESR}$, white blood cell count and differentiation, serum pre-albumin and C-reactive protein).

Ar POD0: all routine clinical postoperative assessments, name of the surgeon, $\mathrm{Hb}$ level.

Ar POD1: blood loss, transfusion data (including units and type of blood products given and $\mathrm{Hb}$ before transfusion), any blood saving techniques used medi- $^{-}$ cations used.

At POD4: serum pre-albumin and pre-transfusion $\mathrm{Hb}$ (only if transfused). At discharge: blood loss, transfusion data (number of units, type of blood products), and length of hospiralisation. 
In addition, during and after surgery until discharge all relevant medical events were documented in a database: infections, wound leakage, superficial wound disturbances, haematomas etc. Wound and urinary tract infections were defined by the presence of a positive culture. Classification of infection as "deep" required joint involvement. Wound disturbance was defined by erythematous inflammation of more than $1 \mathrm{~cm}$, wound fluid discharge, purulent surure, wound dehiscence, blister and/or any degree of wound necrosis. Moreover, certain events were recorded at any moment during the follow-up period: postoperative infections, withdrawal from study (including reason of withdrawal) and death (including cause of death).

\section{STATIST"ICAL ANALYSIS}

Descriptive statistics were used when appropriate. The occurrence of wound disturbances in relation to receiving blood transfusion and other potentially relared factors were calculated with logistic regression analysis. For this purpose use of transfusion and gentamycin cement were coded as binary variables (yes or no), other factors were handled as a continuous variables.

First the effect of each variable was calculated with univariate analysis. Then, using stepwise conditional back and forward selection of variables, multivariate analysis was performed. The effect of variables on the duration of hospitalisation was calculated using linear regression analysis. For this purpose the duration of hospitalisation was log-rormalized. A similar uni- and multivariate analysis approach was used.

\section{RESULTS}

\section{Differences between transfused and non-transfused patients}

Of the 444 consecutive patients studied, 92 received blood transfusions during their peri-operative course, and 352 did not. A comparison between these two groups is provided in table 1. There were significant differences between these groups in gender distribution, length, weight, pre-operative Hb, ESR and pre-albumin levels, operation duration, peri-operative blood loss, total blood loss, and duration of hospitalisation. Of these, the differences in pre-operative 
Table 1 Characteristics of transfused and nom-transfused patients.

\begin{tabular}{|c|c|c|c|c|}
\hline Group statistics (mean) & Totil & No transfusion & Tramsfusion & $\mathrm{p}$ \\
\hline Patients: & 444 & 352 & 92 & \\
\hline Blood transfusions & $0.36(0,83)$ & $0(0)$ & $17(1.0)$ & \\
\hline Age (years) & $63.3(119)$ & $63.1(11.2)$ & $642(145)$ & NS \\
\hline Sex $(\%$ male $)$ & $34(47.3)$ & $39(49)$ & $13(34)$ & $<0.001$ \\
\hline Length (cm) & $169(8.9)$ & $171(8.9)$ & $167(8.6)$ & 00.05 \\
\hline Weight (kg) & $776(14.4)$ & $79(13,8)$ & $72(15.4)$ & $<0,001$ \\
\hline ESR (mm in $1^{\text {se }}$ hour) & $15.3(11.8)$ & $14.5(11.1)$ & $18.3(13.8)$ & $<0.05$ \\
\hline Pre-albumin (mmolld) & $281(557)$ & $285(56,2)$ & $266(51,4)$ & $<0.05$ \\
\hline CRP & $6.23(9.7)$ & $6.250 .6)$ & $617(9.8)$ & NS. \\
\hline Pre-operative Hb (monol/l) & $8.47(0.77)$ & $8.6(0.72)$ & $8,0(075)$ & $<0.001$ \\
\hline Operation time (min). & $73(22,7)$ & $71(19.5)$ & $80(31.6)$ & $<0.05$ \\
\hline Peri-operative blood loss (ml) & $591(363)$ & $540(274)$ & $789(551)$ & $<0001$ \\
\hline Total blood loss $(\mathrm{ml})$ & $975(511)$ & $922(431)$ & $1185(716)$ & 80.001 \\
\hline Genramycine cement used $(\%)$ & $15(30)$ & $14(34)$ & $21(41)$ & $\mathrm{N}, \mathrm{S}$ \\
\hline Wound disturbance (\%) & $21(40)$ & $18(39)$ & $31(47)$ & $<0.05$ \\
\hline Positive wound culture (\%) & $225(15)$ & $1,99(14)$ & $326(18)$ & NS \\
\hline Deep infection $(\%)$ & $1(8)$ & $18)$ & $1(10)$ & NSS \\
\hline Urinary trace infecrions (\%) & $3.6(17)$ & $369(19)$ & $326(18)$ & N.S. \\
\hline Mean hospical stay (days) & $10.2(4.1)$ & $9.8(3.5)$ & $12.3(5.3)$ & $<0.001$ \\
\hline
\end{tabular}

ESR, pre-albumin levels, and length were considered to be so small as to be clinically insignificant. As expected, there were no significant differences in the rate of positive wound cultures or the incidence of deep infection ( $1 \%$ in each group). Nonerheless, the clear trend for increased incidence of positive cultures (1.99 in the non-transfused group vs. 3,26 in the transfused group) suggested that a more detailed analysis of wound healing disturbances would be warranted.

\section{Association of transfusion with wound disturbances}

Comparing the incidence of wound disturbances between the two groups, we found a clear difference: $31 \%$ of the transfused group developed a wound distur- 


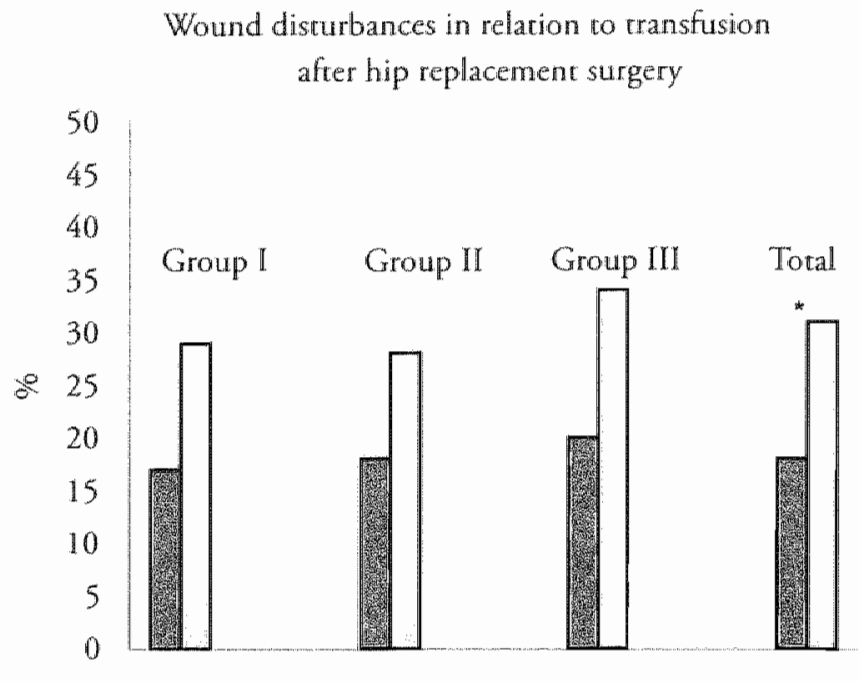

Blood loss category

團 No Transfusion $\square$ Transfusion "p<0,05

Figure 1 Percentages of wound healing disturbances in transfused vs. non-transfused patients. Patients were divided three subgrousps, sustaining peri-operative blood loss of 0-700 $\mathrm{ml}$ (Group ), $701-1000 \mathrm{ml}$ (Group II), or greater than $1001 \mathrm{ml}$ (Group III).

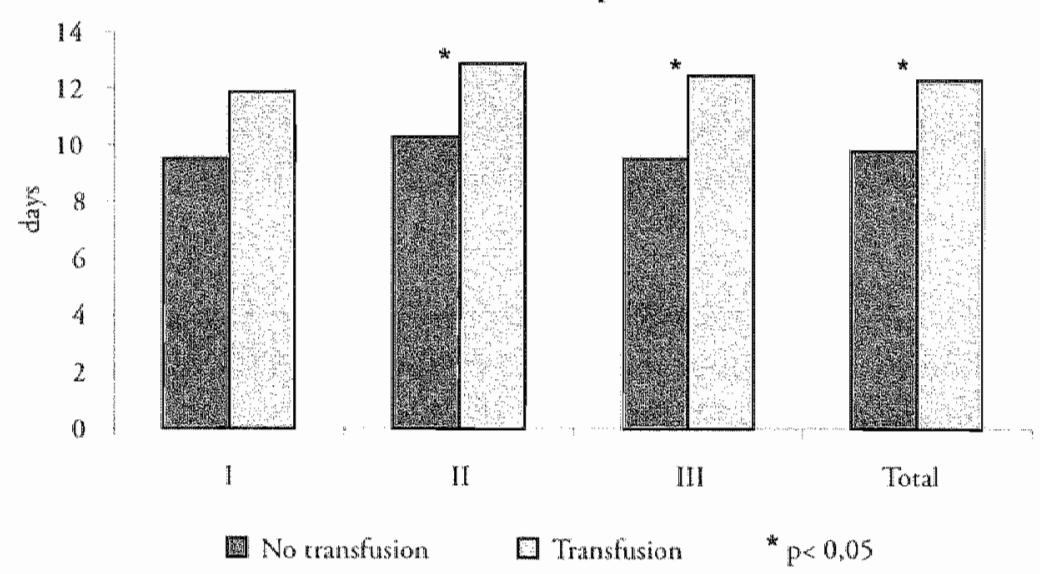

Figure 2 length of hospital admission in transfused vs. non-transfused patienrs, divided into subgroups according to perioperative blood loss volume, 0-700 $\mathrm{ml}$ (Group 1), 701-1000 $\mathrm{ml}$ (Group II), or greater than $1001 \mathrm{ml}$ (Group III). 
bance vs. $18 \%$ of the non-transfused group ( $\mathrm{p}<0.05$, figure 1). To determine whether the amount of peri-operative blood loss affected this relationship, we divided the group into three subgroups, sustaining blood loss of $0-700 \mathrm{ml}$, 701-1000 ml, or more than $1001 \mathrm{ml}$, respectively. For each of these subgroups we observed essentially the same proportion in the incidence of wound disturbances as was found for the groups as a whole (figure 1). Howewer, since the study was not powered for this analysis, the correlation berween transfusions and wound disturbances did not reach statistical significance in these subgroups.

\section{Association between duration of bospitalisation and transfusion}

As a group, transfused patients stayed significantly longer in the hospital than non-transfused patients ( $p<0.001$ ). In addition, the differences in hospitalisation duration (9.8 vs. 12.3 days) suggest a potential major economic impact. However, many factors can affect this important but broad outcome measure. We therefore determined if the duration of hospitalisation was affected by the amount of perioperative blood loss per se. As indicated in figute 2, when the patients were subdivided by amount of perioperative blood loss, we observed (1) that duration of hospitalisation was essentially unaffected by blood loss, and (2) that a similar difference in hospitalisation duration berween transfused and non-transfused patients was maintained among the subgroups. Indeed, although the study was not powered to detect significant differences in this sub-analysis, the difference between transfused and non-transfused patients did reach significance in those patients who lost more than $700 \mathrm{ml}$ of blood perioperative.

\section{Univariate and multwariate analysis}

The requirement for blood transfusion was not the only difference between the two study groups, and some of these other significant factors may also be responsible in part for the increased incidence of wound disturbances. However, many of the factors that showed significant differences between transfused and non-transfused patients can be logically linked to red cell loss, and thereby to transfusion requirement. For example, male gender, greater height and weight, and a higher pre-operative $\mathrm{Hb}$ are all associated with a greater red cell mass, and these patients will therefore tolerate more red cell loss before transfusion triggers are reached. Similarly, longer duration of operation and greater blood loss are logically correlated with transfusion incidence. To analyse this more formally, we performed univariate and multivariate analysis across these facrors, and deter- 
Table 2 Odds ratios berween patient variables and wound disturbances, according to univariate anvalyses:

\begin{tabular}{|c|c|c|}
\hline & Odds Ranio (per unit) & $95 \%$ Confidence lnterval \\
\hline Blood transfusion (yes ks no) & 2.095 & $1239-3542$ \\
\hline Age & 1005 & $0.985-1025$ \\
\hline Sex (male ys fernale) & 199 & $0.739-1947$ \\
\hline length & 0997 & $0.971-1.023$ \\
\hline Weght & 1,009 & $0.993 \quad 1.025$ \\
\hline ESR & 1.017 & $0.988-1.035$ \\
\hline Pre-ab & 0997 & $0.993-1.002$ \\
\hline CRP & 1003 & $0.978-1,029$ \\
\hline Premperative $\mathrm{Hb}$ & 1.020 & $0.743-1.401$ \\
\hline Operation time & 1.010 & $1.001-1.020$ \\
\hline Per-operative blood loss & 1,000 & $0999-1001$ \\
\hline Total blood loss & 1,000 & $1.000-1.001$ \\
\hline (Gentamycin cement (yes vs no) & 1.333 & $0.717-2.248$ \\
\hline
\end{tabular}

mined which of the variables are best predictive of the development of post-operative wound healing disturbances (table 2). With univariate analysis, blood transfusion was clearly the main factor associated (odds ratio 2.1). With back and forward stepwise modelling with multivariate analysis blood transfusion appeared the only statistically significant variable to appear in the model.

\section{Predicting duration of hospital stay}

Based on these data, we developed a regression model to predict duration of hospiral stay from the factors analysed in this study. Duration of stay could be predicted by four significant variables (table 3): requirement for blood transfusion, presence of wound disturbances, duration of operation, and patient age. Whereas each 10 additional years of age adds $0.9+0.16$ days to hospital stay and each 10 minutes additional operarion duration adds $0.2 \pm 0.08$ days to hospital stay, the effects of wound disturbance and transfusion are much more pronounced: the presence of wound disturbances adds $1.25 \pm 0.45$ days, and the requirement for transfusion adds $2.71 \pm 0.47$ days to hospital duration. 
Table 3 Regression model for Duration of Hospitalisation in days.

\begin{tabular}{|c|c|c|c|}
\hline & B & $95 \%$ Confidence Interval & pralue \\
\hline Age (davs per 10 years) & 0.9 & $0.6-12$ & $<0.001$ \\
\hline Operation rime (days per $10 \mathrm{~min}$ ) & 0.2 & $0.05-0.36$ & 0.011 \\
\hline Wound disturbance (days if present) & 125 & $0.36-214$ & 0.006 \\
\hline Transfusion (days if given) & 217 & $1,26-31$ & $<0.001$ \\
\hline
\end{tabular}

\section{DISCUSSION}

The deleterious clinical effects of perioperative HBT in elective orthopaedic surgery are well established $(18,19,16)$. Howewer, the precise impact and mechanisms of these effects are much less clear. It has been postulated that HBT increases postoperative infections through immunomodulation. To test this hypothesis numerous observational studies have been performed, investigating rates of cancer recurrence $(3,5)$ and postoperative infecrions in patients who had received perioperative HBT $(3,4,5,6)$. These studies, however, have produced conflicting results. Controlled trials on this subject have also not resolved the issue $(8,9,10,11,12,13,14,15)$. As the bulk of these studies involve patients undergoing gastrointestinal surgery, the role of HBT in development of adverse effects is even more unclear in elective orthopaedic surgery parients.

In the present prospective observational study we found that HBT is associated with prolonged hospital admission. We found that this prolonged admission is not a straightforward consequence of an increased postoperative infection rate. Deep infections, which have high morbidity (20), occurred at similar rates in both transfused and non-transfused patients. Other infecrions tended to be increased in the transfused group, but this did not reach statistical significance. However, $\mathrm{HBT}$ was the sole significant predictor of the development of wound healing disturbances, and together these two factors were the main predictors of prolongation of hospitalisation (figure 1). No significant infuence on wound disturbance and hospitalisation was found, either by uinivariate or multivariate analysis, of age, sex, length, weight, operation duration, blood loss or the use of gentamycin cement. 
As this was an observational study, the mechanism by which wound healing disturbances and length of hospital stay are related was not studied in detail. A direct effect of tissue hypoxia as a consequence of decreased $\mathrm{Hb}$ seems unlikely. The effect (both on wound disturbances and on hospital admission duration) was evenly distributed among three subgroups with varying volumes of blood loss (figure 1). Frank anaemia can delay wound healing in experimental animals $(21,22)$, but this did not play a role in our patient series. It is conceivable that sub clinical bacterial infection is responsible for disturbed wound healing, but then one would expect to find a concomitant increased body temperature. An alternative explanation might be that HBT induces a small but significant delay in wound healing. Experimental studies have shown that the immunomodulatory effects of HBT (23) might lead to a decrease in pro-angiogenic factors that are essential for wound healing, such as interleukin-8 (24).

Although the narure of the observed wound disturbances remain unclear and warrant further investigation, the more pragmatic conclusion we reach from our data is that prevention of HBT may be of relevance in limiring duration of admission after elecrive orthopaedic surgery. If this is indeed the case measures to prevent perioperative blood loss, cell saving techniques and methods to enhance preoperative $\mathrm{Hb}$ (such as erythropoietin) might be attractive treatment options (25).

\section{REFERENCES}

1. Busch, M. P., T. H. Lee and J. Heiman (1992), "Allogeneic leukocytes but not therapeutic blood elements induce reacrivation and dissemination of latent human immunodeficiency virus type 1 infection: implications for transfusion support of infected partents." Blood 80(8): $2128-35$.

2. Dodd. R. Y. (1992). "The risk of transfusion-ransmirted infecrion." New England journal of medicine $327(6): 419-21$.

3. Blumberg, N. and J. M. Heal (1994). "Effects of transfusion on immune function. Cancer recurrence and infection." Archives of pathology and laboratory medicine 1 18(4): 371-9.

4. Vamvakas, E. C. and S. B. Moore (1994). "Blood transfusion and postoperative septic complications." Transfuision 34(8): 714-27.

5. Vamwakas, E. C. (1995). "Perioperative blood transfusion and cancer recurrence: meta-analysis for explanation." "Transfusion 35(9): 760-8.

6. Duffy, G. and K. R. Neal (1996). "Differences in post-operative infection rates between patients receiving autologous and allogeneic blood transfusion: a meta-analysis of published randomized and nonrandomized studies." Transfusion medicine Oxford, England 6(4): $325-8$. 
7. Vamvakas, E. C. (2002). "Meta-analysis of randomized controlled rrials comparing the risk of postoperative infection berween recipients of allogeneic and autologous blood transfusion." Vox sanguinis $83(4): 339-46$.

8. Jensen, L. S., A. J. Andersen, P. M. Chrisriansen, P. Hokland, C. O. Juhl, G. Madsen, J. Mortensen, C. Moller Nielsen, F. Hanberg Sorensen and M. Hokland (1992). "Postoperative infection and narural killer cell function following blood ransfusion in parients undergoing elective colorectal surgery." British journal of surgery $79(6): 513-6$.

9. Heiss, M. M., W. Mempel, K. W. Jauch, C. Delanof, G. Mayer, M. Mempel, H. J. Eissner and F. W. Schildberg (1993). "Beneficial effect of autologous blood transfusion on infectious complications after colorecral cancer surgery." Lancet 342(8883): 1328-33.

10. Busch, O. R., W. C. Hop, R. L. Marquet and J. Jeekel (1994). "Autologous blood and infections after colorectal surgery." Lancet 343(8898): 668 .

11. Houbiers, J. G., A. Brand, L. M. van de Watering, J. Hermans, P. J. Verwey, A. B. Bijnen, P. Pahl platz, M... Eeftinck Schattenkerk, T. Wobbes, J. E. de Vries and et al. (1994). "Randomised controlled trial comparing transfusion of leucocyte-depleted or bufy-coat-depleted blood in surgery for colorectal cancer." "Lancer 344(8922): 573-8.

12. Jensen, L. S., P. Kissmeyer Nielsen, B. Wolff and N. Qvist (1996) "Randomised comparison of leucocyte-depleted versus buffy-coat-poor blood transfusion and complications after colorectal surgery." Lancet 348(9031): 841-5.

13. Tarter, P. I., K. Mohandas, P. Azar, J. Endres, J. Kaplan and M. Spivack (1998). "Random. ized rrial comparing packed red cell blood transfusion with and without leukocyte depletion For gastrointestinal surgery." American journal of surgery 176(5): 462-6.

14. van de Warering, L. M., J. Hermans, J. G. Houbiers, P. J. van den Brock, H. Bouter, F. Boer, M. S. Harvey, H. A. Huysmans and A. Brand (1998). "Beneficial effects of leukocyte depletion of cransfused blood on postoperative complications in patients undergoing cardic surgery: a randomized clinical trial." Circulation 97(6): 562-8.

15. Tirlestad, I. L., L. S. Ebbesen, A. P. Ainsworth, S. T. Lillevang, N. Qvist and J. Georgsen (2001). "Leukocyte-deplerion of blood components does not significantly reduce the risk of infectious complications. Results of a double-blinded, randomized study." International journal of colorectal disease 16(3): 147-53.

16. Borghi, B. and A. Casari (2000). "Incidence and risk factors for allogenic blood transfusion during major joint replacement using an integrated aurorransfusion regimen. The Rizoli Study Group on Orthopaedic Anassthesia." European journal of anaesthesiology 17(7): 411-7.

17. Vamyakas, E. C. (2002). "Meramanalysis of randomized controlled trials investigating the risk of postoperative infection in association with white blood cell-conaining allogeneic blood transfusion: the effects of the rype of transfused red blood cell product and surgical setting." Transfusion medicine reviews $16(4): 304-14$.

18. Healy, J. C., S. A. Frankforter, B. K. Graves, R. L. Reddy and J. R. Beck (1994). "Preoperative aurologous blood donation in total-hip arthroplasty. A cost-effectiveness analysis." Archives of pathology and laboratory medicine $118(4): 465-70$.

19. Bierbaum, B. E., J. J. Callaghan, J. O. Galante, H. E. Rubash, R. E. Tooms and R. B. Welch (1999). "An analysis of blood management in patients having a total hip or knee arthroplasty." Journal of bone and joint surgery. American volume 81(1):2-10. 
20. Schafroth, M. W. Zimmerli and P. E. Ochsner (1999). "Das infiziertekunstiche Hufrgelenk: Moglichkeiten, Verlauf und Resulate der Behandlung." Schweizerische Rundschau fur Medizin Praxis Revue suisse de medecine Praxis 88(51-52): 2101-5.

21. Kim, K. Z., D. H. Thompson, T. F. George, 2nd, P. M. McQuillan and T. C. Kao (1994). "Effect of anemia on survival of myocutaneous haps in the pig." Otolaryngology head and neck surgery official joumal of American Academy of Onolaryngology Head and Neck Surgery 111(4): 509-12.

22. Buchmiller Crair, T. L., C. S. Kim N. H. Won, H. L. Chopourian, K. S. Shaw and E. W. Fonkalsruc (2001). "Effect of acure anemia on the healing of intestinal anastomoses in the rabbit." Journal of trauma 51(2): 363-8.

23. Svendsen, M. N., K. Werther, H. J. Nielsen and P. E. Kristjansen (2002). "VEGF and cumour angiogenesis. Impact of surgery, wound healing, inflammation and blood transfusion." Scandinavian joumal of gastroenterology 37(4): 373-9.

24. Okano, T., S. Ohwada, Y. Sato, N. Sato, Y. Toyama, Y. Nakasone, T. Ogawa and Y. Morishita (2001). "Blood transfusions impair anastomoric wound healing, reduce luminol-dependent chemiluminescence, and increase interleukin-8." Hepato gastroenterology 48(42): 1669-74.

25. Goldberg, M. A. J. W. MoCutchen, M. Jove, P. Di Cesare, R. J. Friedman, R. Poss, M. Guilfoyle, D. Frei and D. Young (1996). "A safety and efficacy comparison study of rwo dosing reguimens of epoerin alfa in parients undergoing major orrhopedic surgery." American jourmal of orthopedics Belle Mead, N.J. 25(8): 544-52. 



\section{CHAPTER 6}

Slappendel R, Weber EW, Benraad B, Dirksen R, Bugter ML. Published in: Eur J Anaesthesiol. 2002 Nov; 19(11):829-31. 
Background. This study was designed to determine whether a prior exposure to NSAID's has the potential to increase perioperative blood loss after major orthopaedic surgery.

Methods. Patients $(\mathrm{n}=50)$ scheduled for total hip surgery were allocated to two groups (double blind, randomised manner). All patients were pre-treated during 2 weeks before surgery: Group I with placebo drug, and Group II with ibuprofen. For surgical anaesthesia, all patients were injected intrathecally with $20 \mathrm{mg}$ bupivacaine dose plus $0.1 \mathrm{mg}$ morphine in a total volume of $4 \mathrm{ml}$. The presence of severe adverse experiences caused 8 patients of the ibuprofen group and 6 of the placebo group to stop their participation in the rrial.

Results. The perioperative blood loss increased by $45 \%$ in the ibuprofen group comparing placebo. The total blood loss in the ibuprofen group was $1161 \mathrm{ml}$ $(\mathrm{SD} \pm 472 \mathrm{ml})$ versus $796 \mathrm{ml}(\mathrm{SD} \pm 337 \mathrm{ml})$ in the placebo group.

Canclusion. Pre-treatment with ibuprofen before elective total hip surgery increases the perioperarive blood loss significant. Early discontinuation of non-selective NSAID's is advised.

\section{INTRODUCTION}

Non-steroidal anti-inflammatory drugs ( $=$ NSAID's) are used in the perioperarive period for analgesia and reduction of oedema in the surgical field. Beside these benefits there are some unwanted side effects of NSAD's: reduction of renal blood flow, gastric complaints and increase of blood loss during surgery by influencing the coagulation cascade.

NSAID's are widely used in orthopaedic surgery, and ibuprofen is at very commonly used NSAID in the Netherlands. There is concern over the perioperative use of NSAID's since they have the potential to increased peroperative blood loss related to their mechanism of action.

We wish to assess the effect of ibuprofen in every day's practise on perioperarive blood loss in patients having hip arthroplasty, and started a randomised double-blinded placebo controlled study. 


\section{MATERIALS AND METHODS}

The ethical committee of our hospital approved the study and a written informed consent was obrained from all patients. To exclude as much as possible exrernal factors we included in this study patients that undergo first elective total hip replacement surgery for coxarthrosis by intrathecal anaesthesia. Patients were allocated and randomised to rwo groups in a double-blind manner two weeks before surgery. All patients were pre-treated during a 2-week period before surgery: one group with placebo drug, and the other group with ibuprofen $600 \mathrm{mg}$. Borh placebo and ibuprofen $600 \mathrm{mg}$ (total $1800 \mathrm{mg}$ ) were given orally three times a day. The pharmacist prepared identical tablets and was only aware of the type of pre-treatment. Patients using any NSAID's, aspirin and or anticoagulants before starting the trial were excluded from participation. Asso patients with a history of peptic ulcer disease, renal dysfunction or allergy to any NSAID were excluded.

At the day of surgery, all patients were premedicated with $7.5 \mathrm{mg}$ midazolam orally one hour before spinal anaesthesia. Spinal anaesthesia was performed in each of these patients by administering $20 \mathrm{mg}$ bupivacaine plus $0.1 \mathrm{mg}$ morphine solved in $4 \mathrm{ml}$.

The following fluid replacement regimen was used: $500 \mathrm{ml}$ glucose $2.5 \% / \mathrm{NaCl}$ $0.9 \%$ solution after inserting the intravenous line and before starting surgery. A continuous drip was given of the same solution, during surgery $250 \mathrm{ml} /$ hour and after surgery $100 \mathrm{ml} /$ hour. A colloid solurion (Gelofusine) was addec in the same volume amount as blood loss was counted which a maximum of 2.5 litre per 24 hours.

Adequate sedation was provided at patient's request during the procedure: the anaesthesiologist administered $1 \mathrm{mg}$ midazolam at the minimum interval of 5 minutes until the patient indicated that the desired sedation was reached. Non-invasive blood pressure, heart rate (ECG), rranscutaneous oxygen saturation, and respiratory rate were continuously monitored during anaesthesia and in the intensive care unit during the first $24 \mathrm{~h}$ after surgery. 


\section{Peri-operative blood loss}

All operations were performed by one single orthopaedic surgeon. The prophylaxis against thromboembollism was started in all patients the evening before surgery with $3 \mathrm{mg}$ acenocoumarol. At the day of surgery $2 \mathrm{mg}$ acenocoumarol was give just 24 hours after the first dose. The third dose of acenocoumarol was given after the trial was finished. Peroperative blood loss was measured by operating nurses unaware of the NSAID's given. Total blood loss was calculared by taking into account the volume in the suction containers, the weight of the surgical sponges and the irrigation fluid used.

In the postoperative phase all patients stay at an intensive care unit, which is our normal policy. The volume of blood in a high vacuum wound drainage containers was collected and measured twenty-four hours after surgery. The transfusion trigger for homologous packed cells was a haemoglobin level below $8 \mathrm{~g} / \mathrm{l}$ in the whole postoperative period.

\section{Statistical analysis}

Student t-tests were used to identify the sources of differences between the groups. A p-value $<0.05$ was considered as statistically significant.

\section{RESULTS}

Demographic data are given in rable 1. The two groups did not differ for age, height, weight or gender. Likewise other variables, e.g. preoperative use of beta blockers, percentages of patient's which got sedation during surgery, use of cementation, and blood pressure drop ( $>25 \%$ decrease in mean arterial pressure after cementation) showed no differences among the groups. Also there was no difference between the duration of surgery between both groups.

The presence of (severe) adverse effects or an increase of pain caused 8 patients of the ibuprofen group and 6 of the placebo group to stop their participation in the trial (see for details table 2). 
Table 1 Demographic dara.

\begin{tabular}{|c|c|c|}
\hline Group & Duprofen & Placebo \\
\hline$n$ & 17 & 19 \\
\hline Age (years) & $63(12)$ & $59(14)$ \\
\hline Heigh (cm) & $170(8)$ & $169(11)$ \\
\hline Weghr (kg) & $74(13)$ & $72(14)$ \\
\hline Gender $(\mathrm{m} / \mathrm{g}$ & 611 & $5 / 14$ \\
\hline Duration of surgery (minutes) & $67(25)$ & $67(18)$ \\
\hline
\end{tabular}

Age, height, weight and duration of surgery are given as mean values, standard deviation benween arrows, $n=$ number of patients, $m=$ male, $f$-female.

Table 2 Reasons to srop the crial.

$\begin{array}{lll}\text { Lack of efficacy, increase of pain } & \text { lbuprofen } & \text { Placebo } \\ \text { Gastricacid } & 2 & 2 \\ \text { Nausea } & 3 & 1 \\ \text { Total } & 3 & 3\end{array}$

Table 3 Per and postoperative blood loss.

$\begin{array}{lcc}\text { Group } & \text { lbuprofen } & \text { Placebo } \\ \text { Blood los during surger } & 700^{*}(367) & 416(203) \\ \text { Blood loss } 24 \text { hatter surgery } & 461(312) & 380(169) \\ \text { Total blood loss } & 1161 *(472) & 796(337)\end{array}$

Blood loss is given as mean (SD) walue in mi: $=p<0.01, * 0<0.05$. For detalls see text.

\section{Peri-operative blood loss}

The volumes of blood loss were significantly higher in patients pre-treared with ibuprofen than placebo. The volume of peroperative blood loss showed $40 \%$ more in rhe ibuprofen group (mean $700 \mathrm{ml}$ ) versus the placebo group (mean 416 $\mathrm{ml}$ ), which is statistically different ( $p<0.01$ ). The measured blood loss in the first twenty-four hours after surgery showed also a $17 \%$ higher blood loss in the ibuprofen group versus placebo group, which was not statistically different. The over all blood loss, perioperative blood loss plus the blood loss in the first 
twenty-four hours after surgery, showed an increase of $45 \%(p<0.05)$. See table 3. Our study had a $86 \%$ power to demonstrate a $45 \%$ difference in expected blood loss at a level of significance of $\mathrm{p}=0.05$. The number of homologous blood transfusions was 9 in the ibuprofen group and 6 in the placebo group (not statistically significant) during the whole period patient were in the hospital.

\section{DISCUSSION}

The main finding of this study is, that preoperative pre-treatment with ibuprofen showed a relevant increase in blood loss during and the first 24 hours after total hip replacement surgery. Besides the wanted anti-inflammatory, analgesic and antipyretic action of NSAID's this study demonstrates is also a common unwanted negative effect of NSAID's: increase of blood loss.

The anti-inflammatory, analgesic and antipyretic action of NSAID's are mediated through inhibition of prostaglandin synthesis by in hibiting cyclooxygenase. Cyclooxygenase is the major enzyme in the biosynthesis of prostanoids. Following the discovery in the early 1990s of an inducible isoform of COX it is now known that COX exists in at least two isoforms known as COX-1 and COX-2

COX-1 exists in the stomach, intestine, kidneys and blood platelets. COX-1 synthesis the prostaglandin's that regulate the normal physiologic processes involved in protecting the GI mucosa, maintaining renal function as well as vascular homeostasis. This role of COX-1 has been referred as "housekeeping" function. In contrast the inducible isoform COX-2, after expression induced by several cytokines or lipopolysaccharide, produces large amounts of prostanoids mainly contributing to the pathophysiological process of inflammation.

The therapeutic effects of NSAID's are largely the result of inhibition of the enzyme COX-2 whereas toxic effects (platelets, gastrointestinal and renal effects) are primary due to the inhibition of COX-1. In blood platelets this leads to a lack of thromboxane synthesis and impaired plateler aggregation. It has been suggested widely that NSAID's that selectively inhibit COX-2 have fewer side effects. The relationship between platelet aggregation, thromboxane production and serum concentrations of non COX-2 selective ibuprofen has been examined. A single dose of ibuprofen between $300 \mathrm{mg}$ and $800 \mathrm{mg}$ blocked platelet aggregation 2 hours after administration. However, the effect was lost within 24 hours. 
After ibuprofen administration of $200 \mathrm{mg}, 400 \mathrm{mg}$, and $800 \mathrm{mg}$ in healthy volunteers, platelet aggregation was inhibited for 6,8 , and 11 hours respectively. These data and the half life time of ibuprofen ( 2 hours) suggesting to stop the oral use of ibuprofen 24 hours before surgery.

Although we tried to reduce as much possible confounding factors in our study (one type of surgery performed one single orthopaedic surgeon, blinded medicaments), the use of prophylaxis against thromboembolism by acenocoumarol could be a problem in the outcome of our study. The prothrombine time will change due to ibuprofen, and not to the use of a placebo. Other weaknesses of our study are: the technique of measuring blood loss, which is very difficult to get it really accurate and a relatively high drop out rate. The study was not probably powerful enough to show whether an increase in blood loss results in increase transfusion requirement or perioperative morbidity/mortality. These are much more important outcome measures for the patient compared with the actual measured blood loss. They are however much more difficult to measure and were therefore not primary endpoints of this study. In all, to reduce perioperative blood loss two ways are possible. First to stop NSAID's far enough before major orthopaedic surgery. For pain treatment to change NSAID's three days before surgery and replace the drugs to other analgesics, e.g. paracetamol or may be COX-2 selective anti-inflammatory agents, with a better safety profile concerning peroperative blood loss.

\section{REFERENCES}

1. Rorarius, M. G., G. A. Baer, T. Metsa-Ketela J. Miralles, E. Palomaki and H. Vapatalo (1989). "Fffects of peri-operatively administered diclofenac and indomethacin on blood loss, bloding time and plasma prostanoids in man." Eur J Anaesthesiol 6(5): 335-42.

2. Campbell, W. I., R. Kendrick and C. Parrerson (1990). "Intravenous diclofenac sodium. Does its administration before operation suppress postoperative pain?" Anaesthesia 45(9): $763-6$.

3. Schafer, A. I. (1995). "Effects of nonsteroidal antiunflammatory drugs on platelet funcrion and systemic hemostasis." ) Clin Pharmacol 35(3): 209-19.

4. Vane, J. R. and R. M. Botring (1995). "New insights into the mode of action of anti-inflamthatrory drugs." In lamon Res 44(1): 1-10.

5. Mckenna, F. (1999). "COX-2: separaring myth from realicy." Scand J Rheumatol Suppl 109: 19-29.

6. Engelhard, G., R. Bogel, C. Schnirzler and R. Urzmann (1996). "Melloxicam: influence on arachidonic acid metabolism. Part II. In vivo findings." Biochem Pharmacol 51(1): 29-38. 
7. Cryer, B. and M. Feldman (1998). "Cyclooxygenase-1 and cyclooxygenase-2 selectivity of widely used nonsteroidal anti-inflammatory drugs." An J Med 104(5): 413-21.

8. Pardo, A., M. Garcia-Losa, A. Fernandez-Pavon, S. del Castillo, T. Pascual-Garcia, E. Garcia-Mendez and R. Dal-Re (1999). "A placebo-controlled study of interaction berween nabumerone and acenocoumarol." Br J Clin Pharmacol 47(4):441-4.

9. McIntyre, B. A., R. B. Philp and M. J. Inwood (1978). "Effecr of ibuproten on plateler function in normal subjects and hemophiliac patients." Clin Pharmacol Ther 24(5): 616-21.

10. Cox, S. R., J. T. VanderLugt, T. J. Gumbleton and R. B. Smith (1987). "Relationships between thromboxane production, platelet aggregability, and serum concentrations of ibuprofen or flurbiprofen." Clin Pharmacol Ther 41(5): 510-21. 


\section{CHAPTER 7}

Eric W.G. Weber, Robert Slappendel, Marcel E. Durieux, Ris Dirksen, Huub van ler Heide and Maarren Spruit.

Accepted: European Journal of Anaesthesiology. 


\section{SUMMARY}

Background. In this prospective randomised study we tested the hypothesis that use of more cyclooxygenase-2 (COX-2)-selective non-steroidal anti-inflammatory drugs (NSAID's) can reduce perioperative blood loss as compared with non-selective NSAID's.

Methods. Data from 200 patients who underwent total hip replacement were studied. Two NSAID's were compared: indomethacin $50 \mathrm{mg}(\mathrm{n}=82)$ and meloxicam $15 \mathrm{mg}(\mathrm{n}=86)$. Both NSAID's were given orally one hour before surgery.

Results. The two groups were not different with respect to age, gender, ASA class or duration of surgery. When indomethacin was used preoperatively, intraoperative blood loss was $623 \pm 243 \mathrm{ml}$ (mean $\pm \mathrm{SD}$ ) and postoperative blood loss $410 \pm 340 \mathrm{ml}$. After meloxicam these values were $524 \pm 304 \mathrm{ml}$ and $358 \pm 272$ $\mathrm{ml}$, respectively. Total perioperative blood loss after meloxicam was $17 \%$ $(\mathrm{p}<0.05)$ less than that observed after indomethacin.

Conclusion. Perioperative blood loss after meloxicam is less than after indomethacin. These in vivo findings are consistent with in vitro results using selective COX-2 NSAID's.

Keywords. Anti-inflammatory Agents, Non Steroidal; Blood Loss, Surgical; Hip Replacement.

\section{INTRODUCTION}

Non-steroidal anti-inflammatory drugs (NSAID's) are used in the perioperative period for analgesia and reduction of oedema in the surgical field. However, they exhibit several side effects: reduction of renal blood flow, an increased incidence of gastric complaints and increased blood loss during surgery. These adverse effects result from inhibition of the physiologic formation by cyclo-oxygenase (COX)-1 of several prostanoids: PGE2 and PGI2 with a cytoprotective function, and thromboxane $\mathrm{A} 2$, which is responsible for platelet aggregation. In contrast, newer COX-2-selective NSAID's such as meloxicam are considered to influence only the inflammatory response (oedema, pain and fever). We hypothesized that 
this selectivity of action can be extrapolated to clinical practice, and that administration of a COX-2 selective NSAID would result in decreased perioperative blood loss as compared with administration of a non-selective compound. To test this hypothesis, we performed a randomised study in patients undergoing total hip replacement, and compared perioperative blood loss after use of one of two NSAID's: indomethacin and meloxicam.

\section{METHODS}

Patients (ASA 1-3) scheduled for total hip surgery using intrathecal anaesthesia were potentially eligible for the study. Patients with a history of peptic ulcer disease, renal dysfunction or allergy to any NSAID were excluded. The remaining patients were randomised to one of two groups: those receiving meloxicam 15 mg p.o. q.d., or those receiving indomethacin $50 \mathrm{mg}$ p.o. t.i.d. The study was not masked. Patients were asked to stop use of any NSAID two weeks prior to surgery. In case of severe pain paracetamol was available if necessary. Patients who failed to stop the use of NSAID were excluded. The study was approved by the ethical committee of our hospital.

All parients were premedicated with $7.5 \mathrm{mg}$ midazolam p.o. one hour before administration of intrathecal anaesthesia. At the same time the first dose of NSAID was given. Intrathecal anaesthesia (27 gauge pencil point needle) was administered using $20 \mathrm{mg}$ bupivacaine plus $0.1 \mathrm{mg}$ morphine dissolved in $4 \mathrm{~m}$. The anaesthesiologist administered midazolam (1 mg at intervals of no less than 5 min) until the patient indicated that adequate sedation was achieved. Fluid replacement was by protocol: $500 \mathrm{ml}$ glucose $2.5 \% / \mathrm{NaCl} 0.9 \%$ solution was administered after placement of an intravenous line and before starting surgery. The same solution was infused during surgery at $250 \mathrm{ml} / \mathrm{h}$, and after surgery at $100 \mathrm{ml} / \mathrm{h}$. A colloid solution (Gelofusine) was administered to match measured blood loss (see below), wirh a maximum of 2.5 litre per 24 hours. Non-invasive blood pressure, heart rate (electrocardiogram), oxygen saturation ( $\mathrm{SpO} 2$ ), and respiratory frequency were continuously monitored during anaesthesia and in the intensive care unit during the first $24 \mathrm{~h}$ after surgery. 


\section{Blood loss}

One day before surgery, patients received acenocoumarol $3 \mathrm{mg}$. Intraoperative blood loss was measured by operating nurses unaware of NSAID given. Total blood loss was calculated by taking into account the volume in the suction containers, the weight of the surgical sponges, and the irrigation fluid used. In the postoperative phase all patients remained in an intensive care unit for $24 \mathrm{~h}$, which is our normal policy. The volume of blood in a high vacuum wound drainage system was collected and measured for twenty-four hours after surgery.

\section{Pain}

In the post-operative period, all patients were treated with indomethacine $50 \mathrm{mg}$ p.o. t.i.d., or meloxicam $15 \mathrm{mg}$ p.o. q.d. If pain was present morphine was administered intravenously by patient controlled analgesia (PCA) pump. The setrings of the PCA pump (BRAUN ${ }^{\mathbb{B}}$, Melsungen, Germany) were: basal rate 0.0 $\mathrm{mg} / \mathrm{h}$, bolus dose $1.0 \mathrm{mg}$, bolus interval $5 \mathrm{~min}$, maximum $30 \mathrm{mg}$ per $4 \mathrm{~h}$. Pain was evaluated using visual analog scores (VAS, ranging from 0 to 10 , with $0=$ no pain and $10=$ most severe pain). For each individual patient we assessed the maximum VAS score in the $24 \mathrm{~h}$ period and cumulative VAS scores, quantified as area under the curve (AUC) of VAS scores during the $24 \mathrm{~h}$ period.

\section{Statistical analysis}

To detect a difference of $100 \mathrm{ml}$ of blood loss during surgery $($ SD $250 \mathrm{ml})$ with an $\alpha$ error $(2$ sided) of 0.05 and a $\alpha$ error of 0.10 , it was necessary to include 84 patients per group.

Analysis of interval scored data was performed using the Student t-test. Non-parametric techniques (Kruskall Wallis) were used when necessary. Proportions were analysed with Chi-square statistics and Fischer's Exact test. The $\alpha$ level for all analyses was set on $\mathrm{p}=0.05$. Data are reported as means $\pm S D$.

\section{RESULTS}

In total 200 consecutive patients consented to participate during the preoperative outpatient visit. However, at the time of admission 32 patients had failed to stop 
Table 1 Demographic data and intra-operative factors.

\begin{tabular}{|c|c|c|}
\hline Group & meloxican & indomethacin \\
\hline n & 86 & 82 \\
\hline Ape (years) & $64(10)$ & $65(10)$ \\
\hline Heighr (cm) & $168(10)$ & $171(7)$ \\
\hline Weight $(\mathrm{kg})$ & $75(13)$ & $77(11)$ \\
\hline Gender $(\mathrm{m} / \mathrm{l})$ & 27159 & $27 / 55$ \\
\hline Duration of surgery (min) & $67(12)$ & $69(11)$ \\
\hline$M A P(n n n H I)$ & $105(15)$ & $107(13)$ \\
\hline Heart rate (beats/min) & $74(9)$ & $75(10)$ \\
\hline
\end{tabular}

Table 2 lintr-and postoperative blood lioss.

\begin{tabular}{|c|c|c|}
\hline Group & Meloxican & Indomethacin \\
\hline Blood loss during surgeny & $524^{*}(304)$ & $623(243)$ \\
\hline Blood loss 24 h after surgery & $358 *(272)$ & $410(340)$ \\
\hline Total blood loss & $882 *(479)$ & $1034(486)$ \\
\hline
\end{tabular}

use of regular NSAID's, mainly because of pain. Of the remaining 168 patients, 82 were randomised to indomethacine and 86 were randomised to meloxicam. Demographic data of these remaining patients are provided in table 1 . The two groups were similar with regard to age, height, weight, gender, mean arterial blood pressure and heart rate.

\section{Blood loss}

As indicated in table 2, blood loss was significantly greater in patients pre-treated with indomethacin than in those receiving meloxicam. The volume of intraoperative blood loss was $19 \%$ greater in the indomethacin group than in the meloxicam group $(\mathrm{p}<0.01)$. Likewise, blood loss in the first twenty-four hours after surgery was $15 \%$ greater in the indomethacin group than in the meloxicam 


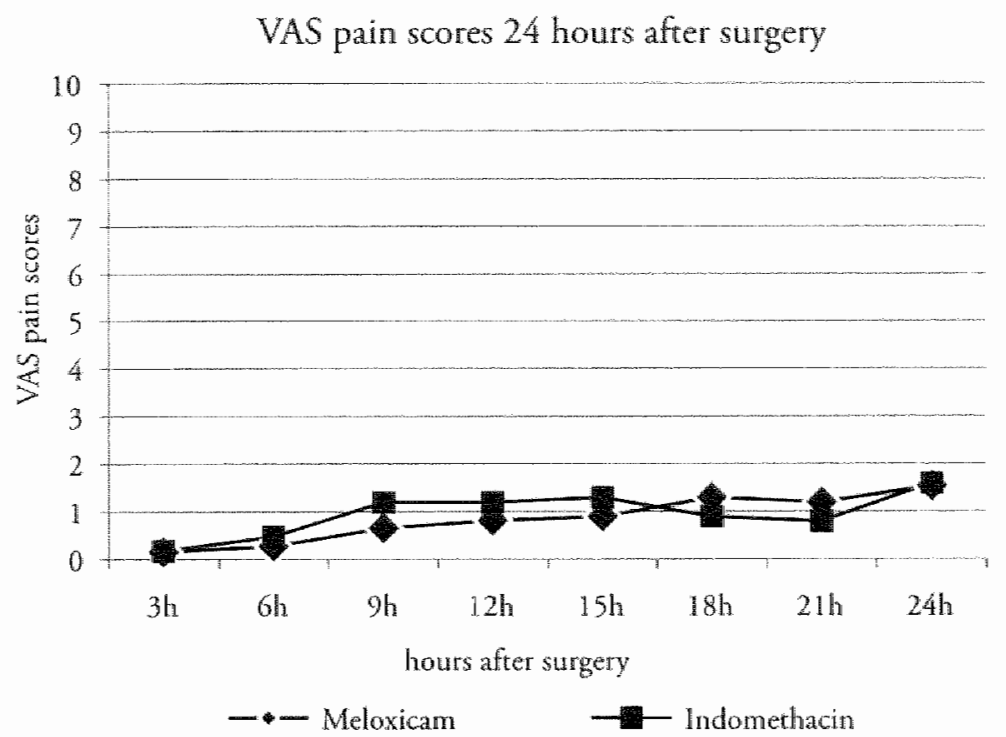

Figure 1 VAS pain scores 24 hours after surgery.

group ( $\mathrm{p}<0.05)$. As a result, total blood loss (i.e. intra-operative blood loss plus blood loss during the first twenty-four hours after surgery) was $17 \%$ greater in the indomethacin group than in the meloxicam group $(\mathrm{p}<0.05)$.

\section{Pain}

VAS scores were less than 3 in the postoperative period in all patients in both groups (figure 1). Cumulative VAS scores were 6.1 for the indomethacin group and 5.3 for the meloxicam group ( $p>0.05$ ). Use of systemic morphine by PCA infusion pump was similar: $18 \pm 9 \mathrm{mg}$ in the meloxicam group and $18 \pm 7 \mathrm{mg}$ in the indomethacin group.

\section{DISCUSSION}

The major finding of our study is that pre-treatment with the COX-2 selective NSAID meloxicam results in less perioperative blood loss than use of the non-selective compound indomethacin. This data from clinical practice is consistent with in vitro studies that demonstrated the COX-2 selective action of meloxicam. Several limitations of the study should be kept in mind, however. We 
did not stratify parients by surgeon, as routine audit data from our hospital show very similar levels of blood loss among the surgical staff. However, this is a potenrial confounder. In addition, we did nor determine if the observed effects on blood loss had a significant impact on patient outcome or management (e.g. haemoglobin levels or transfusion requirements).

NSAID's are used widely in orthopaedic surgery, but concerns remain about their tendency to increase intraoperative blood loss. This side effect results from impairment of plateler aggregation by block of thromboxane formation, and could not be explained by an interaction between indomethacin and acenocoumarol. A breakthrough in the ability to separate the beneficial anti-inflammatory, analgesic and antipyretic action of NSAID's from these side effects resulted from better insights in their mechanism of action. NSAID's inhibit cyclooxygenase (COX), the major enzyme in the biosynthesis of prostaglandins. In the early 1990 s it was recognized that the rate of prostaglandin synthesis could increase dramatically when the formation of a particular isoform of COX is induced by several cytokines or lipopolysaccharide. It is now known that COX exists in at least two isoforms, known as COX-1 and COX-2.COX-1 is found in the stomach, intestine, kidneys and platelets, and is essential for the synthesis of prostaglandins involved in important physiologic processes such as protection of the gastrointestinal mucosa, maintenance of renal function, and circularory homeostasis. This role of COX-1 has been referred to as the "housekeeping" funcrion. In contrast, the inducible isoform COX-2 produces large amounts of prostaglandins that mainly contribute to the pathophysiologic process of inflammation. Thus, the therapeutic effects of NSAID's are largely the result of inhibition of the enzyme COX-2, whereas adverse effects are primarily due to the inhibition of COX-1.

It has been suggested. that NSAID's that selectively inhibit COX-2 have fewer side effects. An example is meloxicam, a NSAID derived from enolic acid which has a favourable $\mathrm{COX}-2 / \mathrm{COX}-1$ ratio. This ratio translates into fewer effecrs on plarelet aggregation in vitro. Indomethacin is a $\mathrm{COX}-2 / \mathrm{COX}-1$ non selective NSAID when tested in virro, but shows a slight preference for COX-2 when rested ex vivo. Studies in vivo show contradicrory results on the effects of indomethacin on blood loss. In this study we compared 2 different NSAID's which inhibit the two COX-isoforms to varying degrees. 
More relevant to clinical practice is the question whether these data from in vitro studies and animal experiments translate in a decreased volume of blood loss. The present study indicates that such is indeed the case: blood loss was approximately $20 \%$ less when meloxicam instead of indomethacin was used. However, wherher this is of clinical significance and influences patient outcome remains to be determined. In addition, the potential beneficial effects of these compounds on blood loss should be weighed against potential detrimental effects (such as a potentially increased risk for cardiovascular events) before routine use can be recommended.

\section{REFERENCES}

1. Rorarius, M. G., G. A. Baer, T. Mersa Ketela, J. Miralles, E. Palomaki and H. Vaparalo (1989). "Effects of peri-operatively administered diclofenac and indomethacin on blood loss, bleeding time and plasma prostanoids in man." Eur I Anaesthesiol 6(5): 335 42.

2. Campbell, W. I., R. Kendrick and C. Parterson (1990). "Intravenous diclofenac sodium. Does its administration before operation suppress postoperatiwe pain?" Anaesthesia 45(9): 763-6.

3. Schafer, A. I. (1995). "Effects of nonsteroidal anuinflammatory drugs on platelet function and systemic hemostasis." J Clin Pharmacol 35(3): $209-19$.

4. Michot, F., K. Ajdacic and L. Glaus (1975). "A double-blind clinical trial to determine if an interaction exists between diclofenac sodium and the oral anticoagulant acenocoumarol (nicoumalone)." IIne Med Res 3(3): 153-7.

5. Pardo, A., M. Garcia Losa, A. Fernandez Pawon, S. del Castillo, T. Pascual Garcia, E. Garcia Mendez and R. Dal Re (1999). "A placebo-controlled study of interaction between nabumetone and acenocoumarol." Br J Clin Pharmacol 47(4): 441-4.

6. Vane, J. R. and R. M. Botring (1995). "New insights into the mode of action of anti-inflammatory drugs." Inflamm Res 44(1): 1-10.

7. McKenna, F. (1999). "COX-2: separating myth from realicy." Scand J Rhewmatol Suppl: $10919-29$.

8. Meade, E. A. W. L. Smith and D. L. DeWirt (1993). "Differential inhibition of prostaglandin endoperoxide synthase (cyclooxygenase) isozymes by aspirin and other non-stcroidal anti-inflammatory drugs." J Bial Chem 268(9): 6610-4.

9. Stichtenoth, D. O., B. Wagner and J. C. Frolich (1997). "Effects of meloxicam and indomethacin on cyclooxygenase parhways in healthy volunteers." I Invesrig Med 45(2): 44-9.

10. de Meijer, A., H. Vollard, M. de Metz, B. Verbruggen, C. Thomas and I. Novalkowa (1999). "Melloxicam, $15 \mathrm{mg} / \mathrm{day}$, spares platelet function in healthy wolunteers." Clin Pharmacol 'Ther $66(4): 425-30$.

11. Giuliano, F. and T. D. Warner (1999). "Ex viwo assay to determine the cyclooxygenase selectivery of non-steroidal anti-inflammarory drugs." Br \ Pharmacol 126(8): 1824-30.

12. Power, I., W. A. Chambers, I. A. Greet, D. Ramage and E. Simon (1990). "Plateler funcrion after intramuscular diclofenac." Anaesthesia 45(1:1): 916-9.

13. Pertunen, K., E. Kalso, J. Heinonen and J. Salo (1992). "IV diclofenac in post-thoracotomy pain." Br 』 Anaesth 68(5): 474-80. 


\section{CHAPTER 8}

E.W.G. Weber, R. Slappendel, Y. Hémon, S. Mähler, T, Dalén,

E. Rouwet. T, 1. Van Os, A. Vosmaer, P. Van der Ark,

Submitted. 


\section{SUMMARY}

Background and objectives. As preoperative epoetin alpha administration reduces transfusion requirements, it may prevent transfusion complications, such as postoperative infections due to immune suppression and thus hospitalisation time. This study tested the impact of preoperative epoetin alpha administration on postoperative recovery and infection rate.

Methods. In a randomised controlled trial in orthopaedic surgery patients the effects of preoperative administration of epoetin alpha (EPO) and best standard of care (BSC) were compared in a daily life setting in six countries. Haemoglobin (Hb) values, transfusions, time to ambulation, time to discharge, infections and safety parameters were evaluated in parients with preoperative $\mathrm{Hb}$ values $10-13$ $\mathrm{g} / \mathrm{dl}$ (on-treatment population: $\mathrm{EPO} \mathrm{n}=460, \mathrm{BSC} \mathrm{n}=235$ ), from study enrry unvil 4-6 weeks after surgery. Outcome was also compared in patients with and without transfusions.

Results. EPO-treated patients had higher $\mathrm{Hb}$ values from the day of surgery until endpoint ( $\mathrm{p}<0.001$; not different at baseline) and lower transfusion rates (12\% vs. $46 \% ; \mathrm{p}<0.001$ ). EPO treatment delivered no significant effect on postoperative recovery (time to ambulation, time to discharge, infection rate). Time to ambulation and time to discharge were, however, longer in transfused than in not-transfused patients $(\mathrm{p}<0.001)$. Side effects in both groups were comparable.

Conclusions. Epoetin alpha increases perioperative $\mathrm{Hb}$ in mild-moderate anaemic patients and reduces transfusion requirements. Patients receiving blood uransfusions require a longer hospitalisations than not-transfused parients. An explanation for the absence of clear effects of epoetin alpha on postoperative recovery is postulated.

\section{INTRODUCTION}

Hip and knee replacement surgery are associated with large blood losses, frequently exceeding $700 \mathrm{~mL}$. As a consequence blood transfusions are frequently required during and after orthopaedic surgery. Apart from the possible serious complications and side effects, such as $A B O$ incompatibility and HIV or hepatitis infections, allogeneic transfusions may also have other complications, such as allo-immunization and immune modulation, which may be responsible for the rise in postoperative infections and possibly increased length of hospitalisations that have been reported in transfused patients. 
Minimizing the number of allogeneic blood transfusions by blood management measures is becoming more and more general practice. Such measures may include introduction of ransfusion protocols that define low transfusion triggers (haemoglobin values at which patients may receive an allogeneic blood transfusion), preoperative autologous blood donations, cell saving, haemodilution techniques, tranexamic acid administration or elevation of the preoperative haemoglobin $(\mathrm{Hb})$ value by means of preoperative epoetin alpha injections.

This last method has proven to increase preoperative $\mathrm{Hb}$ in patients with a $\mathrm{Hb}$ lower than $13 \mathrm{~g} / \mathrm{dl}$ at screening, as well as to reduce the need for allogeneic blood transfusions and to increase the perioperative $\mathrm{Hb}$. However, possible changes in infection rate and postoperative recovery after epoetin alpha administration have not been studied yet in a daily life population of orthopaedic patients. This question was addressed by an international, randomised study were to investigate the effects of preoperative epoetin alpha administration on perioperative haemoglobin levels, and its effects on allogeneic perioperative transfusion requirements in mild to moderare anaemic parients, scheduled for major elecrive orthopaedic surgery. Secondly, the effect of epoetin alpha on postoperative infections and recovery was monitored in the perisurgical setting.

\section{METHODS}

A prospective, open, randomised phase IV trial was conducted in the Netherlands, France, Germany, Sweden, Belgium and Australia. Patients scheduled for elective major orthopaedic surgery (hip, knee, spine, primary or revision) and with a preoperative $\mathrm{Hb}$ value between $10-13 \mathrm{~g} / \mathrm{dl}$ were included. Spine surgery included spinal fusion of at least three segments. All patients received best standard of care (BSC). Patients were randomised in a 1:2 ratio to receive either BSC alone or BSC and epoetin alpha (EPO: 40,000 IU once weekly for 3 weeks before surgery and on the day of surgery + oral iron). This ratio was chosen in order to improve trial acceptability and participation by the patients. Patients in the BSC group could also take iron orally or receive it by intravenous injection, if this was part of usual standard care in the hospital. All patients, irrespective of their group allocation, received blood transfusions when needed. Blood transfusions were only be given according to the hospital transfusion protocol. If no transparent local protocol was available, transfusion with packed cells could only be given 
during and after surgery if the $\mathrm{Hb}$ had dropped below $8.0 \mathrm{~g} / \mathrm{dl}$. Before any blood transfusion, the $\mathrm{Hb}$ value was recorded.

Patients were evaluated for $\mathrm{Hb}$ values from study entry until 4-6 weeks after surgery. Other parameters were blood transfusions (peroperative and postoperative; type of transfusion; numbers of patients transfused and numbers of units rransfused), time to ambulation, time to discharge from hospital, postoperative infections, therapeutic antibiotics use and safety parameters.

Evaluations were carried out at study entry, just before surgery, one day after surgery, at discharge from hospital and at follow-up (planned at 4-6 weeks after surgery).

A patient was considered to have an infection when one of the following items existed:

- wound infection: redness, purulent exudate or positive culture of wound fluid;

- wound abscess: drainage of abscess or spontaneous discharge of pus;

- abscess or infected haemaroma in surgical area or near implantate. Positive culture afrer collection of pus or re-exploration;

- urinary tract infection: abnormal urine sediment with white blood cells and/or a positive urine culture and/or clinical signs;

- respiratory tract infection: clinical signs and/or a positive spurum culture leading to treatment with antibiotics;

- pneumonia: clinical or radiological signs of a pulmonary infiltrate;

- sepricaemia: rypical clinical signs, fever, and positive blood culrure.

Infections were checked by culture. A raised temperature in irself was not indicative of infection.

Time to ambulation was defined as the number of days between surgery and the first day that the patient was able to get out of bed and walk around in the room, with or without support.

Time to discharge was defined as the number of days between surgery and discharge from the hospital where surgery was performed. This implies that there was no correction for hospitalisation for social reasons or for early recovery protocols. The investigators assumed that randomisation should correct for these phenomena. 
An intention-to-treat (ITT) analysis was performed in all patients who were included in the trial and had a study evaluation on the day before surgery. The on-treatment population was defined as those patients included in the trial who underwent surgery. Statistical analysis was two-tailed and on an alpha $=0.05$ level, using Willcoxon's two sample test, Fisher's Exact test and Pearson's Chi-square test. The actual tests are mentioned with the results.

Apart from differences berween both treatment groups, also differences between transfused and not-transfused patients were tested. In order to exclude the influence of variations by country (heterogeneity in blood saving methods, anaesthesia methods, standard hospitalisation periods, etc.) a large and homogenous part of the study population was analysed separately for postoperative infections and recovery data. This population consisted of primary hip replacement arthroplasty patients from one country: the Netherlands ( $n=431)$.

The study was approved by the Institutional Review Board and Local Ethics Committees. All subjects gave informed consent prior to study entry.

\section{RESULTS}

In the study 733 patients were enrolled: 487 in the EPO group and 246 in the BSC group. The ITT population amounted to 704 patients (467 EPO; 237 $\mathrm{BSC}$ ) and the actual surgery population to 695 (460 EPO; $235 \mathrm{BSC}$ ). See table 1 for the division of patients over the participating countries.

\section{Patient characteristics}

There were no differences between both treatment groups regarding age, height, weight, blood pressure, sex, type of surgery, type of anaesthesia and percentage of patients with rheumatoid arthritis or patients possibly having infections (table 2). In both groups $90 \%$ of patients were female; mean age was 67 years. Mean systolic and diastolic blood pressures were 146 and $82 \mathrm{mmHg}$, respectively, $19 \%$ of the patients having a high blood pressure (defined as systolic pressure $>160$ $\mathrm{mmHg}$ or diastolic pressure $>95 \mathrm{mmHg}$ ); $16 \%$ had rheumatoid arthritis, $8 \%$ had elevated CRP or BSE and $90 \%$ was considered as not having a potential infection. 
Table 1 Number of patients by country (TT populanion).

\begin{tabular}{|c|c|c|c|}
\hline Land & $\begin{array}{l}\mathrm{EPO} \\
\mathrm{n}=467\end{array}$ & $\begin{array}{l}\mathrm{BSC} \\
\mathrm{n}=237\end{array}$ & $\begin{array}{l}\text { Overall } \\
\mathrm{n}=704\end{array}$ \\
\hline Australla & 6 & 2 & 8 \\
\hline Belgiam & 11 & 6 & 17 \\
\hline France & 54 & 27 & 81 \\
\hline Germany & 44 & 22 & 66 \\
\hline Netherlands & 334 & 171 & 505 \\
\hline Sweden & 18 & 9 & 27 \\
\hline Total & 467 & 237 & 704 \\
\hline
\end{tabular}

Table 2 Patient characteristics (ITI population). No significant differences between groups.

\begin{tabular}{|c|c|c|c|}
\hline Characteristic & $\begin{array}{l}E P O \\
n=467\end{array}$ & $\begin{array}{l}\mathrm{BSC} \\
\mathrm{n}=237\end{array}$ & $\begin{array}{l}\text { Orerall } \\
n=704\end{array}$ \\
\hline Age (years) & $670 \pm 110$ & $667+10.8$ & $66.9+10.9$ \\
\hline Height $(\mathrm{cm})$ & $16454 \pm 8.4$ & $164.54 \times 7.0$ & $16454 \pm 79$ \\
\hline Weight $(\mathrm{kg})$ & $72,4+13.4$ & $72.9+125$ & $72.6 \pm 13,1$ \\
\hline Sex $(\%$ fenale $)$ & 899 & 89.5 & 89.8 \\
\hline Hypertension (\%) & 20.8 & 143 & 18.6 \\
\hline MBP (mean systolic/mean diastolic, manH Hg) & 147182 & $145 / 82$ & $146 / 82$ \\
\hline $\mathrm{RA}(\%)$ & 161 & 16.0 & 16.1 \\
\hline$\%$ with elevated BSE or CRP & 9.0 & 7.2 & 8.4 \\
\hline
\end{tabular}

Table 3 shows types of surgery and types of anaesthesia, which did not differ between groups either: $61 \%$ underwent primary hip replacement arthroplasty, $27 \%$ primary knee replacement arthroplasty, 9\% a revision hip or knee replacement arthroplasty and $3 \%$ had spine surgery. In most patients (69\%) spinal anaesthesia was used; orhers had general anaesthesia ( $27 \%)$ or mixed forms $(2 \%)$. Only $2 \%$ had local anaesthesia. In the BSC group $77 \%$ of the patients were on oral iron therapy before surgery; in the EPO group $99 \%$. 
Table 3 Type of surgery and rype of anaesthesia (\% of parients; strgery popularion).

\begin{tabular}{|c|c|c|c|}
\hline Type of surgery or anaesthesia & $\begin{array}{l}\mathrm{EPO} \\
\mathrm{n}=460\end{array}$ & $\begin{array}{l}\mathrm{BSC} \\
\mathrm{n}=235\end{array}$ & $\begin{array}{l}\text { Overall } \\
\mathrm{n}=695\end{array}$ \\
\hline Primary hip surgery & 60 & 62 & 61 \\
\hline Primary knee surgery & 28 & 26 & 28 \\
\hline Revision lup/knee suggery & 8 & 9 & 9 \\
\hline Spline surgery & 3 & 3 & 3 \\
\hline Unilareral surgery & 97 & 96 & 97 \\
\hline Bilarefal sungery & 3 & 4 & 3 \\
\hline General maesthesia & 26 & 29 & 27 \\
\hline Spunal anaesthesia & 70 & 68 & 69 \\
\hline Local/mixed anaesthesia & 4 & 4 & 4 \\
\hline
\end{tabular}

\section{Hb values}

Hb walues at screening were $12.2 \pm 0.7 \mathrm{~g} / \mathrm{dl}$ in the BSC group and $12.3 \pm 0.7 \mathrm{~g} / \mathrm{dl}$ in the EPO group (mean \pm s.d.). Hb increased to $14.3 \pm 1.2 \mathrm{~g} / \mathrm{dl}(+2.1)$ on the day of surgery in the EPO group, but did not increase in the BSC group $(+0.1)$. Except for the screening visit, Hb values were different between treatment groups at each time point $(\mathrm{p}<0.05$; Wilcoxon two-sample test). On the day after surgery, $\mathrm{Hb}$ was decreased in both groups: to $11.4 \pm 1.4 \mathrm{~g} / \mathrm{dl}$ in the EPO group and to $9.7 \pm 1.2$ $\mathrm{g} / \mathrm{dl}$ in the BSC group. Hb increased to $12.3 \pm 1.0 \mathrm{~g} / \mathrm{dl}$ and $11.9 \pm 0.9 \mathrm{~g} / \mathrm{dl}$ ar follow-up $(4-6$ weeks after surgery) in the EPO and BSC group, respectively (figure 1).

\section{Transfusions}

In the EPO group $12 \%$ of patients received at least one blood transfusion; in the BSC group 46\% ( $<0.05$; Fisher's Exact test; figure 2 and 3). In most cases, these were allogeneic transfusions: 9\% of EPO patients and 37\% of BSC patients received only allogeneic transfusions ( $p<0.05$; Fisher's Exact test). 3\% of EPO patients and $9 \%$ of BSC patients received autologous transfusions (only autologous or mixed transfusions) ( $\mathrm{p}<0.05$; Fisher's Exact test).

The composition of the transfusions (autologous blood, allogeneic packed cells, allogeneic whole blood, mixed transfusions) was not different between treatment 


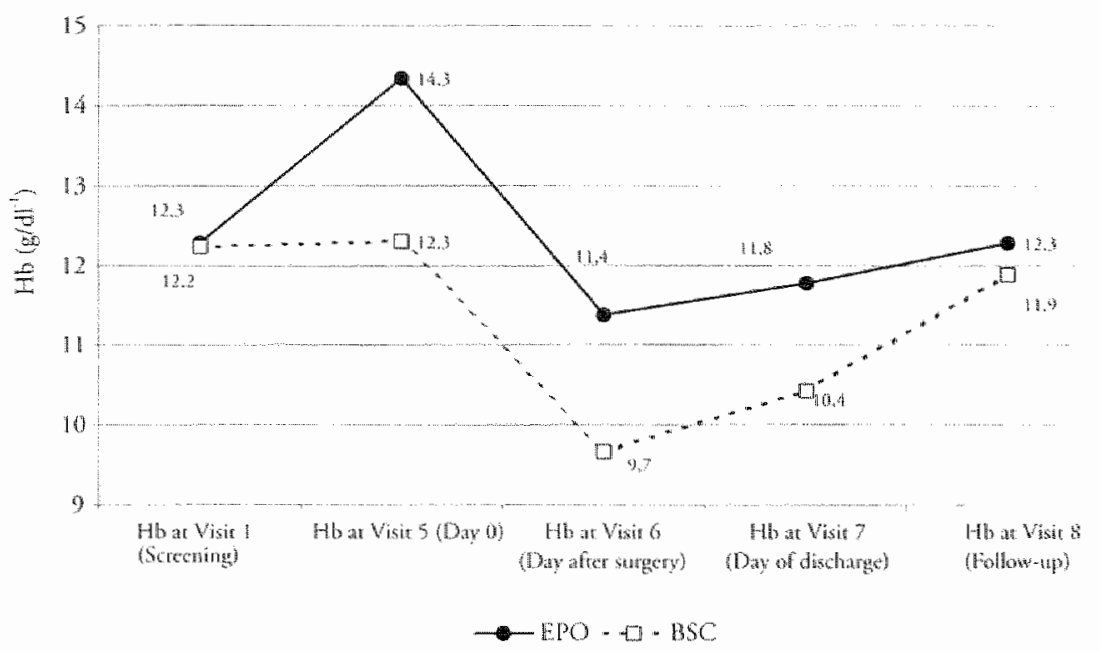

Figure 1 Hb values.

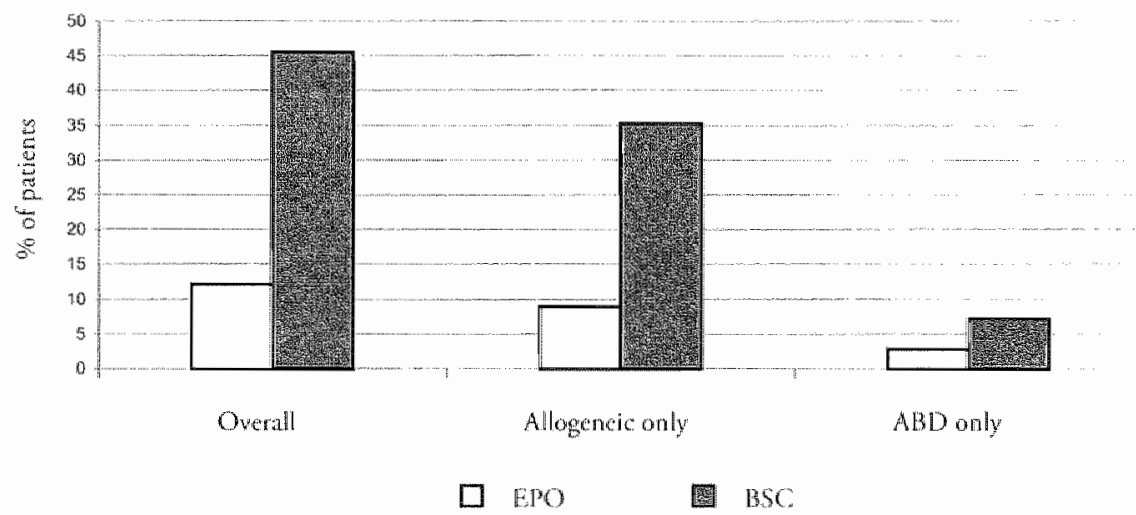

Figure 2 Percentage of patients receiving transfusions.

groups (figure 3): 73 and 78\% in the EPO and BSC groups, respectively, were allogeneic transfusions. For autologous blood, this was 23 and $\$ 6 \%$ respectively.

Transfusion needs were lowest in spine surgery patients (rable 4).

The transfused quantities in both trearment groups were similar. The number of transfusions per transfused patient was not different between treatments $(1.25 \pm 0.51$ and $1.42 \pm 0.70$ for $\mathrm{EPO}$ and $\mathrm{BSC}$, respectively) (NS: $\mathrm{p}=0.141$; Wilcoxon two-sample test,. The number of units transfused per transfused patient was $2.36 \pm 1.95$ and $2.41 \pm 1.24$, respectively (NS: $p=0.126$; Wilcoxon 


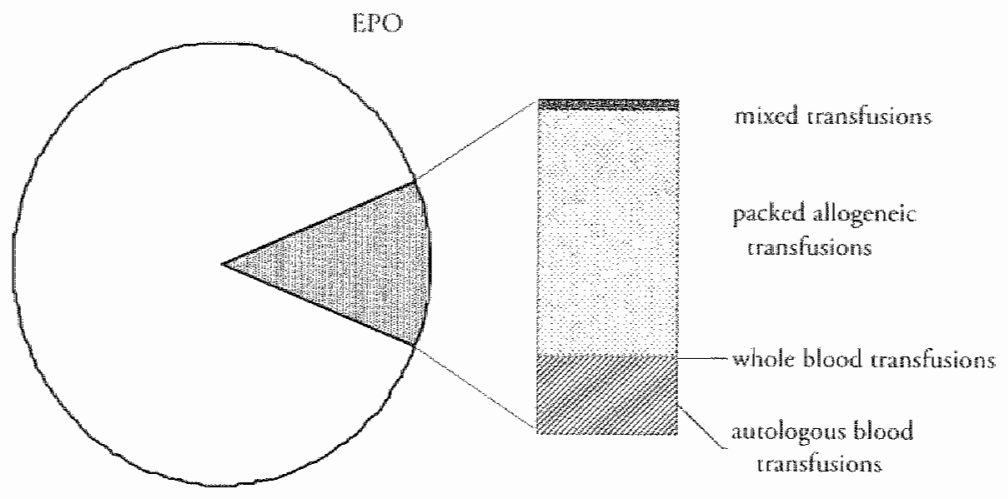

mo tarastiused aransfused

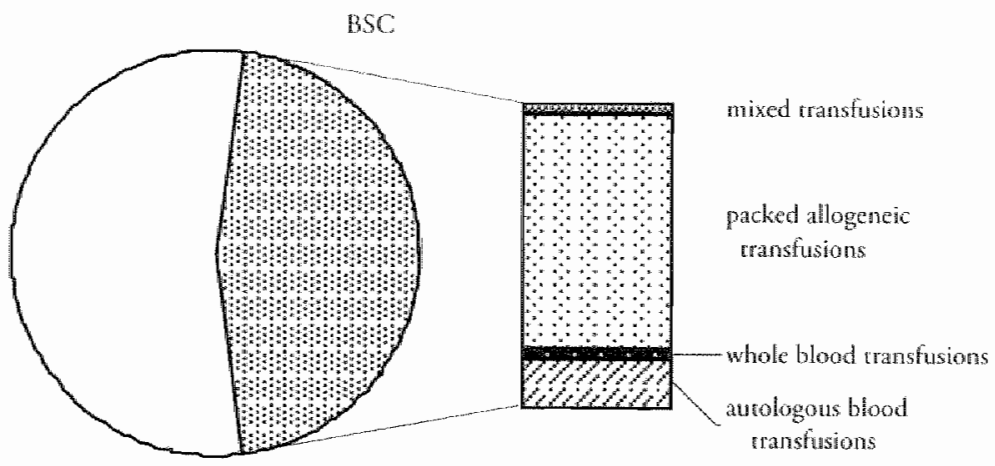

not thansfused transhised

Figure 3 Percentage of patients receiving transfusions and type of transfusions by treatment.

Table 4 Percentage of thansfused patients by type of surgery (surgery population).

\begin{tabular}{|c|c|c|c|}
\hline 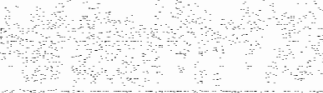 & $\begin{array}{l}\mathrm{HPO} \\
\mathrm{H}=458\end{array}$ & $\begin{array}{l}\mathrm{BSC} \\
\mathrm{n}=235\end{array}$ & $\begin{array}{c}\text { Overall } \\
\mathrm{n}=693\end{array}$ \\
\hline rimary hip surgery & 120 & 479 & 36.4 \\
\hline fimary knee surgery & 108 & 41.0 & 30.2 \\
\hline Revision fhip/knee surgery & 21.1 & 50.0 & 37.8 \\
\hline & 71 & 167 & 119 \\
\hline Eall & 12.2 & 45.5 & 34.1 \\
\hline
\end{tabular}




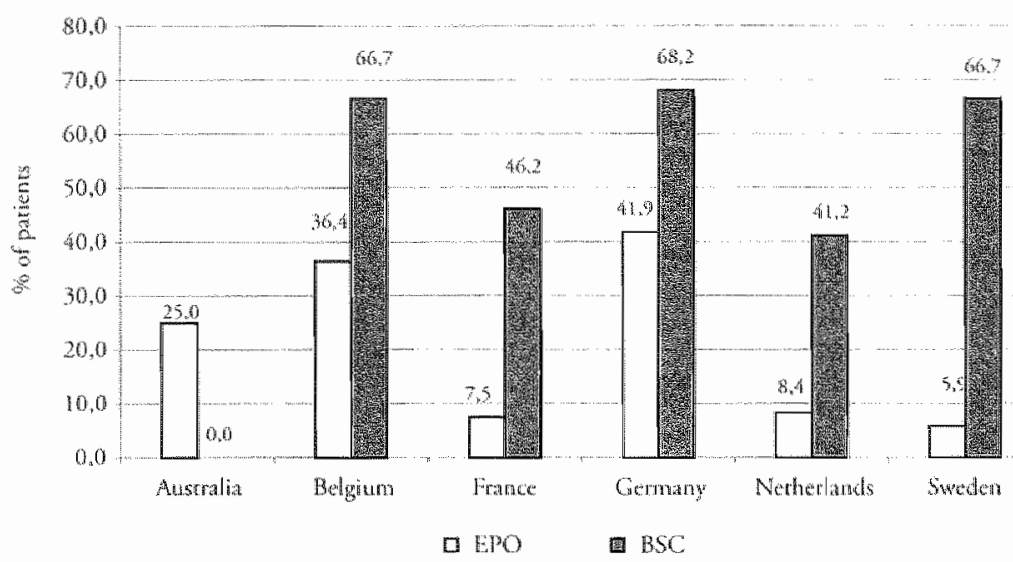

Figure 4 Percentage of transfused patients by country.

two-sample test). Leukocyte filtered blood was used in only $6 \%$ of the transfusions; $94 \%$ were buffy coat-depleted blood transfusions.

The $\mathrm{Hb}$ values just before transfusion did not differ between the EPO and the BSC parients: $8.6 \pm 1.2 \mathrm{~g} / \mathrm{dl}$ for EPO patients and $8.4 \pm 0.9 \mathrm{~g} / \mathrm{dl}$ for BSC patients; overall $8.5 \pm 1.0 \mathrm{~g} / \mathrm{dl}$.

\section{Transfusions by country}

The percentage and composition of transfusions differed between the participating countries (figure 4). One of the major differences between countries is the use of autologous blood transfusions. Autologous blood donation is standard care in France and Germany, but it is rarely used in the other participating countries.

Pre-transfusion $\mathrm{Hb}$ varied by country from 7.8 to $9.1 \mathrm{~g} / \mathrm{dl}$. Apart from Germany, all transfusion triggers were above $8.0 \mathrm{~g} / \mathrm{dl}$.

\section{Time to ambulation, time to discharge}

On average, patients could walk again after 3.3 days ( \pm 2.7 days). Time to ambulation was not different between EPO and BSC, but it was statistically significantly longer in transfused than in not-transfused patients $(3.8 \pm 4.0 \mathrm{vs} .3 .1 \pm 2.2$ days) ( $\mathrm{p}=0.004$; Wilcoxon two-sample test). This was found in both the EPO 


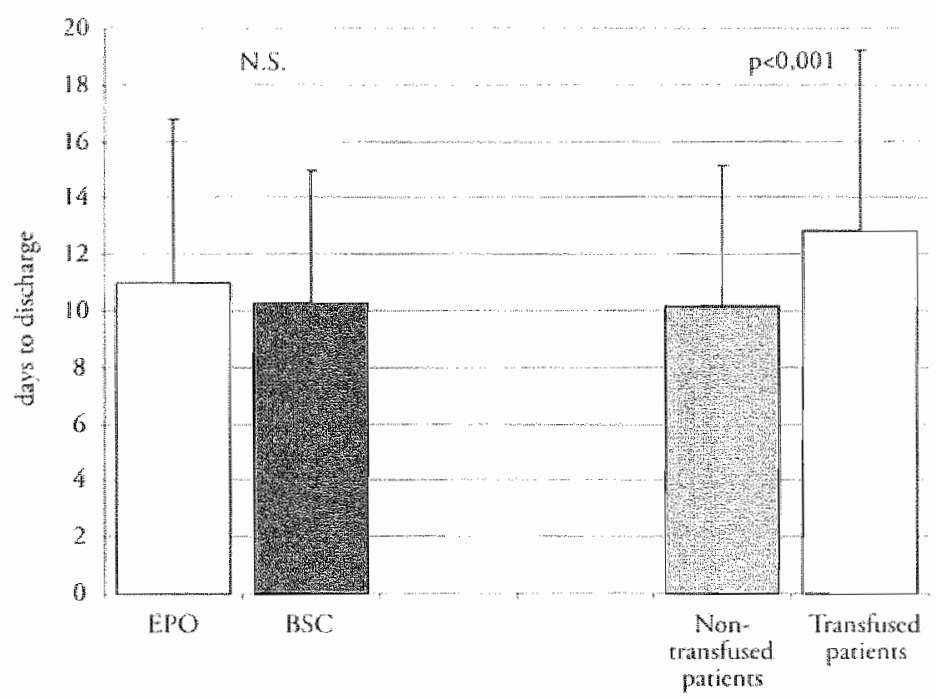

Figure 5 Time to clischarge, by treatment and by ransfusions.

group (transfused vs. not-transfused $4.2 \pm 3.7$ vs. $3.2 \pm 2.3 ; \mathrm{p}=0.01$ ) and the BSC group (transfused vs. not-transfused $3.6 \pm 4.1$ vs. $2.9 \pm 1.7 ; \mathrm{p}=0.07$ ).

For the homogenous subgroup of Dutch patients who underwent primary hip surgery the number of days to ambulation was not statisrically different from that of the total group: $3.5 \pm 2.0$ for EPO and $3.4 \pm 1.9$ for BSC (EPO vs. BSC: $\mathrm{p}=0.354)$, but also in this group time to ambulation was significantly longer in transfused patients: $4.2 \pm 3.1$ vs. $3.3 \pm 1.6$ ( $p=0.038$; Wilcoxon two-sample test). In this group only 24 of 293 (8.2\%) EPO patients received transfusions, versus 63 of $148(42.6 \%)$ BSC parients.

Patients were discharged from hospital after an average stay of 10.8 days $( \pm 5.5)$. Again, this parameter was not different between the EPO and BSC groups, but transfused patients stayed significantly longer in hospital than not-transfused patients: $12.9 \pm 6.4$ vs. $10.2 \pm 5.0$ days, respectively ( $<<0.001$; Wilcoxon two-sample test) (figure 5).

This was found in both the EPO group (transfused vs. not-transfused 15.5 17.2 vs. 10.4.5.3; $p<0.001$ ) and the BSC group (transfused vs. not-transfused $11.5 \pm 5.4$ vs. $9.4 \pm 3.8 ; p<0.001)$. 
Dutch primary hip patients stayed on average in the hospital for $9.8 \pm 5.0$ days. There was no difference between EPO and BSC, but time to discharge was $11.4 \pm 6.1$ in transfused patients vs. $9.4 \pm 4.6$ in not-transfused patients $(p<0.001$; Wilcoxon two-sample test). In the EPO group the difference in time to discharge between transfused and not-transfused patients was 5.5 days (15.1 in transfused patients and 9.7 in not-transfused patients), whereas this difference was 1.5 days in the BSC group.

\section{Infections}

In total $9.8 \%$ of the patients had one or more postoperarive infections, $5.5 \%$ were confirmed by a positive culture. Most patients had the first infection in the hospital: $7.2 \%$, versus $2.6 \%$ after discharge (with positive culture: $4.3 \%$ and $1.2 \%)$. Urinary tract infections were the most common in-hospital infections $(4.3 \% ; 2.9 \%$ with positive culture $)$, followed by wound infections $(2.5 \% ; 1.3 \%$ with positive culture).

The total percentage of infections was not different between EPO $(9.4 \%)$ and $\operatorname{BSC}(10.6 \%)$.

In transfused patients infection rate was $12.9 \%$; in not-transfused patients $8.9 \%$ $(\mathrm{p}=0.130 ; \mathrm{NS}$; Fisher's Exact test). However, it was significantly different in the more homogenous Dutch primary hip patients: 13.8 in transfused vs. $6.8 \%$ in not-transfused patients ( $\mathrm{p}=0.032$; Pearson Chi-square test).

There was no statistically significant difference in the infection rate between patients receiving allogeneic or autologous transfusions, with infections in $12.9 \%$ of patients receiving only allogeneic transfusions versus $10.0 \%$ in those given only autologous transfusions (NS; Fisher's Exact test).

Of all patients $13.5 \%$ took antibiotics for therapeutic use (EPO: $14.0 \%$; BSC: 12.6\%; transfused patients: $16.9 \%$; not-transfused patients: $13.3 \%$ ).

\section{Adverse events}

No differences were observed in the adverse events frequency between EPO and BSC treatments. Three thrombotic events occurred in the population: two in the EPO group and one in the BSC group. 


\section{DISCUSSION}

This study addresses several important questions about blood management in hip and knee arthroplasty. First it studied the effect of preoperative epoetin alpha on perioperative $\mathrm{Hb}$ values and on transfusion requirements in daily hospital care. Secondly the implications of this treatment and of transfusions on postoperative recovery time and postoperative infection rate were evaluated.

The observation that preoperative epoetin alpha treatment enhanced peroperative and postoperative $\mathrm{Hb}$ balues and reduced transfusion requirements confirms earlier results. Furthermore, the observation that iron administration in the BSC group (taken by $77 \%$ ) did not increase the $\mathrm{Hb}$ values confirms previous observations.

EPO treatment was associated with a lower transfusion rate and transfusion was associated with a significant extension of time to ambulation and time to discharge both within the EPO and the BSC treatment groups. However, no differences in time to discharge and infection rate were observed between EPO and BSC treated patients. Possible explanations are that daily life setting in this study may have produced a more heterogeneous population, as parients with several rypes of surgery, with and without rheumatoid arthritis and from several countries were enrolled. Concerning infection rate, this is very low in orthopaedic surgery, especially for clinical relevant infections.

The results might also have been confounded by a higher complication rate in the group of EPO patients who received transfusions, as seen by the outcomes (longer time to ambulation, longer hospital stays and the highest number of antibiotic use). The severe drop in haemoglobin level might be explained by surgical complications, causing major bleedings. In EPO-rreated patients with high pre-operative $\mathrm{Hb}$ values severe blood loss is needed before a transfusion is given. A surgical complication might explain this heavy blood loss and the consecutive bad outcome. Unfortunately this assumption can not be confirmed. This effect is intensified by the very low number of transfused patients in the EPO group (56 patients, $12 \%$.

The finding that infection rate and hospitalisation time are influenced by complications (and thus by transfusions) rather than by anaemia was also observed in unpublished data of 410 primary hip revision parients at the Sint Maartens- 
kliniek, Nijmegen, the Netherlands, in whom hospital procedures regarding surgery techniques, discharge policy and so on were kept similar. Allogeneic transfusions appeared to have the highest prospective value for longer hospitalisation, followed by wound problems, age and operation time. Other facrors such as sex, length, weight, BSE, CRP, preoperative albumen, perioperative blood loss and use of gentamycin cement were no confounding factors.

Several studies have been performed to evaluate the impact of blood transfusions on hospitalisation time, recovery and infection rate. These studies all confirm a relation between allogeneic blood transfusions and increased risk of infections and/or time to discharge, but the absolute data differ considerably between studies. This might be caused by differences in definitions of infection and length of stay. Some studies in surgery only consider wound infections, whereas this study rried to document all infections. Length of hospitalisation is a complex parameter, as it is not merely determined by clinical factors. In this study it has been noticed that decisions to discharge were often based on reimbursement issues, availability of home nurses, private family issues, etc.

Nowadays so-called accelerated stay programs may influence hospitalisation rimes more than transfusions or complications. In many countries hip and knee surgery are performed in such programs, which include hospitalisation times limited to less than a week. But epoetin alpha treatment may be very important in such programs, as extensive rehabilitation starts already on the first day after surgery with low haemoglobin levels. Energy expendure in patients is doubled after surgery (unpublished data Maasland Hospital, Sittard, the Netherlands) and exercise capacity is reduced by $20-25 \%$ on the fourth postoperative day (unpublished data Maasland Hospital, Sittard, the Netherlands). Buick et al. found a reduced $\mathrm{VO}_{2}$ max after phlebotomy and a distinct increase in $\mathrm{VO}_{2}$ max following induced erythrocythaemia. They suggest that oxygen transport limits maximal aerobic capacity. These findings suggest that the postoperative higher haemoglobin levels might become more and more important as rehabilitation becomes more strenuous due to reduction in hospitalisation. Preoperative epoetin alpha administration will thus become more important, especially in the more compromised patients, as they suffer more from the changes in rehabilitation and lower accepted haemoglobin levels.

This study leads to the conclusion that in rourine daily serting of major orthopaedic surgery epoetin alpha treatment is an efficient method to decrease perio- 
perative transfusion requirements and to increase perioperative haemoglobin levels. As hospitalisation time is severely reduced by new rehabilitation procedures, this might be an even more important action.

\section{Acknowledgements}

This trial was sponsored by Ortho Biotech Europe.

Statistics were performed by M. Bassano and M. Borelli, Dimensione Ricerca, Rome, Italy.

\section{Investigators}

Australia: S. Crawford, The Prince Charles Hospital, Chermside

Belgium: M. Mulier, Dienst Orthopedie, Lubbeek

France: V. Chevron-Proust, Clinique De Europe, Rouen; B. Cholley, Hôpital Lariboisière, Paris; J. Debue, Clinique Des Maussins, Paris; F. Dubois, Hôpital De La Côte De Nacre, Caen; L. Dupré, Clinique Cleret, Chambery; D. Envain, Institut Calot, Berck-Sur-Mer; Y. Hémon, Hôpital Ste-Marguerite, Marseille; Y. Nedjar, Clinique Des Lilas, Les Lilas; F. Pamela, Clinique Ambroise Paré, Neuilly-Sur-Seine; N. Rosencher, Hôpiral Cochin, Paris.

Germany: J. Biscoping, St. Vincentius Krankenhaus, Karlsruhe; R. Franz, Universitätsklinikum Carl Gustav Carus, Dresden; E. Hille, Allgemeines Krankenhaus Barmbek, Hamburg; P. Koch, St. Franciskus Hospital, Köln; H. Laubenrhal, St. Josef-Hospital, Bochum; S. Mähler, Kreiskrankenhaus, Langenau; P. Thümler, St. Vinzenzkrankenhaus, Düsseldorf; L. Zichner, Orthopädische Klinik Friedrichsheim, Frankfurt.

Sweden: T. Dalến, Norrlands Universiterssjukhus, Umeå; C. Eriksson, Sundsvalls Sjukhus, Sundsvall.

The Netherlands: J. de Waal Malefijt, Sint Elisabeth Ziekenhuis, Tilburg; T. Euverman, Stichting Christelijk Ziekenhuis Refaja, Stadskanaal; H. Hoekstra, St. Anna Ziekenhuis, Geldrop; P. Houweling, Diakonessenhuis, Utrecht; H. Kerkkamp, St. Joseph Ziekenhuis, Veldhoven; E. Klop, Sint Jans Ziekenhuis, Weert; A. Koopman-Van Gemert, Albert Schweitzer Ziekenhuis, Dordrecht; J. 
Lahaye, Antonius Ziekenhuis, Sneek; C. Matthijssen, Elkerliek Ziekenhuis, Helmond; J. Megens, Velp Ziekenhuis, Velp; H. Naber, Isala Ziekenhuis, Zwolle; D. Paré, Ziekenhuis Midden-Twente, Hengelo; E. Rouwet, Ziekenhuis Koningin Beatrix, Winterswijk; M. Simon, Medisch Spectrum Twente, Enschede; R. Slappendel, Sint Maartenskliniek, Nijmegen; A. van de Wiel, Ziekenhuis Eemland Locatie Lichtenberg, Amersfoort; F. van der Lely, Catharina Ziekenhuis, Eindhoven; H. van der Vis, Ziekenhuis Hilversum, Hilversum; J. van Os, Maasland Ziekenhuis, Sirtard; R. van Seventer, Ziekenhuis De Baronie, Breda; B. Verbiesr, IJsselland Ziekenhuis, Capelle aan den IIssel; A. Vosmaer, Ikazia Ziekenhuis, Rotterdam; O. Wajer, Rivierenland Ziekenhuis, Tiel; E. Weber, Sint Maartenskliniek, Nijmegen.

\section{REFERENCES}

1. Rosencher, N., H. E. Kerkkamp, G. Macheras, L. M. Munuera, G. Menichella, D. M. Barton, S. Cremers and I. L. Abraham (2003). "Orthopedic Surgery Transfusion Hemoglobin European Overview (OSTHEO) study: blood management in elective knee and hip arthroplasty in Europe." Transfusion 43(4): 459-69.

2. Marquet, R. L., M. A. Hoynck van Papendrecht, O. R. Busch and J. Jeekel (1993). "Blood donation leads to a decrease in narural killer cell acriviry: a study in normal blood donors and cancer patients." "Transfusion 33(5): 368-73.

3. Landers, D. F., G. E. Hill, K. C. Wong and I. J. Fox (1996). "Blood transfusion-induced immunomodulation." Anesth Aralg 82(1): 187-204.

4. Innerhofer, P., G. Luz, L. Spot, P. Hobisch-Hagen, W. Schobersberger, M. Fischer, W. Nussbaumer, A. Lochs and E. Irschick (1999). "Immunologic changes after transfusion of autologous or allogeneic buffy coat-poor versus white cell-reduced blood to patients undergoing arthroplasty. I. Proliferative T-cell responses and the balance of helper and suppressor T cells." Transfusion 39(10): 1089-96.

5. Goldberg, M. A., J. W. McCutchen, M. Jove, P. Di Cesare, R. J. Friedman, R. Poss, M. Guilfoyle, D. Firei and D. Young (1996). "A safery and efficycy comparison study of two dosing regimens of epoetin alfa in patients undergoing major orthopedic surgery." Am J Orhop 25(8): $544-52$.

6. Bierbaum, B. E., J. J. Callaghan, J. O. Galante, H. E. Rubash, R. E. Tooms and R. B. Welch (1999). "An analysis of blood management in patients having a cotal hip or thee arthroplasty." J Bone Joint Surg Am 81(1): 2-10.

7. Slappendel, R, and E. Weber (2003). "Blood transfusions and postoperative recovery in orthopaedic surgery. The European Eprex surgery trial." Transfusion Altermatives in Transfusion Medicine in press.

8. Adamson, J. (1996). "Perisurgical use of epoetin alfa in orthopedic surgery patients." Semin Hematol 33(2 Suppl 2): 55-8; discussion 59. 
9. de Andrade, J. R. M. Jove, G. Landon, D. Frei, M. Guilfoyle and D. C. Young (1996). "BaseIne hemoglobin as a predictor of risk of transfusion and response to Epoerin alfa in orthopedic surgery patients." Am J Orthop 25(8): 533-42.

10. Feagan, B. G., C. J. Wong. A. Kirkley. D. W. Johnston, F. C. Smith, P. Whitsitr, S. L. Wheeler and C. Y. Lau (2000). "Erychropoitein with iron supplementation to prevent allogeneic blood ransfusion in total hip joint arthroplasty. A randomized, controlled trial, "Ann Intern Med 133(1.1): $845-54$.

11. van Lperen, C. E. R. J. Kraaijenlagen, D. H. Biesma, Y. Beguin, J. J. Marx and A. van de Wiel (1998). "Iron merabolism and erythropoiesis after surgery." Brr J Surg 85(1):41.5.

12. Olifhoek, G., J. G. Megens, P. Musto, L. Nogarin, C. Gassmann-Mayer, E. Vercammen and S. A. Hayes-Licitra (2001). "Role of oral versus IV iron supplementarion in the erythropoiecic response to rHuEPO: a randomized, placebo-controlled trial." Transfusion 41 (7): 957-63.

13. Blumberg, N. (1997). "Allogeneic transfusion and infection: economic and dinical implicatons." Semin Hematol 34(3 Suppl 2): $34-40$.

14. Houbiers, J. G., C. J. wan de Velde, L. M. van de Watering, J. Hermans, S. Schreuder, A. B. Bijner, P. Pahlplarz, M. E. Schattenkerk, T. Wobbes, J. E. de Vries, P. Klementschirsch, A. H. van de Maas and A. Band (1997). "Transfusion of red cells is associated with increased incidence of bacterial infection after colorectal surgery: a prospective study." "Transfusion $37(2)$ : 1.26-34.

15. Vamvakas, E. C. and J. H. Carven (1998). "Allogeneic blood transfusion, hospiral charges, and length of hospitalization: a study of 487 consecurive parients undergoing colorectal cancer resection." Arch Pathol Lab Med 122(2): 145-51.

16. Carson, J. L., D. G. Atman, A. Duff, H. Noveck, M. P. Weinstein, F. A. Sonnenberg. J. I. Hudson and G. Prowenzano (1999). "Risk of bacterial infecrion associated with allogeneic blood transfusion among parients undergoing hip fraceure repair." Transfusion $39(7)$ : $694-700$.

17. Innerhofer, P, C. Walleczek, G. Luz, P. Hobisch-Hagen, A. Benzer, B. Srock, G. Hessenbergen, W. Nussbaumer and W. Schobersberger (1999). "Transfusion of buffy coat-depleted blood components and risk of postoperative infection in orthopedic patients." Transfusion 39(6): 625-32.

18. Sonnenberg, F. A. P. Gregory, R. Yomowian, L. B. Russell, W. Tierney, M. Kosmin and I. L. Garson (1999). "The costeffectiveness of autologous twansfusion revisited: implications of an increased risk of bacterial infection with allogeneic transfusion." Transfusion 39(8): 808-17.

19. Buick, F. J. N. Gledhill, A. B. Froese, L. Spriet and E. C. Meyers (1980). "Effect of induced erythrocythemia on acrobic work capaciry." I Appl Physiol 48(4): 636-42. 



\section{CHAPTER 9}

E.W.G. Weber and R. Slappendel.

Submitted. 


\section{ABSTRACT}

Background. The treatment protocol of epoetin alpha prior to orthopaedic surgery consists usually of a fixed weekly dose. Although easy to use, ir has its limirations. In some patients the dose is too low to produce an adequate increase in serum haemoglobin level. This study was developed to determinate a more appropriate dosage method for the individual patient.

Study design and results. 334 parients with a preoperative haemoglobin level of $100-130 \mathrm{~g} / 1$ scheduled for major orthopaedic surgery participated in the study. Patients were treated following a fixed protocol with three subsequent subcuraneous injections of 40,000 IU epoetin allpha at day 21,14 and 7 before surgery. The increase of haemoglobin level was measured. Simple formula calculates the amount of haemoglobin in grams. This erythropoietin output $(=\mathrm{EO}-40,000)$ was 34 gram haemoglobin $(\mathrm{SD} \pm 17)$.

Conclusion. Factor EO- 40,000 can be used as an aid to predict the increase in the serum haemoglobin level in the individual patient. Also the number of epoetin alpha injections $(40,000 \mathrm{IU})$ needed to reach the desired serum haemoglobin level can be calculared for the individual patient. With this knowledge, patients can be better prepared for surgery and homologous blood transfusions can be avoided as far as possible.

\section{INTRODUCTION}

Transfusions of allogeneic red blood cells can have risks and complications for the individual patient. This problem still exists despite increased care in the preparation of homologous red blood cells in Europe. Especially for orthopaedic surgery a causal relationship has been established between homologous red blood cell transfusions and an immunosuppressive response in the individual patient. The immunosuppressive response results in an increased risk of postoperative infections, problems with wound healing, and a longer hospital stay $(1,2,3,4,5)$.

One of the most elegant measures to avoid homologous red blood cell transfusions in patients with a lowered haemoglobin level $(10-13 \mathrm{~g} / \mathrm{dl})$ is erythropoietin. The current treatment protocol of erythropoietin consists of a fixed dose in all parients, according to Goldberg (6). Although easy to use, it has its limita- 
tions. In some patients the dose is too low to produce an adequate increase in serum erythropoietin level. In other cases a lower treatment dose will suffice.

A total of 334 patients scheduled for major orthopaedic surgery were treated for decreased serum haemoglobin levels. Erythropoietin and iron were used three weeks prior to surgery to increase the level of serum haemoglobin. Afterwards we calculated the exact erythropoiesis outpur in grams of haemoglobin. These calculated data can be used to determine a more appropriate dosage method for the individual patient.

\section{MATERIALS AND METHODS}

Altogether, 334 patients scheduled for major orthopaedic surgery were asked to participate in the study. The ethics committee approved the study and written informed consent was obtained from all patients. The inclusion criteria consisted of major orthopaedic surgery such as toral hip replacement, revised total hip replacement, spinal fusion surgery and total knee replacement surgery. Further, a preoperative haemoglobin level of $10-13 \mathrm{~g} / \mathrm{dl}$ was required at the preoperative screening three weeks before surgery. All in- and exclusion crireria are summarised in table 1.

Patients were treated following a fixed protocol with three subsequent subcutaneous injections of 40,000 IU epoetin alpha ar day 21, 14 and 7 before surgery. Elementary iron $200 \mathrm{mg}$ a day was given orally from day 21 before surgery until discharge after surgery.

The hamoglobin level was measured at day 21 before surgery and thus prior to epoetin alpha administration, and on the day of surgery. If surgery was postponed for more than nine days after the last dose of epoetin alpha, patients were excluded from further calculations.

The following formula was used to calculate the amount of haemoglobin $(\mathrm{Hb})$ in grams after the above treatment with epoetin alpha and iron.

1. $\mathrm{EBV}=$ patient's estimated blood volume in litres $=$ body weight in $\mathrm{kg} \times 0,07$ $\mathrm{l} / \mathrm{kg}$ 
Table 1 Inclusion and exdusion criceria.

\section{Andusion crteria}

Major orthopedic surgery

Hemoglobin level between $100-130 \mathrm{~g} /$

Over 18 years of age

\section{Exchsion oriteria}

Infection of any body system at preoperative screning of by elevared sedimentation rate or by elevared C-reactive protein.

Patients with autologous blood donarion

Any homologous blood transhision in the past 6 weeks

Any surgery in the past 6 weeks

Presence of dinically significant disease/dysfunction of the hepatic pulmonary hematological, neurological endocrine, gastrointestinal or genitourinary systems

Clinical of laboratory evidence of untreated ron, folate or vitumin B 12 deficiency

Presence of concominant malignancy

Uncontrolled hypertension (diasiolic blood pressure $>100$ mmilg)

History of seizures

Administration of medication known to suppress erythropolesis (e.g cytotoxic agents, immunosuppressants) within one mondh prior to enrolnient. Low-dose stenoids were permitred

Pregnancy or lactarion

Known hypersensitivity to epoetin alpha or one of its components

2. EO- $120,000=$ erythropoiesis output in grams after three subsequent injections of $40,000 \mathrm{IU}$ epoetin alpha $=\mathrm{EBV} \times(\mathrm{Hb}$ (in $\mathrm{g} / \mathrm{l})$ day of surgery $-\mathrm{Hb}$ (in $\mathrm{g} / \mathrm{l})$ prior to administration of epoerin alpha)

3. $\mathrm{EO}-40,000=$ calculared erythropoiesis output in grams after 40,000 IU epoetin alpha $=\mathrm{EO}-120,000 / 3$.

When it is known how many grams of haemoglobin are produced after a single subcutaneous injection of 40,000 IU epoetin alpha, the number of epoetin alpha injections needed to reach the desired serum haemoglobin level can be calculated. The formula is: 
Number of epoetin alpha (40,000 IU) injections:

$\mathrm{EBV} \times($ desired serum $\mathrm{Hb}(\mathrm{g} / \mathrm{l})$ level - serum $\mathrm{Hb}(\mathrm{g} / \mathrm{l})$ level prior to epoetin)

$$
\mathrm{EO}-40,000
$$

\section{RESULTS}

Of all the patients ( $n=334), 30$ did nor receive three doses of epoetin alpha. In another five patients the haemoglobin level was not measured prior to surgery. This left data from 299 patients (19 males, 280 females) which were used for further calculations. All these patients received three epoetin alpha subcutaneous injections $(40,000$ IU) at day 21,14 , and 7 before surgery and iron therapy $(200$ mg elementary iron a day) was also used in this same period. At day 21 before surgery and thus before the first epoetin alpha injection, the mean serum haemoglobin was $123 \mathrm{~g} / \mathrm{l}$, while on the day of surgery the mean haemoglobin had increased to $143 \mathrm{~g} / \mathrm{l}$. The mean EO- 120,000 was $102 \mathrm{~g}$ and the EO- 40,000 was $34 \mathrm{~g}$ (table 2). The increase in haemoglobin according to body weight is shown in figure 1.

Using this factor EO-40,000 together with the individual body weight and individual serum haemoglobin level, the number of epoetin alpha injections needed to reach a preoperative haemoglobin level of $150 \mathrm{~g} / \mathrm{l}$ can be calculated (see table 3).

There was no significant difference for EO-40,000 berween males (mean $30 \mathrm{~g} / \mathrm{l}$; SD 20) and fernales (mean $33 \mathrm{~g} / \mathrm{l}$; SD 17).

To calculate the number of epoetin alpha doses $(40,000$ IU) the following formula was used:

$\mathrm{EBV} \times($ desired serum $\mathrm{Hb}(\mathrm{g} / \mathrm{l})$ level - serum $\mathrm{Hb}(\mathrm{g} / \mathrm{l})$ level prior to epoetin)

$$
\mathrm{EO}-40,000
$$


Table 2 Results and EO 40,000. EBV=estimated blood rolume, dara are presented as mean values, standard deviation berween brackers. For further explanation see text.

\section{Outcome}

Number of patients $(n)$ 334

Patients with incomplete data 35

Male $/$ female $(\%)$

Mean body weight (kg) 73

Mean EBV (liter)

Hb prior to epoetin alpha admunstration (gram)

Hb day of surgery (gram)

$\mathrm{EO}-120,000$ (gram)

$\mathrm{EO}-40,000$ (gram)

Table 3 Number of preoperative epoetin al pha injections $(40,000$ UU) needed to reach a hemoglobin level of $150 \mathrm{~g} / \mathrm{l}$ pror to surgery, according to preoperative hemoglobin levels and body weighr.

Body weight in $\mathrm{kg}$

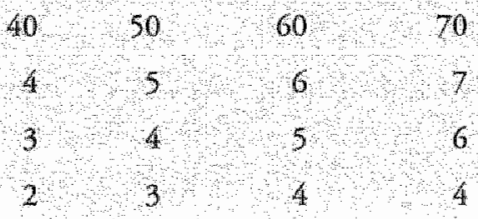

Preoperative hemoglobin $100 \mathrm{~g} /$

Preoperative hemoglobin $110 \mathrm{~g} /$

Preoperantive hemoglobin $120 \mathrm{~g} /$

Hemoglobin production after 40.000 IU subcutaneous epoetine alfa

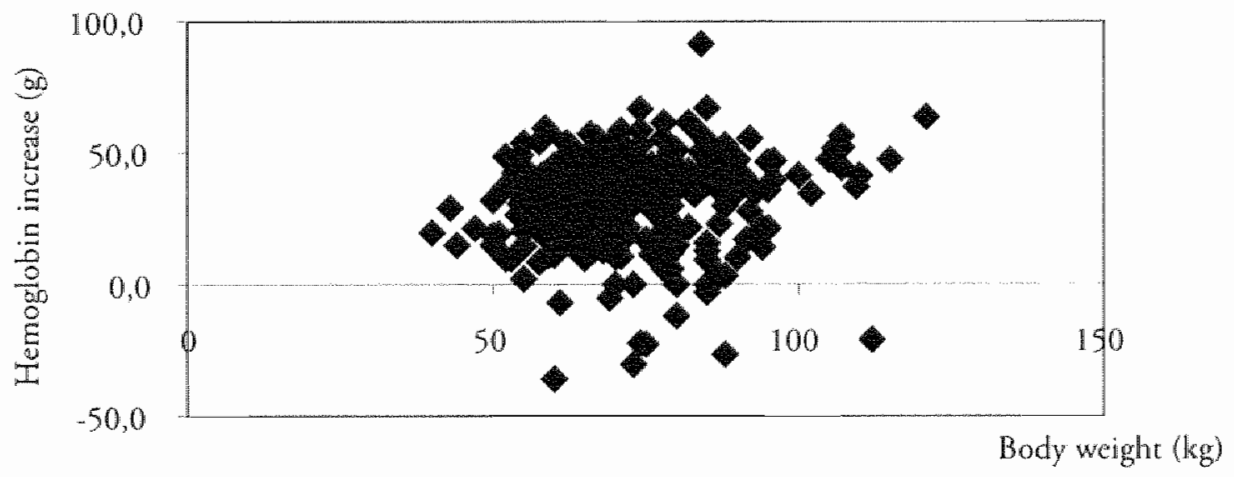

Figure 1 Hemoglobin poduction. 
Table 4 Prices of different sources of hemoglobin Prices are according to Dutch price levels. Assumption: the use of non-COX-2 selective NSAID increases blood loss by $15 \%$, mean low? vacuun drainage is $350 \mathrm{ml}$ with a mean hemoglobin level of $120 \mathrm{~g} / \mathrm{d}$

\begin{tabular}{|c|c|c|}
\hline & $\begin{array}{l}\text { Potal amount in } \\
\text { gram hemoglobin }\end{array}$ & $\begin{array}{l}\text { Price in Euros per gram } \\
\text { hemoglobin }\end{array}$ \\
\hline 1 patient $(20 \mathrm{~kg}, 1 \mathrm{~b} / 28 \mathrm{~g} / \mathrm{l})$ & 640 & Pricelless \\
\hline 1 unir homologous packed cells & 53 & 32 \\
\hline 1 unir autologgous packed cells & 53 & 36 \\
\hline $110,40,000$ & 34 & 136 \\
\hline $\begin{array}{l}\text { Dostoperatue low vaciudu cell saving } \\
(\text { Bellovac ABD }\end{array}$ & 43 & 12 \\
\hline Non-COX 2 selective MSAIDs & 75 & \\
\hline
\end{tabular}

\section{DISCUSSION}

Factor EO-40,000 was calculated precisely to 34 gram in 299 healthy patients prior to elective orthopaedic surgery. Factor EO-40,000 can be used as an aid to predict the increase in the serum haemoglobin level in the individual patient. Also the number of epoetin alpha injections $(40,000 \mathrm{IU})$ needed to reach the desired serum haemoglobin level can be calculated for the individual patient. As depicted in table 2, more than the usual three epoetin alpha injections are needed to reach the desired serum haemoglobin $(150 \mathrm{~g} / \mathrm{l})$ level prior to surgery. With this knowledge, patients can be better prepared for surgery and homologous blood transfusions can be avoided as far as possible.

A second important use of factor EO-40,000 is for making a financial comparison. As we know the price of one injection of epoetin alpha $(40,000 \mathrm{IU})$, we can work out the price of 1 gram of haemoglobin. It is now easy to compare this with orther sources of haemoglobin (homologous blood, autologous blood donation, cell-saving procedures, etcetera). For instance, one homologous or autologous red blood cell transfusion consists of $300 \mathrm{ml}$ red blood cells with a haemoglobin level of $180 \mathrm{~g} / \mathrm{l}, 54 \mathrm{gram}$ in total. Again the price can be calculated accurately per gram or $\mathrm{mmol}$ (see table 4). Prices are shown in table 4 according to the initial expense. Costs related to laboratory (cross match, irregular antibodies, storage), adverse effects or complications of disposables, transfusions or epoetin alpha are not included. 
In all, the calculated factor EO-40,000 can help to target treatment better to the individual patient to reach the optimum preoperative haemoglobin level prior to surgery. In cases where the haemoglobin level is low prior to surgery, epoetin alpha treatment can be used more precisely before major orthopaedic surgery.

\section{REFERENCES}

1. Murphy, P., J. M. Heal and N. Blumberg (1991). "Infection or suspected infection after hip replacement surgery with aurologous or homologous blood transfusions." Transfusion $31(3)$ : $212-7$.

2. Blumberg, N. (1997). "Alogeneic transfusion and infecrion: economic and dinical implications." Semin Hematol 34.(3 Suppl 2): 34-40.

3. Bierbaum, B. E. J. J. Callaghan, J. O. Galante, H. E. Rubasin, R. E. Tooms and R. B. Welch (1999). "An analysis of blood management in pacients having a total hip or knee arthropilasty:" J Bone Joine Surg Am 81(1):2-10.

4. Innerhofer, P., C. Walleczek, G. Luz, P. Hobisch-Hagen, A. Benzer, B. Srock, G. Hessenberger, W. Nussbaumer and W. Schobersberger (1999). "Transfusion of buffy coat-depleted blood components and risk of postoperative infection in orthopedic patients." Transfusion 39(6): 625-32.

5. Borghi, B. and A. Casati (2000). "Incidence and risk factors for allogenic blood rransfusion during major joint replacement using an integrated autotransfusion regimen. The Rizzoli Study Group on Orthopaedic Anaesthesia." Eur J Anaesthesiol 17(7):411-7.

6. Goldberg, M. A., J. W. McCurchen, M. Jove, P. Di Cesare, R. J. Friedman, R. Poss, M. Guilfoyle, D. Frei and D. Young (1996). "A safery and efficacy comparison study of two dosing regimens of epoetin alfa in patients undergoing major orthopedic surgery." Am I Orthop $25(8): 544-52$. 


\section{CHAPTER 10}

E.W.G. Weber, S. Gielen-Wijffels, R. Van Drumpt, S. Bulstra, R. Slappendel, M.E. Durieux and M.A.E. Marcus.

Submitted. 


\section{SUMMARY}

In orthopaedic surgery blood loss is often compensated for by homologous blood transfusion (HBT). However, HBT might have deleterious effects because of transfusion-related immunomodulatory effects. In an effort to reduce HBT we evaluated the efficacy of an auto transfusion system for shed blood. We performed a prospective observational quality assessment study in 135 consecurive patients scheduled for elective total knee arthroplasty (TKA) or total hip arthroplasty (THA). The control group consisted of a historic group of 96 patients. Autotransfusion reduced the percentage of patients receiving HBT from $35 \%$ to $22 \%(\mathrm{p}<0.001)$. The reduction was more pronounced in TKA ( $18 \%$ to $6 \%, \mathrm{p}<0.001)$ compared with THA (47\% to $34 \%, \mathrm{p}<0.05)$. In TKA, transfused packed red cells per operation decreased from $0.45 \mathrm{HBT} /$ operation to 0.11 HBT/operation $(\mathrm{p}<0.001)$, a reduction of $0.34 \mathrm{HBT}(75 \%)$ in every TKA. These results indicate that autotransfusion may be a useful method to reduce HBT during major orthopaedic surgery.

\section{INTRODUCTION}

Preventing homologous transfusion after hip and knee arthroplasty can decrease transfusion-related complications and duration of hospital stay (1). Several techniques can reduce the need or perioperative transfusion: the use of erythropoietin to increase preoperative haemoglobin concentration, preoperative blood donation, and surgical methods to prevent blood loss.

Cell saving techniques are another effecrive approach to prevent blood transfusion (2). Shed blood may be re-infused after filtration (unprocessed) or after treatment in a cell separator (processed). Transfusion of unprocessed shed blood is a relatively simple and inexpensive method to restore normovolaemia, in contrast to autotransfusion of processed blood, which requires an expensive cell separator and disposables. However, since the first widely applied perioperative (unprocessed) autotransfusion system was applied in clinical practice by Dyer (1966) (3), some authors published severe complications, primarily haemostatic disorders and impairment of renal function. Although the incidence of these symptoms seemed to be very low and were related to large transfusion volumes (4), these reports have hampered further developments of this promising technique. 
In the present study, we evaluated a postoperative wound drainage and re-infusion system with filter in patients undergoing total hip or knee replacement. The aim of the study was to determine the effecr of re-infusion of shed blood on the requirement for homologous blood transfusion ratio in primary total hip or knee arthroplasty.

\section{MATERIALS AND METHODS}

Using a prospective observational quality assessment design, we compared 135 patients scheduled for elective total knee arthroplasty (TKA) or total hip arthroplasty (THA) at the University Hospital Maastricht, the Netherlands, with a historic group of 96 patients who underwent similar surgery at the same institution. In the study group the Bellovac ${ }^{\text {B }}$ A.B.T. autotransfusion system (Astra Tech, Gotenburg, Sweden) was used. It consists of a blood collection suction bellows connected to an autorransfusion bag with a $200 \mu \mathrm{m}$ filter. The bellows inlet and the autotransfusion bag inlet each contain a one-way valve. The autotransfusion bag is connected to a transfusion set with a $40 \mu \mathrm{m}$ filter. Before closure of the surgical wound a drainage tube is inserted and connected with the suction bellows. By empting the bellows the drained blood is transported to the transfusion bag. The shed blood is re-transfused either when $500 \mathrm{ml}$ is collected (collection is then resumed with a new transfusion bag) or at most 6 hours after the operation. Blood collected more than 6 hours after the operation is not re-transfused. In the control group, standard suction drains (redondrain Medinorm) were used and the drained blood was discarded. All patients were treated according to standard hospital protocol. All knee operations were done in a bloodless field using pneumatic tourniquets. All patients received nadroparin (2850 IE) s.c. the evening before the operation for prophylaxis of thrombosis. Homologous blood was transfused according to standard protocol (post-operarive $\mathrm{Hb}$ of less than $9.6 \mathrm{~g} / \mathrm{dl}$ or clinical symptoms of anaemia). The following data were obtained in both groups: haemoglobin levels (preoperatively, first postoperative day and on the day of discharge), total volume of blood collected in the drain in the study group, volume of blood reinfused in the study group, and number of homologous blood units transfused.

The results were analysed statistically using ANOVA followed by Student's T-test when approptiate and published as mean (SD) or percentage. A p-value of $<0.05$ was considered statistically significant. 


\section{RESULTS}

In the study group 135 patients, and in the historic control group 96 parients were available for analysis. Of the 135 patients, 129 patients received re-transfusion of drained blood. These 129 patients consisted of 41 cementless THA, 35 cemented THA, 10 cementless TKA and 43 cemented TKA.

\section{Haemoglobin levels}

We observed no statistical differences between the pre-operative, postoperative, and discharge haemoglobin concentrations in the control and study group (rable 1). Haemoglobin concentrations for all subgroups were comparable also. There were no complications or adverse events after re-transfusion of autologous shed blood.

Table 1 Haemoglobin levels g/dl mean (SD) for all groups.

\begin{tabular}{|c|c|c|c|c|}
\hline & & No-BELLOVAC & BELLOVAC drain & $\mathrm{P}$ \\
\hline All & $\mathrm{n}=231$ & $\mathrm{n}=96$ & $n=135$ & \\
\hline Hb pre-operative & $14.0(1.22)$ & $14.0(1.26)$ & $141(1.2)$ & N.S. \\
\hline Hb post-operative & $10.4(1.49)$ & $10.4(1.39)$ & $10.3(1.55)$ & NS. \\
\hline Hb discharge & $10.4(1.14)$ & $10.4(1.17)$ & $10.3(1.12)$ & N.S. \\
\hline THA & $n=138$ & $n-58$ & $n=80$ & \\
\hline Hb pre-operative & $140(126)$ & $139(1.36)$ & $14,0(1,22)$ & $\mathrm{Ns}$ \\
\hline Hb post-operative & $92(1.41)$ & $10.2(1.41)$ & $9.6(1,36)$ & N.S. \\
\hline Hb discharge & $10.2(1.04)$ & $10.3(1.04)$ & $10(1.04)$ & N.S. \\
\hline TKA & $n=93$ & $\mathrm{n}=38$ & $n=55$ & \\
\hline Hb pre-operative & $14.2(1.14)$ & $14,2(1,12)$ & $14.2(1,18)$ & N.S. \\
\hline Hb post-operative & $11.0(1.3 .4)$ & $10.8(1.33)$ & $112(1.34)$ & N.S. \\
\hline Hb discharge & $107(1.23)$ & $105(1.36)$ & $10.8(1.14)$ & N.S. \\
\hline
\end{tabular}


Patients transfused $[\%]$

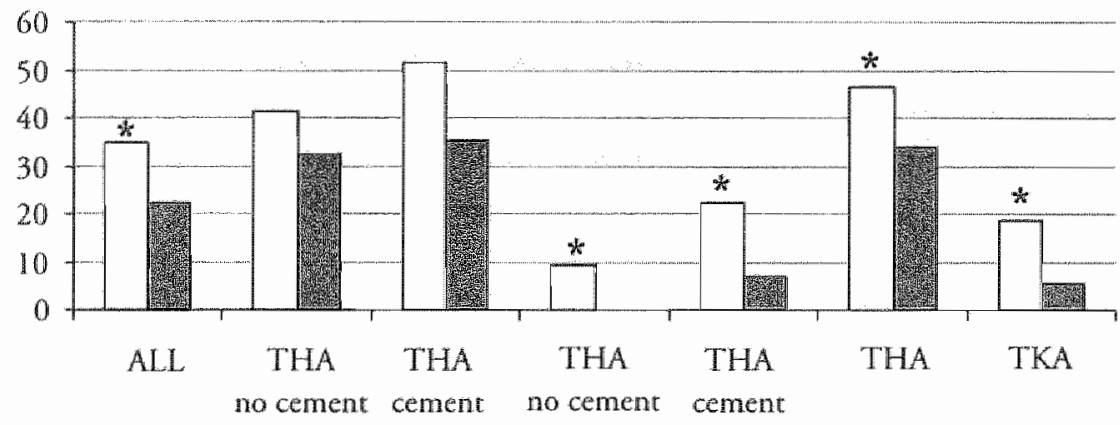

No Bellovac 圈 Bellovac

Figure 1 Transfusion incidence $[\%]$ in relation with type of surgery $\left({ }^{*} \mathrm{p}<0,05\right.$; $\left.{ }^{* *} \mathrm{p}<0,001\right)$.

Table 2 Transfused HBT per operation; THA - Total Hip arthoplasty, TKA - Tona Knee Arthroplasty, $\rightarrow=$ cementless, $t=$ cenented

\begin{tabular}{|c|c|c|c|c|c|c|c|}
\hline & & & No & LLLOVAC & $\mathrm{BEI}$ & OVAC Drain & \\
\hline & $n$ & Mean (SD) & n & Mean $(S D)$ & $\mathrm{n}$ & Mean (SD) & P \\
\hline All & 231 & $0,68(1,34)$ & 96 & $0.85(1,37)$ & 135 & $0,56(1,30)$ & 0,059 \\
\hline IHA- & 72 & $0.83(1,18)$ & 29 & $0,90(1,14)$ & 43 & $0,79(1,22)$ & 0,978 \\
\hline $7 \mathrm{HA}+$ & 66 & $1,14(1,82)$ & 29 & $1,34(1,70)$ & 37 & $0,97(1,92)$ & 0,79 \\
\hline $\mathrm{TKA}_{-}$ & 22 & $0,09(0,43)$ & 11 & $0,18(0,60)$ & 11 & $0,00(0,00)$ & 0,038 \\
\hline TKAt & 71 & $0,30(0,92)$ & 27 & $0,56(1,31)$ & 4 & $0,14(0.5 .1)$ & 0,001 \\
\hline AITTA & 138 & $0,98(1,53)$ & 58 & $1,2(1,45)$ & 80 & $0,87(1,58)$ & 0717 \\
\hline All TKA & 93 & $0,25(0,83)$ & 38 & $0,45(1,16)$ & 55 & $0,11(0,46)$ & 0 \\
\hline
\end{tabular}

\section{Homologous Transfusion Requirements}

Autotransfusion reduced the number of patients receiving HBT overall from $35 \%$ to $22 \%$ (p<0.001, figure 1$)$.

In the THA group there was a statistically significant decrease of blood transfusion requirement from $47 \%$ to $34 \%$. There were no statistical differences in transfusion rates between the cemented and non-cemented THA subgroups. 
Table 3 Reinfused wolume in patients with autotransfusion device in relation with allogenic rransfusion Perioperative THA - Toral Hip ardhroplasty, TKA - Total Knee Arthroplasty - cementless, + = cemented.

\begin{tabular}{|c|c|c|c|c|c|c|c|}
\hline \multicolumn{3}{|c|}{ All } & \multicolumn{2}{|c|}{ No transfiusion } & \multicolumn{2}{|c|}{ Transfusion } & \\
\hline & n & Mean $(S D)$ & $\mathrm{n}$ & Mean (SD) & n & Mean (SD) & $\rho$ \\
\hline All & 135 & $516(352)$ & 105 & $533(366)$ & 30 & $467(304)$ & NS. \\
\hline $\mathrm{THA}$ & 43 & $417(271)$ & 29 & $419(320)$ & 14 & $427(147)$ & NS \\
\hline $\mathrm{THA}+$ & 37 & $378(308)$ & 24 & $296(172)$ & 13 & $530(435)$ & NS \\
\hline $\mathrm{TKA}-$ & 11 & $634(340)$ & 11 & $634(340)$ & - & $\rightarrow$ & + \\
\hline $\mathrm{IKA}$ + & 44 & $700(380)$ & 41 & $723(383)$ & 3 & $383(126)$ & N.S. \\
\hline AlIHA & 80 & $399(287)$ & 53 & $362(267)$ & 27 & $476(318)$ & NS \\
\hline$A 1 \mathrm{TKA}$ & 55 & $687(371)$ & 52 & $704(373)$ & 3 & $383(126)$ & $\mathrm{N}$ \\
\hline
\end{tabular}

The homologous transfusion requirement after TKA was decreased from $18 \%$ to $6 \%(\mathrm{p}<0.001)$. In cementless vs. cemented TKA this was $9 \%$ to $0 \%$ and $22 \%$ to $7 \%$ respectively $(\mathrm{p}<0.001)$. The total number of transfused packed cells in the TKA group was reduced from 0.45 pcloperation to 0.11 pcloperation $(\mathrm{p}<0.001)$, a $75 \%$ reduction per operation (tabel 2 ).

\section{DISCUSSION}

Re-transfusion of autologously shed blood has been shown to be a safe and effective method to reduce exposure to homologous blood in orthopaedic and cardiovascular surgery $(5,6,7,8)$, allhough conflicring data have been published concerning the efficacy of the use in cardiac surgery (9). In this study re-transfusion of drained blood using a Bellovac ${ }^{(B)}$ A.B.T. significant reduced homologous blood transfusion after TKA, whereas we did not observe a statistically significant reduction after THA. This may be related to surgical technique: as in most hospitals, TKA surgery was performed using a bloodless field, so that blood loss occurred only in the post-operative period, in contrast ro THA surgery where blood loss occurred during the whole procedure. Re-transfusion of shed blood is most effective if all lost blood can be collected (table 3). This is the case in TKA surgery, but not in THA surgery, where significant blood loss occurs during the operation. In THA we can not recover intra-operative blood loss (and even then visible blood loss is only $50 \%$ of total intra-operative blood loss (10)), and so the efficacy or auto-transfusion will be reduced. 
Although we observed no complications during re-transfusion, our group may have been too small for a safety assessment. One of the most common side effects is a febrile reaction after autotransfusion of shed blood, and this complication may have been reduced by the presence of the filter in the system used in this study. When blood is shed, the composirion changes. The intrinsic and common coagulation pathway are activated, which results in formation of clot and fibrinogen degradation products. Several authors have demonstrated high concentrations of C3a, SC 5b-9, TNF- $\alpha, I L-1 \beta, I L-6$ and IL- 8 in shed blood, but only elevated IL-6 plasma levels after transfusion of filtered shed blood $(11,12,13)$. Handel et al reports a relation between increased interleukin- 6 concentrations in shed drainage blood and the occurrence of febrile reactions after re-transfusion of such blood (14). If the collection duration of shed blood is extended, the IL-6 concentrations increase further with a possible increase in febrile reactions (15). Another concern would be the presence of merhyl methacrylate monomer (MMM) in re-transfused blood. However, systemic blood showed no evidence of MMM after re-infusion of salvaged blood (16) in cemented TKA surgery. After spine surgery one study showed a tendency of increased blood serum levels of $\mathrm{CK}, \mathrm{GOT}$ and $\mathrm{LDH}$, if postoperarive re-transfusion was used as a blood saving method (8). Therefore, caution should be taken when these serum enzyme levels are used for diagnosis.

A cost-benefit analysis of the system is difficult to make, because of the complex costs involved in blood transfusion (which really should include the cost of complications, increased duration of hospital stay, etc.). In TKA surgery, transfusions were reduced by 0.34 packed red cells per operation. The costs for the Bellovac drain system are approximately $€ 75$.- per operation in the Netherlands. In our hospital a HBT costs approximately $€ 180$.-. Therefore, a reduction of 0.34 reduces the costs by $€\left(180^{*} 0.34\right)=€ 61.20$ per operation. Thus, calculated on rhis basis, the autorransfusion system is still more expensive than HBT. However, this approach is simplistic: the HBT cost does not include handling costs of the hospital of HBT and the possible extended hospitalisation and other immunomodulatory effects due to a homologous blood transfusion (17). Thus, a formal cost-benefit study is required to address this issue.

We conclude that the Bellovac ${ }^{8}$ A.B.T. device reduced homologous blood transfusions in TKA. The use of the system is less complicated and less expensive compared to auto re-transfusion using a cell separator. This method of auto re-transfusion should therefore be considered in TKA surgery. 
No funds have been received to support this study.

\section{REFERENCES}

1. Vamvakas, E. C. and I. H. Carven (1998). "Allogeneic blood mansfusion, hospital charges, and length of hospiralization: a study of 487 consecutive parients undergoing colorectal cancer resection." Arch Pathol Lab Med 122(2): 145-51.

2. Goodnough, L. T., A. Shander and R. Spence (2003). "Bloodless medicine: dinical care without allogeneic blood transfusion." Transfusion 43(5): 668-76.

3. Dyer, R. H., Jr. (1966). "Intraoperative aurotransfusion. A preliminary report and new method." Am J Surg 112(6):874-8.

4. Rakower, S. R. M. H. Worth, Jr. and H. Lackner (1973). "Massive intraoperative autotransfusion of blood." Surg Gynecol Obster 137(4): 633-6.

5. de Varennes, B., D. Nguyen, F. Denis, P. Ergina, D. Larter and J. E. Morin (1996). "Reinfusion of mediastinal blood in CABG patients: impact on homologous transfusions and rate of re-exploration." J Card Surg 11(6): 387-95.

6. Flom-Halvorsen, H. I., E. Ovrum, G. Tangen, F. Brosstad, M. A. Ringdal and R. Oystese (1999). "Autorransfusion in coronary artery bypass grafting: disparity in laboratory rests and clinical performance." J Thorac Cardiovasc Surg 118(4): 610-7.

7. Martin, J., D. Robitaille, L. P. Perrault, M. Pellerin, P. Page, N. Searle, R. Cartier, K. Hebert, L. C. Pelletier, H. T. Thaler and M. Carrier (2000). "Reinfusion of mediastinal blood after heart surgery." I Thorac Cardiovasc Surg 120(3): $499-504$.

8. Sebastian, C., R. Romero, E. Olalla, C. Ferrer, J. J. Garcia-Vallejo and M. Munoz (2000), "Postoperative blood salvage and reinfusion in spinal surgery: blood quality, effecriveness and impact on parient blood parameters." Lur Spine J 9(6): 458-65.

9. Body, S. C., J. Birmingham, R. Parks, C. Ley, R. Maddi, S. K. Shernan, L. C. Siegel, E. P. Stover, M. N. D'Ambra, J. Levin, D. "T. Mangano and B. D. Spiess (1999). "Safery and efficacy of shed mediastimal blood transfusion after cardiac surgery: a mutricenter observational study. Multicenter Sndy of Perioperative Ischemia Research Group." J Cardiathorac Vasc Anesth 13(4): 410-6.

10. Sehar, K. R, R. Evans and J. H. Newman (2000). "How much blood is really lost in tocal knee arthroplasty?. Correct blood loss management should kake hidden loss into account." 7(3): $151-155$.

1.1. Amestad, J. P., A. Bengtsson, J. P. Bengtson, M. Tylman, H. Redl and G. Schlag (1994). "Formation of cytokines by retransfusion of shed whole blood." $\mathrm{Br}$ J Anaesth 72(4): $422-5$.

12. Bengtsson, A. A. Awall, M. Hyllner and J. P. Benguson (1998). "Fonmation of complement split products and proinflammatory cytokines by reinfusion of shed autologous blood." Toxicol Lett 100-101: 129-33.

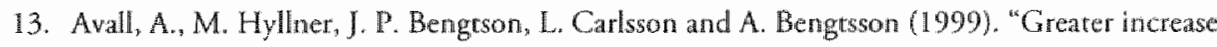
in cytokine concentration afrer salvage with filtered whole blood than with washed red cells, but no difference in postoperative hemoglobin recovery." Trarsfusion 39(3): 271-6. 
$106 \mid$ CHAPTER 10

14. Handel, M., J. Winkler, R. F. Hornlein, H. Nomhoff, P. Heeg, M. Teschner and S. Sell (2001). "Increased interleukin-6 in collected drainage blood after total knee arthroplasty: an association with febrile reactions during etransfusion." Acta Orthop Scand 72(3): 270-2.

15. Handel, M., J. Winkler, R. F. Hornlein, H. Northoff, P. Heeg and S. Sill (2001). "Time-related changes of collected shed blood in autologous retransfusion after total knee arthroplasty." Arch Orthop Trauma Surg 121(10): 557-60.

16. Hand, G. C., M. Henderson, P. Mace, N. Sherif, J. H. Newman and D. J. Goldie (1998). "Methyl methacrylate levels in unwashed salvage blood following unilateral rotal knee arthroplascy." I Arthroplasty 13(5): 576-9.

17. Blumberg. N. (1997). "Allogeneic transfusion and infection: economic and dinical implications." Semin Hematol 34(3 Suppl 2): 34-40. 



\section{CHAPTER 11}

Robert Slappendel, Ris Dirksen, Eric W. G. Weber, Dick B, van der Schaaf.

Accepred: Acra Orthopaedica Scandinavica 


\section{ABSTRACT}

Introduction. In an earlier prospective study we have corroborated that transfusion-related immunosuppression favours postoperative infections, perturbs postoperative wound healing and thereby results in protracted hospital stay. This adds to the well known risks such as transmission of infectious illness or transfusion reactions, and urged us to redefine transfusion guidelines. Goal: to redefine a comprehensive scheme that allows for relevant reduction of homologous red cell transfusions in orthopaedic surgery.

Method. A relational database with data on 28.861 orthopaedic surgery patients was used to identify where and how to improve these guidelines for transfusions.

Results. The survey disclosed the issues related to a high incidence of homologous red cell infusion: negligence of guidelines, the preoperative use of non-selective NSAID's, low preoperative Hb level, non-retrieved blood loss, and high cut-off values for homologous red cell transfusion. The first step was the restriction that the $\mathrm{Hb}$ level should be assessed prior to red cell infusion to ensure compliance with pre-defined cut-off values. Subsequent measures included: confinement to COX-2-selective NSAID in the perioperative period; erythropoietin and iron therapy at the $\mathrm{Hb}$ level below $13 \mathrm{~g} / \mathrm{dl}$; consequent cell salvage during and after surgery; administration of aprotinine in cases with expected high blood loss. The type of anaesthetic procedure was found to be not relevant for blood-sparing effect.

Discussion. The steps do not involve a medical novelty. Rather, we show that strict rules with the appropriate steps and in sequence resulted in an $80 \%$ reduction of use of homologous red blood cells. Noteworthy, the yield of sparing blood goes beyond financial saving. The incidence of deep wound infections decreased by $40 \%$.

Conclusions. The outcome is described in an algorithmic format summarising steps in a comprehensive perioperative blood management scheme.

\section{INTRODUCTION}

Inherent risks in homologous transfusions persist despite all efforts to minimise and exclude as many of these as possible. In addition to well-known risks such as transmission of infectious illness or transfusion reactions, concern is raised - espe- 
Table 1 hidence of postoperative infection, perturbed postopetarive wound luealing, and duration of hospital stay in uelation to presence or absence of allogenic red blood cell infusion $(n=9) 75$.

\begin{tabular}{|c|c|c|c|}
\hline $\begin{array}{l}\text { blood transfusion } \\
\text { trumber of parieniss }\end{array}$ & $\begin{array}{l}\text { Incidence of } \\
\text { infection }\end{array}$ & $\begin{array}{l}\text { Incidence of perturbed } \\
\text { wound healing }\end{array}$ & $\begin{array}{l}\text { Duration of } \\
\text { Hospital stay (days) }\end{array}$ \\
\hline $01 \mathrm{n}=867$ & $3.8 \%$ & $16 \%$ & 83 \\
\hline $1 / n=108$ & $630 \%$ & $31 \%$ & 117 \\
\hline
\end{tabular}

0=no blood ransfusion, 1 an more blood transfusions, $\mathrm{n}=$ namber of patients

cially for orthopaedic surgery - over the issue of a causal relationship between homologous red blood cell transfusions and immunomodulation. The transfusion related immunosuppression is considered to favour postoperative infections, perturb postoperative wound healing and thereby to result in protracted hospital $(1,2,3,4,5)$. In our prospective study - that included 975 major orthopaedic surgical procedures such as total hip arthroplasty and knee replacement surgery, fusion surgery of the lumbar, thoracic or cervical spine - we corroborate this notion (table 1).

These data on the consequences of infusion of homologous red blood cells warrant guidelines for proper use of red cell transfusion. Bellow we summarise how we developed our guidelines and the quantitative contribution of each step added to our guidelines. At present we have artained an $80 \%$ reduction of the incidence of red cell infusion.

\section{Relational database underlying the development of transfusion guidelines}

A mainstay in redefining the guidelines for red cell infusion was the inventory of detailed clinical data gathered in the past. Starting in 1991, all details regarding all orthopaedic surgical procedures in our clinic were fed into a relational database. We registered for each patient: date of surgery, date of birth, hospital registration number, surgeon, anaesthesiologist, type of surgery, diagnose, duration of surgery, volume of blood loss during surgery, and the anaesthetic procedure. This database is coupled to the database of the financial department that contains for example the details on hospital stay and that of our laboratory with the data on red cell transfusions, infections, etc. We analysed these data for 28.861 patients in order to identify the most relevant issues for improved guidelines in our clinic. 
Table 2 Outcome of analysis for relevant issues in liming need for allogenic red blood cell trans fusions.

\begin{tabular}{|c|c|}
\hline Period & Relevant issues \\
\hline \multirow[t]{2}{*}{ Preoperative } & $\mathrm{Hb}_{3} \mathrm{H}, \mathrm{MCV}$ \\
\hline & Drugs that perturb clorting cascade \\
\hline \multirow[t]{4}{*}{ During surgery } & Cut-off values for transfusion (ransfusion riggen) \\
\hline & Meastres to activate dotring cascade \\
\hline & Cell saving \\
\hline & Normothermial \\
\hline \multirow[t]{3}{*}{ Postoperative } & Cut-of values fon transfusion (rransfusion rrigger) \\
\hline & Blood loss \\
\hline & Cell saving \\
\hline
\end{tabular}

Table 2 outlines the outcome of the analysis of our database that taught us where to focus for improved management.

\section{Relevant issues and restrictive strategies to minimise transfusion of bomologous red blood cells}

We recognise that the steps added to our general intent not to transfuse homologous red cells unless considered necessary, bears no involve medical novelties. Rather, this review shows how a well-chosen algorithm effected an $80 \%$ reduction of use of homologous red blood cell transfusions. We will describe the steps for minimising the need to transfuse homologous red blood cells in a fore ward progression, and show how the gain from each step sums with the prior one. The algorithmic format summarises these steps in a comprehensive perioperative blood management scheme (figure 1).

\section{Preoperative assessment}

In our clinic, the anaesthesiologist is part of the team that evaluates each of the 4,500 patients per year scheduled for orthopaedic surgery. Preoperative assessment is performed at least 3 to 4 weeks before surgery. The preoperative evaluation at this stage and involving anaesthesiologists allows for the appropriate clinical evaluations in preparation for delivery of the anaesthetic, and management of special requirements to the surgical procedure. Part is the definition of the indi- 
1. Expected blood loss $<0.5$ litre No laboratory measurements

Actons main iatin normothermia pertoperatively
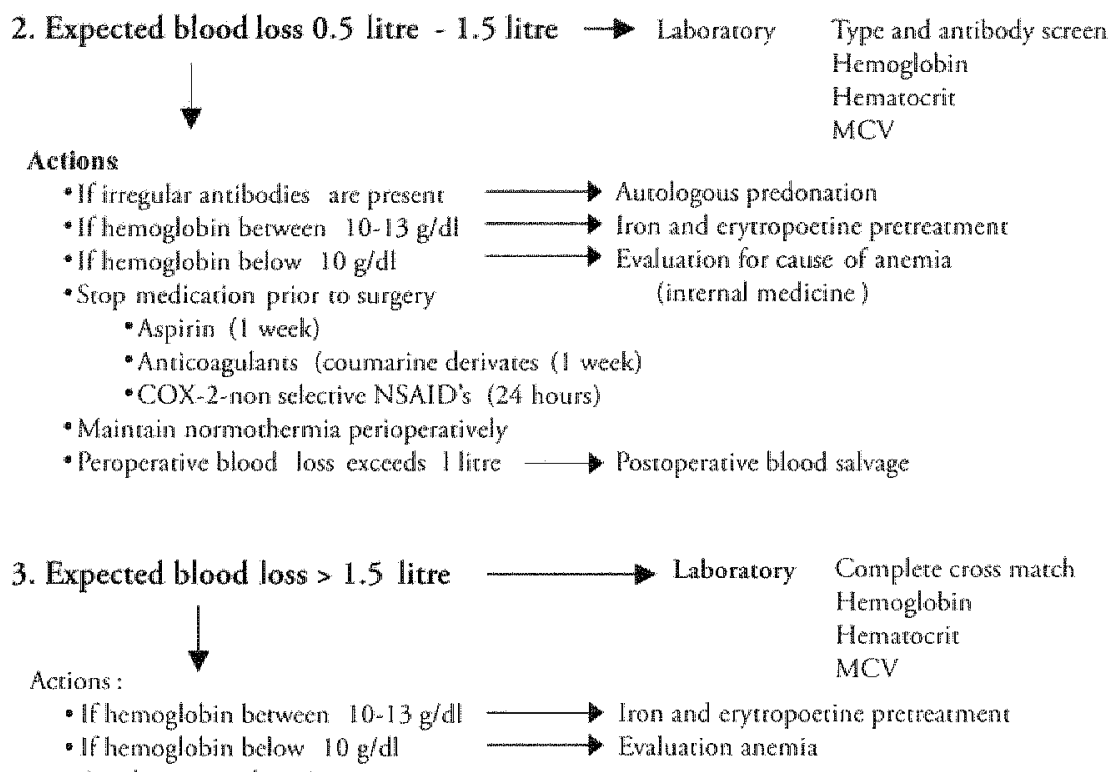

- Ancologous predonarion

- Stop medicition prior lo sugery

- Aspirin ("l weelé)

- Anticoagulants hcoumarine derivates) (1 weokt

- COX-2.nor selective NSALD' (24 tronts)

- Aprotinin peroperatively

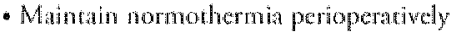

- Isowalemic hamoditurion

- Per-and postoperative blond salvage

Figure 1 Blood management in elective orthopedic surgery in adult patients.

Table 3 Peroperative blood los in first elective total hip surgery patients for coxarthrosis.

\begin{tabular}{|c|c|c|c|}
\hline Year: & 1994 & 1997 & 2000 \\
\hline Numbet of procedures & 226 & 362 & 420 \\
\hline NSAID & Diclofenac & Didofenac/Melloxicam & Meloxican \\
\hline Average blood loss per procedure & 701 & 562 & 515 \\
\hline Duration of surgery & 65 & 71 & 63 \\
\hline
\end{tabular}


vidualised guideline for blood management. Analysis of the relational database learned that two items were of special interest: preoperative NSAID's medication that can perturb coagularion of the blood during surgery, and preoperative laboratory studies for $\mathrm{CBC}$ to identify the need for erythropoietin administration. Noteworthy, other factors had been controlled and the most relevant ones are included in the algorithm presented in figure 1 and table 2 .

\section{NSAID:}

Non steroidal anti-inflammatory drugs (=NSAID's) used in the perioperative period for analgesia and reduction of oedema in the surgical field have well known unwanted side effects, including COX-1 related effects that leads to impaired platelet aggregation. These data were produced in laboratory studies, and - in order to corroborate the relevance of this data in the clinic - we evaluated blood loss for 1 specific surgical procedure (coxarthrosis: first hip replacement) for the period that we switched from non-specific to COX-2 selective NSAID's. The data show that total blood loss declined with $26 \%$, with other factors (e.g. duration of surgery), anti thrombosis prophylaxis unchanged (see table 3).

These data and the above considerations made us decide to evaluared the effect of the NSAID's on blood loss in clinical studies.

In the first double blind randomised study, blood loss of 50 parients during and after total hip surgery was compared for the conditions of two-week preoperative use of ibuprofen or placebo (6). We showed that ibuprofen pre-treatment was associated with a $45 \%$ higher perioperative blood loss than after placebo (ibuprofen $1161 \mathrm{ml}(\mathrm{SD} 472 \mathrm{ml}$ ) versus placebo $796 \mathrm{ml}(\mathrm{SD} 337 \mathrm{ml}) ; \mathrm{p}<0.001$ ). In a subsequent double blind randomised study we included 169 totall hip surgery patients, wherein we compared blood loss after prescription of the NSAID's indomethacin $50 \mathrm{mg}(\mathrm{n}=83)$ and meloxicam $15 \mathrm{mg}(\mathrm{n}=86)$ given orally one hour before surgery. We assessed that when indomethacin was used preoperatively the mean volume of peroperative blood loss was $623 \mathrm{ml}($ SD $243 \mathrm{ml})$ and postoperative blood loss $410 \mathrm{ml}$ (SD $340 \mathrm{~mL}$ ), after meloxicam $524(\mathrm{SD} 304 \mathrm{ml}$ ) and 357 $\mathrm{mL}(\mathrm{SD} 272 \mathrm{ml})$. The latter blood loss is $17.1 \%(\mathrm{p}=0.0095)$ less than that after the indomethacin. We conclude that these in vivo findings are consistent with the in vitro results and showed that avoiding the use of non-selective NSAID's will spare $17 \%$ of blood loss. 


\section{Recombinant buman erytbropoietin}

Recombinant human erythropoietin has been approved for use in patients undergoing major orthopaedic surgery in the Netherlands. The cut-off value for including a patient for this treatment is $10-13 \mathrm{~g} / \mathrm{dl}$. This value was chosen when the analysis of our relarional database had shown that $50 \%$ of all allogenic red cell transfusions had occurred in this group of parients. The standard treatment consists of 4 administrations of 40,000 IE erythropoletin at weekly intervals, independent of age and gender (7). This treatment is started strictly 3 weeks before surgery, with the final dose administered directly post-operatively if haemoglobin is below $15 \mathrm{~g} / \mathrm{dl}$. The variability of the response to erythropoietin relates to iron-restricted erythropoiesis, the iron consumption due to enhanced erythropoiesis should be covered with iatrogenic iron depletion to be avoided. Therefore, we co-medicate with $200 \mathrm{mg}$ elemental iron per day. We assessed in 127 patients the gain, and showed an average gain of $1.9 \mathrm{~g} / \mathrm{dl}(\mathrm{SD} 0.48) \mathrm{in} \mathrm{Hb}$ content in the blood.

\section{During surgery}

\section{Intra-operative blood saluage}

Intra-operative blood salvage is presently common pracrice is hospitals involved in major surgery. In our clinic rwo cell savers 5 (Haemonetics) are used when the blood loss is expected to be over 1.5 litre, e.g. during revision hip and spinal surgery.

\section{Intersurgeon variations in blood loss.}

Relevantly, we keep tract of the blood loss for each surgeon. The data are presented to the group anonymously, and each individual surgeon is informed on his / hers performance. Thereby, meticulous techniques and appropriate salvage are sustained.

\section{Medicaments to reduce bleeding}

\section{Aprotinine}

A naturally occurring serine protease inhibitor-modifies the haemostatic system and reduces bleeding. We introduced the drug for infusion when the estimated blood loss exceeds 2 litre (8). In our clinic, major spinal fusion surgery of the lumbothoracic spine (scoliosis, M. Bechterew) or major revision hip surgery result in such losses. The dose regiment is: test dose; after the induction of anaesthesia 
Table 4 The inrroduction of aprotinine in major spinal surgery (scoliosis)

\begin{tabular}{|c|c|c|}
\hline Pिए & No aprotinine & aprotinine \\
\hline$N$ & 21 & 22 \\
\hline Duration of surgery (min) & 205 & 221 \\
\hline Average blood loss $(\mathrm{ml})$ & 2772 & 2172 \\
\hline Mean number of units of red cells per patienr & 13 & 0.4 \\
\hline
\end{tabular}

$10^{6} \mathrm{KIU} / \mathrm{h}$ and, subsequently infuse the drug in the rate of $0.5 \times 10^{6} \mathrm{KIU} / \mathrm{h}$. We evaluated the effect in 43 patients for scoliosis surgery by 1 orthopaedic surgeon and found a $20 \%$ lower blood loss (table 4).

\section{Factor Vha}

In specific cases in cases of severe bleeding we do use thrombocytes and coagulation factors to treat coagulopathy caused by specific deficiencies. More recently we introduced the use of recombinant blood coagulation factor VIIa (rFVIIa, NovoSeven ${ }^{(B)}$ ). The drug forms a complexes with tissue factor (TF) which is present in the wound bed, and thereby acting as catalyst of local blood coagulation. It proved effective in some patients, but has not been used rourinely. Although controlled trials are required to prove the potential benefit in cases of massive blood loss the first case reports and experience is very hopeful for the future $(9,10)$.

\section{Normothermia}

Two independent studies claimed the effect of normothermia in total hip surgery $(1.1,12)$. A decrease in body tempetature of $1.5^{\circ} \mathrm{Celsius}$ at the end of surgery increased the perioperative blood loss by $500 \mathrm{ml}$. Although we didn't evaluate the effect of normothermia, the finding was important enough to introduce optimal warm air fields during surgery.

\section{The postoperative period}

\section{Transfusion trigger}

Restrictive use of cutmoff values for homologous red cell infusion in the post-operative period. In Dutch hospitals some $60 \%$ of the units of homologous red cells are ordered when relevant blood loss was anticipated $(13,14)$. Noteworthy, the actual infusion of homologous red cells was independent of a low $\mathrm{Hb}$ content in $96.2 \%$ of the patients. These unrestricted infusions are based on "clinical signs" such as fatigue, paleness, or blood is infused as a matter of "routine". In 
Table 5 Transfusion policy - based on the Hblevel as transfusion trigger - incorporates most recen nationat (Dutch) ransfusion guideline.

Within 4 hours of surgery

$1 \mathrm{Hb}>6.4 \mathrm{~g} / \mathrm{dl}=0$ padked cells

$1 \mathrm{~b}<6.4 \mathrm{~g} / \mathrm{dl}=1$ packed ocls

$116<4.8 \mathrm{~g} / \mathrm{dl}=2$ packed cells

Within 4 hours of surgery

$\mathrm{Hb}>72 \mathrm{~g} / \mathrm{dl}=0$ packed cells $1 \mathrm{~b}<7,2 \mathrm{~g} / \mathrm{dl}=1$ packed cells

$\mathrm{Hb}<6.4 \mathrm{~g} / \mathrm{dl}=2$ packed cells

Within 4 hours of surgery

$\mathrm{Hb}<8.8 \mathrm{~g} / \mathrm{dl}=0$ packed cells $H b<8.0 \mathrm{~g} / \mathrm{dl}=1$ packed cells $\mathrm{Hb}>7.2 \mathrm{~g} / \mathrm{dl}=2$ packed cells
More than 4 hours after surgery

$\mathrm{Hb}, 64 \mathrm{~g} / \mathrm{dL}=0$ packed cells

$\mathrm{Hb}<6.4 \mathrm{~g} / \mathrm{dl}=1$ packed cells

$\mathrm{Hb}, 56 \mathrm{gdl}=2$ packed cells

More that 4 hours after surgery

Hbs $80 \mathrm{~g} / \mathrm{dl}=0$ packed cells

$\mathrm{Hb}<8.0 \mathrm{~g} / \mathrm{dl}=1$ packed cells

$\mathrm{Hb} 72 \mathrm{~g} / \mathrm{dl}=2$ packed cells

More than 4 hours afrer surgery

$\mathrm{Hb}<8.8 \mathrm{~g} / \mathrm{dl}=1$ packed cells

$\mathrm{Hb}<8.0 \mathrm{~g} / \mathrm{dl}=2$ packed cells

Hb<7.2 g/dl $=2$ packed cels

Table 6 Mean transfusion rate according to three different transfusion guidelines and transfuision triggers.

Number of surgical procedures:

Type of anaesthesia $\%$ general/spinallplexus

Male/female $(\%)$

Average age (years)

Average duration of surgical procedure (min)

Number of allogente red cell infusions

$\begin{array}{lll}\text { Period A } & \text { Period B } & \text { Period C } \\ 4620 & 5703 & 4264 \\ 38 / 56 / 6 & 37 / 55 / 17 & 39 / 56 / 11 \\ 39 / 61 & 39 / 61 & 39 / 61 \\ 40.6 & 37.1 & 425 \\ 48.0 & 491 & 50.1 \\ 2218 & 1882 & 981\end{array}$

our hospiral we made a simple but major step foreward by simply forbidding any infusion of homologous red cells when $\mathrm{Hb}$ - and the Ht-values are unknown. The trigger value applied was adapted from Dutch national guidelines $(15,16)$, which for that purpose were transformed in a practical format (table 5). For the first 4 hours postoperatively, we took the effect of haemodilurion into account and allowed for the lower $\mathrm{Hb}$ level (table 5)

These guidelines were introduced in our intensive care unit in May 1996, and several months later the guideline was applied for the hospital.

It was of interest to evaluate the effectiveness of such a simple measure. For that purpose, 3 periods were sampled: period A (no guideline), period B (guideline 
Table 7 Number of allogenic red cell infusions in total knee surgey.

Year: 1997

2000

Number of procedures

137

153

Number of allogenic red cell infusions

77

Table 8 Allogenic red cell infusions in the Sint Martenskliniek in the period $1995-2001$.

\begin{tabular}{|c|c|c|c|c|c|c|c|}
\hline Year & 1995 & 1996 & 1997 & 1998 & 1999 & 2000 & 2001 \\
\hline Number of surgical procedures & 3398 & 4246 & 4034 & 4253 & 1078: & 1242 & 4610 \\
\hline Total blood loss () & 8453 & 8592 & 8251 & 8174 & 876 & 795 & 780 \\
\hline Average blood loss (m) & 265 & 209 & 201 & 192 & 210 & 187 & 169 \\
\hline Number of allogenic red cell infusions & 1172 & 1022 & 918 & 734 & 867 & 382 & 340 \\
\hline Average rransfusion rate & 0.34 & 0,24 & 0.23 & 0.17 & 0.21 & 0.09 & 0.07 \\
\hline
\end{tabular}

applied in the ICU only) period $\mathrm{C}$ (restricted guideline for the hospital). Demographic data and type of surgery were not different for the patients in the three groups. We found that the number of units per procedure diminished from 0.48 , to 0.33 and 0.23 in period $A, B$, and C respectively (16) (see table 6).

\section{Postoperative cell saving (Bellovac ${ }^{B}$ A.B.T)}

The Bellovac ${ }^{\text {in }}$ A.B.T system (A.B.T. = autologous blood transfusion) concerns a form of postoperative cell saving where blood from the operation wound is collected and filtered and then returned to the patient. This blood salvaging system helped to reduce the number of blood transfusions at our clinic to zero in rotal knee replacement surgery. Also, the system is used when patients subjected to total hip arthroplasty and revision hip arthroplasty show blood loss of more than $500 \mathrm{ml}$. Knee replacement surgery is performed using a tourniquet and the benefit of the postoperative salvage drain was marked (table 7).

The effect of blood sparing measures as a function of time.

The sequence of above described measures produced a steady decline in the use of packet red cells (table 8). 


\section{DISCUSSION}

An overwhelming selection of therapeutic modalities is available to minimise the need for homologous red cell infusions. Rather than simply including measures at random, we choose to rely on our relational database and identified which conditions associate with homologous red cell transfusions. Thereby, a tremendous decline of $80 \%$ in the use of red cells was achieved. In the algorithmic format (figure 1) the sequences are presented.

Every day's practice in our hospital was not different from that in any general hospital in the Netherlands. Systematic presentations on "how we did ir" resulted in the introduction of the measures in several of the hospitals in the region and a steady $5-7 \%$ decline per year in the urilisation of the use of homologous red cell transfusions.

It is of relevance to realise that each blood sparing measure on its own produces but a little decline. The full algorithm plus specific measures for the individual hospital results in a tremendous decline in the use off homologous red cells. Above we stated that a major reason for further efforts to reduce homologous red cell infusion relates to the notion that it is associated with transfusion-related immunosuppression favours postoperative infections, percurbs postoperative wound healing and thereby results in protracted hospital stay. One may expect that have achieved such decline in transfusions shows in these figures as well. Analysis of our database for these data showed a decline of the postoperative infecrions with $42 \%$ (table 9 ).

Table 9 Infection rate in the Sint Maartenskliniek $1997-2001$.

$\begin{array}{llllll}\text { Ycar } & 1997 & 1998 & 1999 & 2000 & 2001 \\ \text { Number of surgical procedures } & 4034 & 4253 & 4078 & 4242 & 4610 \\ \text { Incidence (\%) of postoperitive wound infections } & 2.6 & 2.1 & 1.7 & 1.8 & 1.5\end{array}$

\section{CONCLUSIONS}

Simple inexpensive measures help to reduce the need for homologous red cell transfusions. The savings in health care cost can be used for further improvement, and eventually, such infusions may occur anecdotally. 
Based on our above experience and other systematic improvements in the chain of patient care, we recommend:

- Restrictive guidelines for homologous red cell infusion;

- Automared relational databases that allow for feedback on clinical practice;

- Preoperative assessment that involves the anaesthesiologists and allows for preoperative planning along a comprehensive algorithm.

\section{REFERENCES}

1. Murphy, P., J. M. Heal and N. Blumberg (1991). "Infecrion or suspected infection after hip replacement surgery wich autologous or homologous blood transfusions." "Transfusion 31(3): $212-7$.

2. Blumberg, N. (1997). "Allogeneic transfusion and infecrion: economic and clinical implicarions," Semin Hematol 34 (3 Suppl 2): 34-40.

3. Bicrbaum, B. E., J. J. Callaghan, J. O. Galante, H. E. Rubash, R. E. Tooms and R. B. Welch (1999). "An analysis of blood management in patients having a total hip or knce arthroplasty." J Bone Joine Surg Am 81(1): 2-10.

4. Innerhofer, P., C. Walleczek, G. Luz, P. Hobisch-Hagen, A. Benzer, B. Stockl, G. Hessenberger, W. Nussbaumer and W. Schobersberger (1999). "Transfusion of buffy coat-depleted blood components and risk of postoperative infection in orthopedic paticnts." Transfusion 39(6): 625-32.

5. Borghi, B. and A. Casati (2000). "Incidence and risk Gactors for allogenic blood ransfusion during major joint replacement using an integrated autotransfusion regimen. The Rizzoli Study Group on Orthopaedic Anaesthesia." Eur I Anaesthesiol 17(7): 411-7.

6. Slappendel, R. E. W. Weber, B. Benraad, R. Dirksen and M. L. Bugter (2002). "Does ibuprofen increase perioperative blood loss during hip arthroplasty?" Eur J Anatesthesiol 19(11): $829-31$.

7. Goodnough, L. T., T. H. Price and C. A. Parvin (1995). "The endogenous erythopoietin response and the erythropoieric response ro blood loss anemia: the effects of age and gender."I Lab Clin Med 126(1): 57-64.

8. Samama, C. M., O. Langeron, N. Rosencher, X Capdevilla, P. Rowche, M. Pegoix, I. Bernicre and $P$. Coriat (2002). "Aprotinin versus placebo in major orthopedic surgery: a randomized, double-blinded, dose-ranging study." Anesth Analg 95(2): 287-93, table of contents.

9. Slappendel, R, F. C. Huvers, B. Benraad, I. Novakova and G. G. wan Hellemonde (2002). "Use of recombinant (actor VIla (NowoSeven) to reduce postoperative bleeding after rotal hip arthroplasty in a patient wirh cirthosis and thrombocyropenia." Anesthesiology 96(6): $1525-7$

10. Weiskopf, R. B. (2002). "Intraoperative use of recombinant activated coagulation factor wll." Anesthesiology $96(6): 1287-9$.

11. Schmied, H., A. Kurz, D. I. Sessler, S. Kozek and A. Reiter (1996). "Mild hypothermia increases blood loss and rransfusion requirements during total hip arthroplasty." Lancet $347(8997): 289-92$. 
12. Winkler, M., O. Akca, B. Birkenberg, H. Hetz, T. Scheck, C. F. Arkilic, B. Kabon, E. Marker, A. Crubl, R. Czepan, M. Greher, V. Goll, F. Gotisaner-Wolf, A. Kurz and D. I. Sessler (2000). "Aggressive warming reduces blood loss during hip arthroplasty." Anesth Analg 91(4): $978-84$

13. Buiting, A. M. and R. B. Dinkelaar (1998). "Survey on blood transfusion policy withn Durch hospitals: wide discrepancies. Central Guidance Organization for Peer Review]." Ned Tijdschr Geneskd 142(6): 293-7.

14. Van der Jagt, C., D. Trip and M. Dekker (2001). "Effectiviteir en veiligheid wan epoetine alfa bij grove electieve orthopedische operaries: een gerandomiseerde, placebogecontroleerde doseringsstudie." Nederlands vijdschrift voor Orthopaedie (8): 12-20.

15. Slappendel, R, E. Weber and D. van der Schaaf (1999). "Aanpassing en invoering wan het CBO transfusieprotocol in de dagelijkse praktijk wan de Sim Maartenskliniek leverde een halwering van het packed cell verbruik op." Kawaliteitsjournaal (augustus),

16. Weber, E., R. Slappendel and D. van der Schaaf (2000). "Halvering van de toediening van packed cells bij geprotacolleerde indicariestelling." Nederlands tijdschrift woor Orthopaedie(7): $10-12$. 
$\mathrm{I} \mathrm{s}$ 
CHAPTER 12 
The identification of different blood types by Landsteiner at the beginning of the 20 th century was the first major improvement of the safery and efficacy of blood transfusion (Chapter 2). Later on, developments in storage technology and screening for infectious agents made transfusion of blood even safer (Chapter 3 ). This progress, however, has led to the paradoxical situation that, although transfusions are safer than ever, both doctors and patients are much more aware of its risks, and thus more teluctant to use them. In terms of peri-operative patient management, one of the major challenges to the anaesthetist then has become to avoid blood transfusions. With this guiding principle in mind, this thesis set out to answer two questions: What are the deleterious effects of blood transfusions in elective orthopaedic surgery, and what can the anaestherist do to minimize these?

Perioperative blood loss is still a major problem in elecrive orthopaedic surgery. Homologous blood transfusion (HBT) is the standard approach to treat porenrially detrimental decreases in haemoglobin ( $\mathrm{Hb}$ ) concentration. However, HBT is associated with various adverse events, including febrile reactions, transmission of infectious diseases, and an immunomodulatory effect, which is hypothesized to increase the frequency of postoperative infections. This issue is far from resolved, as observational cohort studies, randomised controlled studies and a recent meta-analysis on the subject produced conflicting results. Nonerheless, the clinical observation that patients who receive any $\mathrm{HBT}$ after major orthopaedic surgery do stay in the hospital significantly longer is undisputed. As postoperative infections are relarively rare $(1-3 \%)$, and as the role of HBT herein is not yet established, other factors are likely to be responsible for the prolonged hospital stay. To address this issue we undertook a prospecrive observational study (Chapter 4). In 444 patients who underwent elective total hip arthroplasty, we studied (among orher parameters) the frequency of $\mathrm{HBT}^{\top}$, wound disturbances, superficial and deep wound infecrions, and length of hospital admission.

In this prospective observational study we found that $\mathrm{HBT}$ is associaced with prolonged hospital admission. We found that this prolonged admission is not a straightforward consequence of an increased postoperative infection rate. However, HBT was the sole significant predictor of the development of wound healing disturbances, and together these rwo factors were the main predictors of prolongation of hospitalisation. No significant influence on wound disturbance and hospitalisation was found, either by univariare or multivariate analysis, of age, sex, length, weight, operation duration, blood loss or the use of gentamicin cement. 
Although we did not study the mechanism underlying of wound disturbances, the more pragmatic conclusion we reach from our study is that prevention of HBT may be of relevance in limiting duration of admission after elective orthopaedic surgery. If this is indeed the case, measures to prevent perioperarive blood loss, cell saving techniques and methods to enhance preoperative $\mathrm{Hb}$ (such as EPO) might be attractive treatment options.

One of the simplest and cheapest ways to optimise the use of blood transfusions would theoretically be the development of a transfusion protocol. Indeed, in the light of the risks described above and the fact that blood supply in The Netherlands is not infinite, a nationwide consensus on guidelines for packed red blood cells (PRBC) transfusions in the perioperative period was reached in 1997. This nationwide consensus resulted in a transfusion protocol for our hospital in which the haemoglobin concentration was the sole indication for homologous blood transfusion (HBT). We investigated the HBT ratio before and after the introduction of the new protocol in our hospital (Chapter 5). Over a 33-month period 14587 patients were included in the study. We found a 50\% decrease in PRBC transfusions after implementation of the guidelines.

Of course is it not possible to maintain constant all confounding factors that can affect perioperative blood loss during a period of evaluation as long as our study. Several important factors changed in our hospital during the evaluation period. Changes occurred in the surgical staff, and the percentage of loco-regional anaesthesia increased. Also, during the evaluation period the introduction of more COX-2 selective NSAID's took place. Undoubtedly, these factors were, to some extent, responsible for the decreased blood loss and thus for decreased perioperative rransfusion requirements. Still, our study clearly shows the benefits of employing strict perioperative transfusion guidelines, as a $50 \%$ decrease in PRBC rransfusions was seen during the observation period compared to the $25 \%$ decrease in blood loss during the same periods. Perioperative transfusions are responsible for $60 \%$ of all transfusions in the Netherlands. According to a representative survey, the indications were poorly specified for $40 \%$ of these: blood loss, routine practice, cardiovascular changes, weakness or fatigue were cited. Current guidelines, which our study corroborates, indicate that in the peri-perative period a patient should only be transfused if the haemoglobin concentration is known. 
Apart from adherence to a strict protocol, there are more specific methods with the porential to minimise the use of blood transfusions. Among these is the use of the new generation non-steroidal anti-inflammatory drugs (NSAID's), the COX-2 antagonists with less influence on blood coagulation. Moreover, sophisticated technology now enables the anaestherist to retrieve RBC's peri- and post-operarively. Finally, the hormone EPO may be used to boost the number and contents of the RBC's pre-operarively. We studied all these potential blood sparing methods sequentially.

NSAID's are used in the perioperative period for analgesia and reduction of oedema in the surgical field. Besicte these benefits there are unwanted side effects: reduction of renal blood flow, gastric complaints and increase of blood loss during surgery by influencing the coagulation cascade. Ibuprofen is a commonly used NSAID in the Netherlands, and we wished to assess its effects on perioperative blood loss in patients undergoing hip arthroplasty in a randomised double-blinded placebo controlled study in 50 patients (Chaprer 6).

In this study preoperative ( 2 weeks) pre-treatment with ibuprofen showed an increase in blood loss of $46 \%$ incra-operatively and during the first 24 hours after total hip replacement surgery. Confounding factors in our study were the use of prophylaxis against thromboembolism by acenocoumarol, and the technique of measuring blood loss. The sudy was also nor designed to prove that an increase in blood loss resulted in increased transfusion requirements or perioperarive morbidity / mortality. However, although we thus did not prove that the increased blood loss was clinically relevant, the fact remains that compared to a placebo, ibuprofen caused more blood loss perioperatively.

To tackle this problem there are two options: discontinue NSAID's far ahead of scheduled major orthopaedic surgery, or change NSAID's three days before surgery into COX-2 selective agents, with a potentially better safety profile with regard to perioperative blood loss.

The anti-inflammatory, analgesic and antipyretic action of NSAID's are mediated through inhibition of prostaglandin synthesis by inhibiting cyclo-oxygenase $(\mathrm{COX})$, which is now known to exists in at least two isoforms known as COX-1 and COX-2. COX-1 is important in "housekeeping" functions at the gastro-intestinal mucosa, kidneys and vasculature. In contrast, the inducible isoform COX-2, mainly contributes to the pathophysiological process of inflammation. 
From this one could reason that selective COX-2 inhibiting NSAID's have fewer side effects.

We have taken this idea further and designed a prospective randomised study to test the hypothesis that use of more cyclooxygenase-2 (COX-2)-selective NSAID's can reduce perioperative blood loss compared with non-selective NSAID's. We studied 200 patients who underwent total hip replacement (Chapter 7). Two NSAID's were compared: conventional NSAID indomethacin ( $3 x$ $50 \mathrm{mg}$ daily) and the COX-2 selective meloxicam (1x $15 \mathrm{mg}$ daily). Total perioperative blood loss after meloxicam was $17 \%(\mathrm{p}<0.05)$ less than that observed after indomerhacin. However, whether this is of clinical significance and influences patient outcome remains to be determined. In addition, the potential beneficial effects of these compounds on blood loss should be weighed against potential detrimental effects (such as a potentially increased risk for cardiovascular events) before routine use can be recommended.

One of the more elegant measures to avoid red blood cell cransfusions in parients with a lowered haemoglobin level $(10-13 \mathrm{~g} / \mathrm{dl})$ is epoetin alpha (EPO). To study the effects of EPO on the number of perioperative BTs we undertook a multi-centre randomised controlled trial (RCT) (Chapter 8). In this RCT the effects of preoperative administration EPO and best standard of care (BSC) in 695 orthopaedic surgery patients were compared in normal clinical routine in six countries. EPO-treated patients had higher $\mathrm{Hb}$ values from the day of surgery until endpoint and lower transfusion rates ( $12 \%$ vs. $46 \%$ ). EPO treatment delivered no significant effect on postoperative recovery (time to ambulation, time to discharge, infection rate). Time to ambulation and rime to discharge were, however, longer in transfused than in not-ransfused parients. Side effects in both groups were comparable. EPO increased perioperative $\mathrm{Hb}$ in mild-moderate anaemic patients and reduced transfusion requirements. Patients receiving blood transfusions required a longer hospitalisation than not-transfused patients.

Apart from the above EPO probably also plays an important role in post-operative rehabilitation. In many countries hip and knee surgery are performed in accelerated rehab programs, which limit hospitalisation times to less than a week. Thus postoperative higher haemoglobin levels might become more important as rehabilitation becomes more strenuous due to reduction in hospitalisation. Preoperative EPO administration will thus become more important, especially in the more compromised patients, as they suffer more from the changes in rehabili- 
tation and lower accepted haemoglobin levels. This study leads to the conclusion that in routine daily serting of major orthopaedic surgery EPO treatment is an efficient method to decrease perioperative transfusion requirements and to increase perioperative haemoglobin levels. As hospitalisation time is severely reduced by new rehabilitation procedures, this will become even more important.

The current treatment protocol of EPO consists of a fixed dose in all patients, according to Goldberg. Although easy to use, it has its limitations, since the inter-patient variability in response is considerable. In a prospective study we investigated whether pre-operative EPO dosing can be specifically tailored to the individual patienr's needs (Chapter 9). A total of 334 patients scheduled for major orthopaedic surgery were treated for decreased serum haemoglobin levels. EPO and iron were used three weeks prior to surgery to increase the level of serum haemoglobin. Afterwards we calculated the erythropoiesis output in grams of haemoglobin after one injection of 40,000 IU of EPO (i.e. Factor EO-40,000). In our study factor EO-40,000 was 34 grams. Factor EO-40,000 $\mathrm{can}$ be used to predict the increase in the serum haemoglobin level in the individual patient, as the number of EPO injections $(40,000$ IU) needed to reach the desired serum haemoglobin level can now be calculared. With this knowledge, patients can be better prepared for surgery and homologous blood transfusions can be avoided as far as possible.

As stated above another method to reduce perioperative blood transfusions is the use of an autotransfusion system for shed blood. Cell saving techniques are an effective approach to prevent blood transfusion. Shed blood may be re-infused after filtration (unprocessed) or after treatment in a cell separator (processed). Transfusion of unprocessed shed blood is a relatively simple and inexpensive method to restore normovolaemia, in contrast to autorransfusion of processed blood, which requires an expensive cell separator and disposables. We performed a prospective observational quality assessment study of the Bellovac ${ }^{\text {iti }}$ post-operarive wound drainage and reinfusion system in 135 consecurive patients scheduled for elecrive tocal knee arthroplasty or total hip arthroplasty (Chapter 10). The control group consisted of a historic group of 96 patients. Aurotransfusion reduced the percentage of patients receiving HBT from $35 \%-22 \%)$. The reduction was more pronounced in the knee surgery patients ( $18 \%$ to $6 \%$ ) compared with the hip surgery parients $(47 \%$ to $34 \%$ ). In the knee patients, transfused packed red cells per operation decreased from $0.45 \mathrm{HBT} /$ operation to 0.11 
HBT/operation, a reduction of $0.34 \mathrm{HBT}(75 \%)$ in every total knee arthroplasty. This was also found in the hip surgery patients, although this did not reach statiscical significance. This may be related to surgical rechnique: as in most hospitals, knee arthroplasty surgery was performed using a tourniquet, so that blood loss occurred only in the post-operative period, in contrast to the hip surgery where blood loss occurred during the whole procedure. Re-transfusion of shed blood is of course most effecrive if all lost blood can be collected, as is the case in knee surgery, but not in hip surgery, where significant blood loss occurs during the operation.

Although we observed no complications during re-transfusion, our parient group may have been too small for a safery assessment. One of the most common side effects is a febrile reaction after autotransfusion of shed blood, which we did nor see. Another concern would be the presence of methyl methacrylate monomer (MMM) in re-transfused blood. However, systemic blood showed no evidence of MMM after re-infusion of salvaged blood in cemented knee arthroplasty surgery.

A cost-benefit analysis of the system is difficult to make, because of the complex costs involved in blood transfusion. At first glance autotransfusion is more expensive, but a future formal cost-benefit study should also take into account possible exrended hospitalisation and immunomodulatory effects due to a homologous blood transfusion. We condude that the Bellovac ${ }^{\circledR}$ A.B.T. device reduced homologous blood transfusions in TKA. The use of the system is less complicated and less expensive than auto re-transfusion using a cell separator. This method of auto re-transfusion should therefore be considered in knee surgery.

Having defined several methods to decrease perioperative blood transfusion, we subsequently implemented these improvements in our daily clinical routine. The first step was the restriction that the $\mathrm{Hb}$ level should be assessed prior to red cell infusion to ensure compliance with pre-defined cut-off values. Subsequent measures included: confinement to COX-2 selective NSAID in the perioperative period; EPO and iron therapy at the Hb level between 10 and $13 \mathrm{~g} / \mathrm{dl}$; consequent cell salvage during and after surgery; administration of aprotinine in cases with expected high blood loss $(>1.51)$. We then studied the effect of these alterations in our clinical routine. To this end we surveyed a relarional database with data on 28.861 orthopaedic surgery patients in our clinic before and after implementation (Chapter 11). The survey disclosed the following issues related to a high incidence of homologous red cell infusion: negligence of guidelines, the pre- 
operative use of non-selective NSAID's, low preoperative Hb level, non-retrieved blood loss, and high cut-off values for homologous red cell transfusion. The type of anaesthetic technique was found to be not relevant for blood-sparing effect.

The steps mentioned above do not involve a medical novelty. Rather, we show that strict rules with the appropriate steps and in sequence resulted in an $80 \%$ reduction of use of homologous red blood cells. Of note is that the incidence of deep wound infections decreased by $40 \%$ over the same time, but whether this is related solely to our blood-saving measures remains to be seen.

Daily clinical practice in our hospital was not different from that in any general hospital in the Netherlands. Systematic presentations on "how we did it" resulted in the introduction of the measures in several of the hospitals in the region and a steady $5-7 \%$ decline per year in the urilisation of the use of homologous red cell transfusions.

One needs to keep in mind that each blood sparing measure on its own produces but a little decline. However the combination of all measures for the individual hospital results in a tremendous decline in the use of homologous red cells. Does this decline in $\mathrm{HBT}$ also result in a decrease in postoperarive infections, as one would expect from the literature? Analysis of our database for these data showed a decline of the postoperative infections with $42 \%$, but whether this temporal relation is also a causal one is unsure.

Based on our above experience and other systemaric improvements in the chain of patient care, we recommend:

- Restrictive guidelines for homologous red cell infusion.

- Automated relational databases enabling feedback on clinical practice

- Preoperative assessment that involves the anaesthesiologists and allows for preoperative planning along a comprehensive algorithm (Chapter 11) 
HOOFDSTUK 13 
De identificatie van de verschillende bloedrypes door Landsteiner in her begin van de 20 e euw was één van de eerste grote verbeteringen op het gebied van veiligheid en gebruik van bloedtransfusies (Hoofdstuk 2). De latere ontwikkelingen in opslag en het testen op infecrieuze agentia hebben de veiligheid van bloedtransfusies verder verbeterd (Hoofdstuk 3). Deze wooruitgang heeft echter tor de paradoxale situatie geleid dat alhoewel bloedtransfusies veiliger zijn dan ooit, zowel de dokter als de patiënt zich meer bewust zijn van de eventuele risico's en daarom minder genegen zijn een bloedrransfusie te accepteren. Maar zonder negatieve gevolgen zal een bloedtransfusie wellicht nooit worden. In termen wan perioperatief patiëntenbeleid, blijft het voorkomen van een bloedtransfusie een van de uitdagingen voor de anesthesioloog.

Met deze principes in gedachten proberen we in dit proefschrift twee vragen te beantwoorden: wat zijn de schadelijke effecten van een bloedtransfusie bij electieve orthopedische chirurgie, en wat kan de anesthesioloog doen om een bloedtransfusie te verminderen?

Perioperatief bloedverlies is een van de problemen bij elecrieve orthopedische chirurgie. Een homologe bloedtransfusie (HBT) is de standaard benadering om de potentieel schadelijke effecten van een te lage hemoglobine concentratie ( $\mathrm{Hb})$ te voorkomen. Echter een HBT wordt geassocieerd met verschillende schadelijke bijwerkingen, koortsreacties, verspreiding van infectieuze ziekten en immuun modulerende effecten. Door deze immuun modulerende effecten verdenkt men dat een HBT mogelijk een toename kan geven van postoperatieve infecties. Deze hypothese is echter nog lang nier opgelost. Observationele cohort onderzoeken, gerandomiseerde gecontroleerde onderzoeken en een recente meta-analyse hebben tegenstrijdige resultaten opgeleverd. Maar de klinische observatie dat patiënten die een HBT krijgen na grote orthopedische chirurgie langer in het ziekenhuis blijven is onweerlegbaar. Omdat postoperatieve infecties relatief zeldzaam $(1-3 \%)$ zijn en de rol van een HBT hierin nog niet bewezen, zijn mogelijk andere factoren verantwoordelijk voor de verlengde ziekenhuisopname. Om dit nader te onderzoeken hebben we een prospectief observationeel onderzoek gedaan (Hoofdstuk 4). Bij 444 patiënten die een elecrieve totale heupoperatie ondergingen hebben we "behoudens andere parameters" de frequentie van HBT, wondrandstoomissen, oppervlakkige en diep wondinfecties en de opnameduur onderzocht. In dit prospectief observarioneel onderzoek hebben we gevonden dat een HBT geassocieerd is met een verlengde opnameduur. We vonden dat her verlengde opnameduur niet direct het gevolg was van een verhoogde postoperatieve 
infectie ratio. Een HBT was de enige significante voorspeller voor de ontwikkeling van wondrandstoornissen, en deze factoren samen waren voorspellers voor de verlenging van het ziekenhuisverblijf. Er werd geen significante invloed op wondrandstoornissen en ziekenhuisopname duur gevonden bij univariaar en multivariaat analyse van leefrijd, geslacht, lengte, gewicht, operatieduur, bloedverlies, of het gebruik van gentamycine cement. Alhoewel we niet her mechanisme van de wondrandstoornissen hebben onderzocht kunnen we de meer pragmatische conclusie uit ons onderzoek stellen dat het voorkomen van een HBT mogelijk relevant is in het beperken van de opnameduur na elecrieve orthopedische chirurgie. Als dit inderdaad het geval is kunnen maatregelen om het perioperatief bloedverlies te verminderen goede behandelingsopties zijn. Een van de meest simpele en goedkoopste manieren om her gebruik van bloedtransfusies te oprimaliseren is in principe het ontwikkelen van een transfusieprotocol. Inderdaad is in het licht van de hierboven beschreven risico's en het feit dar de bloedvoorraad in Nederland niet oneindig is een nationale consensus over transfusies opgesteld in 1997. Deze consensus resulteerde in een aangepast transfusieprotocol voor de St. Maartenskliniek waarin de hemoglobine concentratie de enige indicatie voor een HBT was. Retrospectief hebben we de HBT ratio voor en na introductie van het nieuwe protocol in de St. Maartenskliniek onderzocht (Hoofdstuk 5). Gedurende 33 maanden werden 14.587 patiënten geïncludeerd in het onderzoek. We vonden een $50 \%$ reductie in "packed cells" gebruik na implementatie van de strak geprotocolleerde richtlijnen. Natuurlijk is het niet mogelijk om alle medebepalende factoren die peri-operatief bloedverlies gedurende deze lange periode van het onderzoek beïnvloeden, constant te houden. Enkele belangrijke factoren veranderden gedurende deze evaluatie periode in de St. Maartenskliniek. Er vonden mutaties plaats in de chirurgische staf en her percentage locoregionale anesthesie nam toe. Tevens vond gedurende deze periode de introductie van de meer COX-2 selectieve NSAID's als standaard NSAID plaats. Natuurlijk zijn deze factoren medebepalend ( $r o t$ een bepaalde hoogte) voor het verminderde bloedverlies en dus ook van het perioperatief transfusiegebruik. Echter ons onderzoek laat duidelijk de voordelen van strikte perioperatieve transfusie richtlijnen zien; een 50\% reductie in "packed cells" gebruik bij een $25 \%$ reductie in bloedverlies.

Perioperatieve transfusies zijn verantwoordelijk voor $60 \%$ van alle transfusies in Nederland. Volgens een onderzoek is de indicatie bij $40 \%$ slechr gespecificeerd; bloedverlies routine, cardiovasculaire veranderingen, zwakte en vermoeidheid werden genoemd. Ons onderzoek laat zien dat in de perioperatieve periode een 
patiënt alleen een transfusie mag krijgen indien de hemoglobine concentratie bekend is.

Anders dan een strikt transfusieprotocol zijn er nog andere methoden om het aantal perioperatieve bloedtransfusies te verminderen. Onder deze andere methoden is her gebruik van de nieuwe generatie nier steroidale anci-inflammatoire geneesmiddelen (NSAID's), de meer COX-2 specifieke remmers mer minder invloed op de bloedstolling. Buiten dit zijn er nieuwe technieken ter beschikking gekomen die het mogelijk maken om in de perioperatieve fase verloren gegane erytrocyten re hergebruiken. Ook is het nu mogelijk om met behulp van her hormoon erytropoietine (epo) het aantal erytrocyten preoperatief te verhogen. We hebben al deze methoden afzonderlijk onderzocht.

NSAID's worden in de perioperarieve periode gebruikr in verband met analgesie en vermindering van oedeem in het chirurgisch veld. Behoudens deze voordelen zijn er ook nadelige bijwerkingen: verminderde nier doorbloeding, maagklachten en toename van het chirurgisch bloedverlies door invloed op de stollingscascade.

Ibuprofen is een veelgebruikt aspecifiek NSAID in Nederland en we hebben de effecten op het perioperatief bloedverlies onderzocht in een gerandomiseerde dubbelblinde placebo gecontroleerd onderzoek bij 50 patiënten die geopereerd werden aan een totale heupvervanging (Hoofdstuk 6). In dir onderzoek hadden patiënten die 2 weken werden voorbehandeld met ibuprofen $46 \%$ meer bloedverlies in de eerste 24 uur na een totale heupvervanging. In dit onderzoek hebben we alleen gekeken naar bloedverlies en niet naar verminderde transfusiebehoefte. Alhoewel we niet onderzocht hebben of her verminderd bloedverlies dus $\mathrm{klinisch}$ relevant is, laat übuprofen een duidelijk hoger perioperatief bloedverlies zien. Om dit probleem te ondervangen zijn er 2 mogelijkheden: het staken van NSAID's ver voor de operatie of het NSAID eventueel omzetten in een meer COX-2 specifiek NSAID.

We hebben dit dan ook onderzocht in een prospectief gerandomiseerd onderzoek of de hypothese dat her gebruik van meer COX-2 specifieke NSAID's perioperatief bloedverlies kan verminderen in vergelijking mer niet specifieke NSAID's (Hoofdstuk 7). In dit onderzoek waarbij 200 patiënten werden geopereerd aan een totale heupoperatie hebben we 2 NSAID's vergeleken: het niet specifieke NSAID indomethacine ( $3 \times$ daags $50 \mathrm{mg}$.) en her meer COX-2 specifieke NSAID meloxicam ( $1 \mathrm{x}$ daags $15 \mathrm{mg}$.). Het totale perioperatieve bloedverlies was 
bij meloxicam gebruik $17 \%$ minder dan bij indomethacine. Of dit verschil klinisch relevant is en een betere resultaar voor de patiënt heeft, valt nog te bezien. Wat betreft het perioperatieve bloedverlies is het staken van klassieke NSAID's zeker zinvol voorafgaand aan een electieve operatieve ingreep, vergelijkbaar met anticoagulantia en aspirine. Een van de meer elegante maatregelen om een HBT bij pariënten met een verlaagd hemoglobine gehalte (10-13 gram/dl) te voorkomen is EPO (Hoofdstuk 8). Om het effect van EPO op het aantal perioperatieve bloedransfusies te onderzoeken hebben we een multi-centrum gerandomiseerde gecontroleerde studie gedaan. In dit onderzoek is het effect wan preoperatieve toediening van EPO bij 695 orthopedisch chirurgische patiënten vergeleken met "standaard zorg" in 6 verschillende landen. De met EPO behandelde patiënten hadden een hoger $\mathrm{Hb}$ gehalte van de dag vanaf operatie tot het eind van de opname en een verminderde transfusieratio ( $12 \%$ versus $46 \%$ ). EPO behandeling had geen significant effect op postoperarief herstel (bedrust, oprameduur en infectictatio). De bedrust en opnameduur waren bij patiënten die een transfusie hadden gehad langer. De bijwerkingen in beide groepen waren vergelijkbaar. Behalve bovenstaande speett EPO mogelijk ook een belangrijke rol in de postoperatieve revalidatie. In veel landen worden heup- en kniechirurgie vaak verricht in een versneld revalidatieprogramma waarbij de ziekenhuisopnameduur verminderd is tot minder dan $\mathbb{1}$ week. Deze verkorte revalidatie vraagt meer inspanning van de patiënt; reden waarom een hoger $\mathrm{Hb}$ belangrijk kan zijn. Preoperatief EPO kan dus eventueel belangrijk zijn, speciaal bij meer gecompromitteerde patiënten die mogelijk meer last hebben van een laag $\mathrm{Hb}$ gehalte bij deze meer inspannende revalidatie. Dit onderzoek leidt tot de conclusie dat in een routinematige grote orthopedische chirurgie EPO behandeling een efficiënte methode is om her perioperatieve transfusiebehoefte te verminderen en het perioperatief $\mathrm{Hb}$ te verhogen, zonder het optreden van ernstige bijwerkingen.

Het huidige behandelingsprotocol mer EPO bestaat uit een vaste dosering bij alle patiënten volgens Goldberg (1996). Alhoewel makkelijk in gebruik heeft het zijn beperkingen, daar de interpatiènt variabiliteit aanzienlijk is. In een prospectief onderzoek hebben we onderzochr of de EPO dosering bij de individuele pariënten behoefte kan worden aangemeten (Hoofdstuk 9). Bij 334 patiënten die op de wachtlijst stonden voor grote orthopedische chirurgie werden behandeld wegens een lichte anemie. EPO en ijzer werden 3 weken voor operatie toegediend. Naderhand hebben we het erythropoietische effecr in grammen hemoglobine na 1 injectie van 40.000 eenheden EPO (factor EO-40.000) berekend. In onze studie was de factor EO-40.000 34 gram. Factor EO-40.000 kan gebruikt worden 
om de toename in serumhemoglobine van de individuele patiënt te voorspellen als het aantal injecties EPO om het gewenste serumhemoglobine te bereiken. Met deze kennis kan de patiënt beter voorbereid worden voor de chirurgie en een HBT zoveel mogelijk voorkomen worden.

Een andere methode om het aantal perioperatieve bloedtransfusies te verminderen is het gebruik van autotransfusie systeem voor verloren gegaan bloed. "Cell-saving" technieken zijn een effectieve benadering ter voorkoming van een HBT.

Verloren gegaan bloed kan gereinfundeerd worden na filtratie (= onbehandeld) of na behandeling in een cellseparator (=behandeld) mer behulp van cell-saver. Transfusie van onbehandeld verloren gegaan bloed is een relatief simpele en een goedkope manier om normovolemie te herstellen, in vergelijking met autotransfusie van behandeld bloed dat een dure cellseperator (cell-saver) en disposables verlangd. We hebben een prospectief observationeel kwaliteirsonderzoek gedaan met de Bellovac postoperatief wonddrainage en re-infusiesysteem bij 135 achtereenvolgende patiënten woor electieve heup- en knievervanging (Hoofdstuk 10). De controlegroep bestond uit een historische groep van 96 patiënten. Autotransfusie verminderde het percentage patiënten die een $\mathrm{HBT}$ ontvingen van $35 \%$ naar $22 \%$. De vermindering was meer uitgesproken bij patiënten die een knievervanging kregen ( $18 \%$ naar $6 \%$ ) in vergelijking met pariënten die cen heupvervanging kregen ( $47 \%$ naar $34 \%$ ). Bij patiënten die een knievervanging kregen verminderde het aantal transfusies van $0,45 \mathrm{HBT}$ /operatie naar $0,11 \mathrm{HBT} /$ operarie, een reductie van $0,34 \mathrm{HBT}(75 \%)$ bij elke knieoperatie. Een vermindering werd ook gezien bij heupvervanging maar bereikte nier de statistische significantie.

Waarschijnlijk is dit tengevolge van de chirurgische techniek. Een totale knievervanging wordt voornamelijk verricht tijdens bloedleegte zodar het bloedverlies alleen optreedt in de postoperatieve fase. In tegenstelling tot heupvervanging waarbij het bloedverlies tijdens de gehele procedure platsvindt. Retransfusie van verloren gegaan bloed is uiteraard her meest effectief als alle bloed verzameld kan worden zoals het geval bij knievervangende operaties.

Alhoewel we geen complicaties tijdens retransfusie hebben gezien, is onze patientengroep mogelijk te klein om iets over veiligheidsaspecten te zeggen. Een van de meest voorkomende bijwerkingen is rillen na autotransfusie hetgeen wij echter nier gezien hebben. Een andere zorg zou mogelijk de aanwezigheid van methyl methaa- 
crylaat (MMM=cement) in transfusiebloed zijn. Echter systemisch bloed liet geen anwezig MMM zien na reinfusie bij gecementeerde totale knievervanging.

Een kostenbaten analyse wan het systeem in vergelijking met een $H B T$ is moeilijk te maken in verband met de complexe kosten die gepaard gaan met een bloedtransfusie. Op het eerste gezicht is autotransfusie duurder maar een toekomstige kostenbaten onderzoek zou ook rekening moeten houden met de verlengde opnameduur en immuunmodulerende effecten ten gevolge van een HBT. We concluderen dat het Bellovac systeem het aantal HBT's bij rotale knievervangingen reduceert. Het gebruik wan het systeem is minder gecompliceerd en goedkoper dan autotransfusie met behulp van een cell separator. De autotransfusie met behulp van het Bellovac systeem zou dan ook overwogen moeten worden bij totale knievervanging.

A $\mathrm{mer}$ al hebben we enkele merhoden gedefinieerd ter vermindering wan een aantal perioperatieve bloedtransfusies en deze hebben we achtereenvolgens geïmplementeerd in de Sint Maartenskliniek. De eerste stap was de restrictie dat her $\mathrm{Hb}$ gehalte bekend moest zijn en voldoen aan een gedefinieerde waarde woordat overgegaan mocht worden tot een transfusie. Andere maatregelen waren het gebruik van COX-2 specifieke NSAID's in de perioperatieve fase; epo en ijzer therapie preoperatief bij een $\mathrm{Hb}$ lager dan $13 \mathrm{gram} / \mathrm{dl}$.; consequente cellsaving gedurende en na operatie; toediening van aprotinine bij gevallen met een verwacht hoog bloedverlies. We hebben de effecten van deze veranderingen onderzocht in onze kliniek. Om deze effecten te bestuderen hebben we een relationele database met gegevens van 28.861 orthopedische chirurgische patiënten in de St. Maartenskliniek nagekeken woor en na implementatie (Hoofdstuk 11). Oorzaken die voor implementatie van de veranderingen een hoge incidentie van een HBT gaven waren: her niet opvolgen wan de richtlijnen, het preoperatief gebruik van non-selectieve NSAID's, een laag preoperatief $\mathrm{Hb}$ en bloedverlies dat nier gereïnfundeerd kon worden. De anesthesietechniek bleek geen invloed te hebben op bloedbesparing.

De woomoemde stappen zijn geen medische nouveautés. Echter, het strikt navolgen van de opeenvolgende stappen resulteerden in een $80 \%$ reductie van het aantal HBT"s. Vermeldenswaard is in hetzelfde tijdsinterval het aantal diepe wondinfecties $40 \%$ daalde. Of dit echter alleen toe te schrijven is an de bloedbesparende technieken valt moelijijk te bewijzen. 
De dagelijkse praktijk in de St. Maartenskliniek is niet anders dan in welk ander ziekenhuis in Nederland. De presentatie van "how we did it" resulteerde in maatregelen in enkele ziekenhuizen in de regio mer een vermindering van her HBT gebruik van $5-7 \%$ per jaar. Men moet in gedachten houden dat een enkele bloedbesparende maatregel op zichzelf weinig effect heeft, echter dat cen combinatie van maatregelen een enorm verschil kan geven. En geeft deze vermindering in HBT ook een vermindering in postoperarieve infecries zoals men mag verwachten uit de literatuur? Analyse van de database laat een $42 \%$ vermindering zien van de postoperatieve infecties. Of dit echter een causaal effect is, is onduidelijk.

Gebaseerd op onze bovenstaande ervaring en andere systematische verbeteringen in de keten van pariëntenzorg kunnen we aanbevelen:

- Restrictieve richtlijnen voor homologe bloedtransfusies, gekoppeld aan een hemoglobine gehalte.

- Het gebruik van een geautomatiseerde relationele database voor terugkoppeling van de klinische praktijk

- Preoperatief beleid met behulp van de anesthesioloog voor de implementatie van het algoritme zoals beschreven in hoofdstuk 11 . 


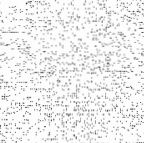

l.

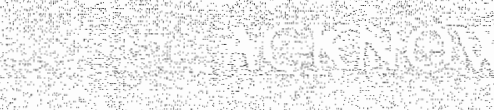


I would like to thank everyone who helped me in completing this thesis, especially:

Prof. dr. M.E. Durieux, promotor, for his encouragement and advice during the complerion of this thesis.

Dr. R. Slappendel, co-promotor, without his help it would have been almost impossible to finish the thesis.

Dr. W.E.J. Weber, who taught me how to write a scientific paper.

Mrs. R. Vanderbroeck, who helped me to prepare the manuscript.

The staff members and residents of the departments of Anesthesiology and Orthopedic Surgery of the Sint Maartenskliniek Nijmegen and the Universiry Hospital of Maastricht for their participation in the studies.

The staff members of the department of Anesthesiology of the Catharina Hospital for providing the facilities to complete this thesis.

The anesthesia assistants, operating personnel and recovery nurses of the Sint: Maartenskliniek in Nijmegen and the University Hospital in Maastricht for their assistance in the studies.

All patients who gave their consent to participate in the studies.

And finally I thank my wife Geertje and the children Thomas, Floor and Karlijn for their patience and support. 

Eric Weber was born on 31. May 1960 in Oranjestad, Aruba, where he went to elementary school. He finished secondary school in Maastricht, The Nerherlands, in 1979. In 1985 he graduated from the Medical School of the University of Maastricht. After residencies in Internal Medicine and General Surgery at the Universiry Hospital Maastricht he started his training in Anesthesiology in 1987 at the Department of Anesthesiology (Chair Prof. dr. L.H.D.J. Booij of the Universiry Hospital of Nijmegen, The Netherlands). In February 1992 he was registered as anesthesiologist. From 1992 until 1996 he was staff anesthesiologist at the deparment of Anesthesiology of the University Hospital Nijmegen. From 1996 until 2001 he worked as an anesthesiologist in the Sint Maartenskliniek in Nijmegen, a tertiary referral centre for orthopedic surgery, where he specialized in loco-regional anesthesia. From 2001 to 2003 he was staff anesthesiologist in the Department of Anesthesiology (Chair: Prof.dr. M.E. Durieux, and Prof.dr. M. van Kleef) of the University Hospital in Maastricht. Since August 2003 he is anesthesiologist in the Cartharina Hospital in Eindhoven. 